Aus der Klinik für Kardiologie und Pneumologie

(Prof. Dr. med. G. Hasenfuß)

der Medizinischen Fakultät der Universität Göttingen

\title{
Einfluss der Herzinsuffizienz auf Membranstrukturen und lokale cAMP-Dynamiken der SERCA2a-Mikrodomäne
}

\author{
INAUGURAL - DISSERTATION \\ zur Erlangung des Doktorgrades \\ der Medizinischen Fakultät der \\ Georg-August-Universität zu Göttingen
}

vorgelegt von

Sandra Hofmann

aus

Coburg

Göttingen 2015 
Dekan:

I. Berichterstatter: Prof. Dr. rer. nat. V. Nikolaev

II. Berichterstatter: Prof. Dr. med. S. E. Lehnart

III. Berichterstatter/in:

Tag der mündlichen Prüfung: 05.07.2016 


\section{Inhaltsverzeichnis}

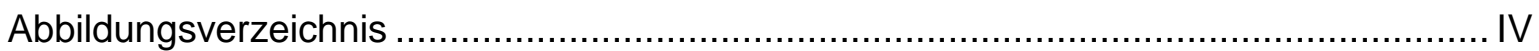

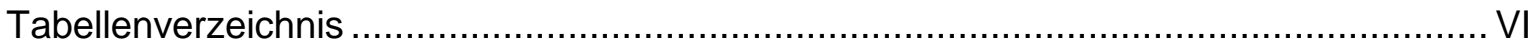

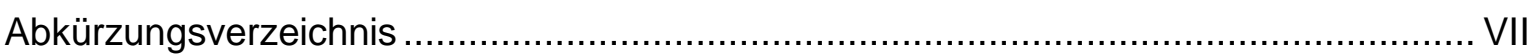

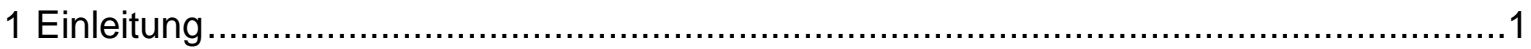

1.1 Bedeutung und Entstehung der Herzinsuffizienz .............................................

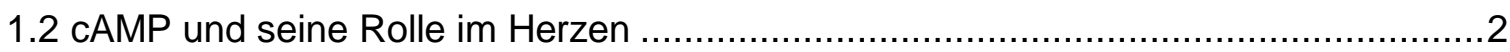

1.3 Kompartimentierung von cAMP in Kardiomyozyten ........................................

1.4 Funktion der SERCA2a und Bestandteile ihrer Mikrodomäne ................................ 8

1.5 Relevante pathologische Veränderungen im Rahmen der Herzinsuffizienz .............11

1.5.1 Das transversal-axiale Tubulus-System (TATS) und sein pathologisches

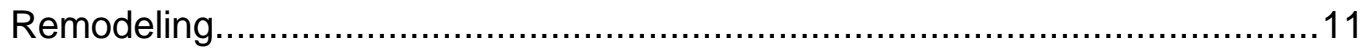

1.5.2 Veränderungen der SERCA2a-Mikrodomäne im Rahmen des cAMP-

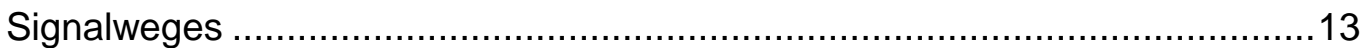

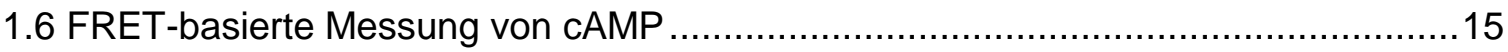

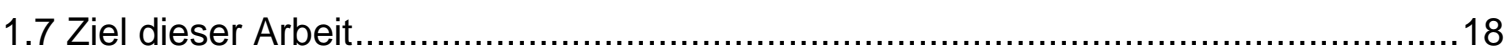

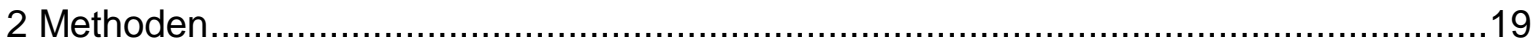

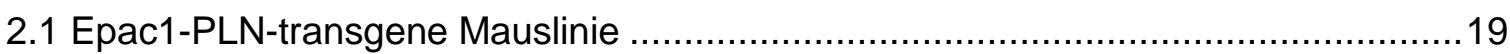

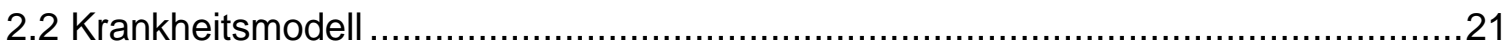

2.2.1 Ligatur des RIVA zur Induktion eines Myokardinfarktes...............................21

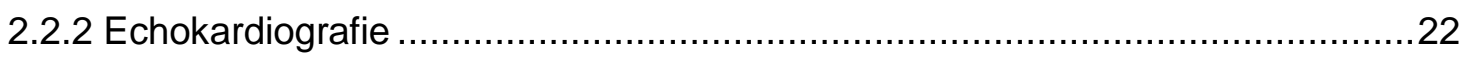

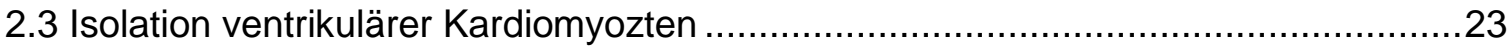

2.4 Epifluoreszenzmikroskopie und FRET-Messungen .........................................25

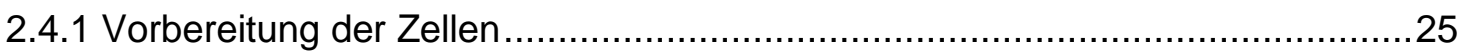

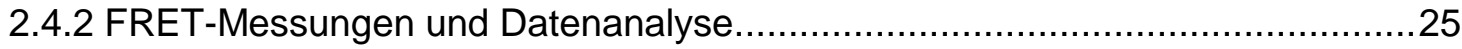

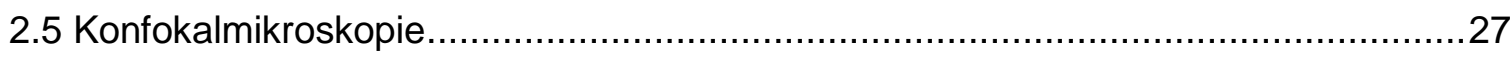

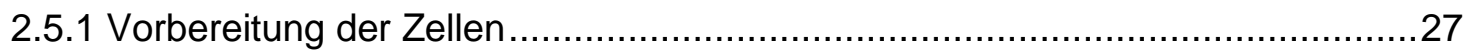


2.5.2 Membranfärbung mit di-8-ANEPPS und Lebendaufnahmen ..........................28

2.5.3 Immunfärbungen fixierter Kardiomyozyten und deren Aufnahmen ...................28

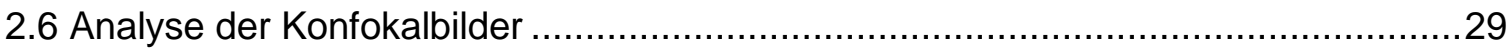

2.6.1 Kolokalisationsanalyse des Epac1-PLN-Sensors mit SERCA2a ....................29

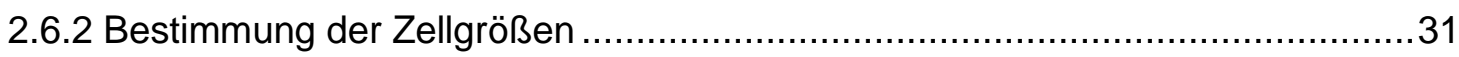

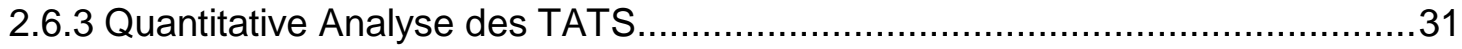

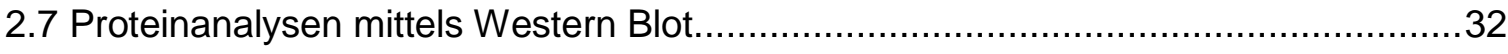

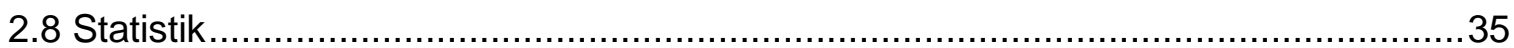

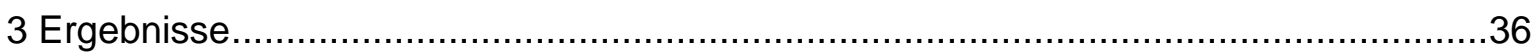

3.1 Validierung der Ausbildung des Krankheitsbildes Herzinsuffizienz...........................36

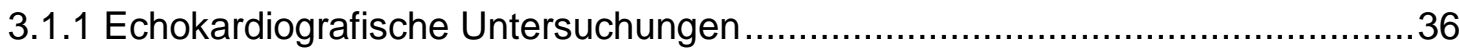

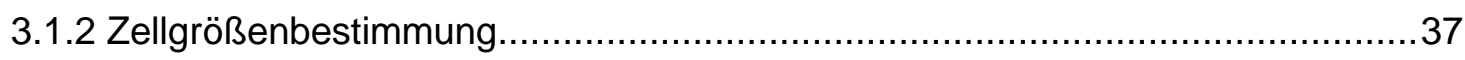

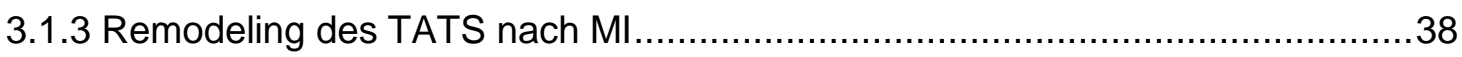

3.2 Unveränderte Lokalisation des Sensors nach MI ...............................................44

3.3 Expression relevanter Proteine in der Mikrodomäne..........................................48

3.4 FRET-Messungen an Epac1-PLN-transgenen Kardiomyozyten zeigen

Veränderungen im PDE-Profil der Mikrodomäne 12pMI......................................51

3.4.1 PDE-Profile von Sham- und 12pMI-Kardiomyozyten nach $\beta$-adrenerger

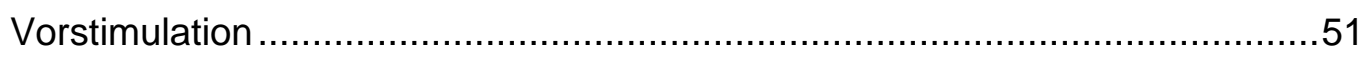

3.4.2 PDE-Profile von Sham- und 12pMI-Kardomyozyten unter basalen Bedingungen.

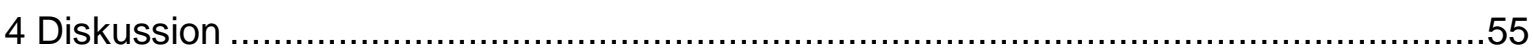

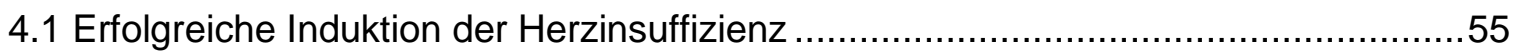

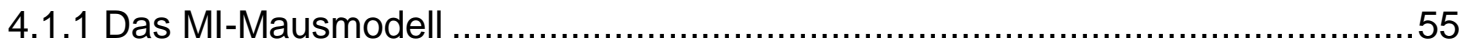

4.1.2 T-Tubulus Remodeling in Epac1-PLN-transgenen Kardiomyozyten gibt Hinweise auf Ausmaß der Erkrankung .56

4.1.3 Epac1-PLN-transgene Mäuse zeigen Herzinsuffizienz-typische Veränderungen der Proteinexpression 
4.2 Eignung des Epac1-PLN-Biosensor für Anwendung im Krankheitsmodell 60

4.3 Veränderungen im PDE-Aktivitätsprofil der SERCA2a-Domäne 12pMI nachweisbar

4.3.1 $\beta$-adrenerge Vorstimulation hat keinen Einfluss auf den lokalen cAMP-Pool der SERCA2a-Mikrodomäne.

4.3.2 Beitrag der PDE4 zum Abbau des cAMP-Pools der SERCA2a-Mikrodomäne nach $\beta$-adrenerger Vorstimulation und unter basalen Bedingungen 12pMl reduziert.

6 Anhang

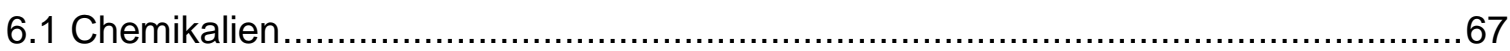

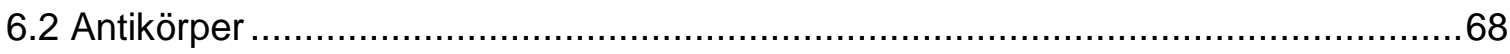

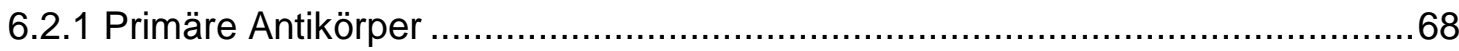

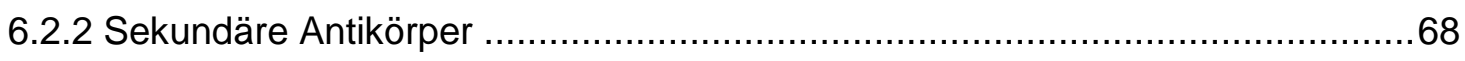

6.3 Verbrauchsgegenstände und andere Materialien................................................. 68

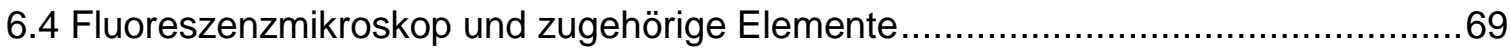

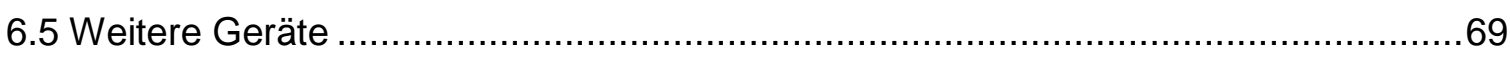

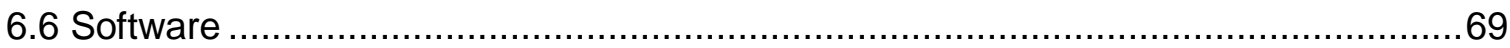

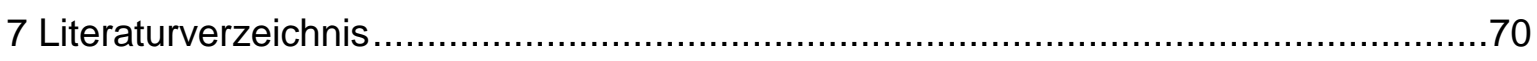




\section{Abbildungsverzeichnis}

Abbildung 1: Schematische Darstellung der cAMP-Signalkaskade im Herzen ............... 4

Abbildung 2: Regulation der SERCA2a ....................................................... 10

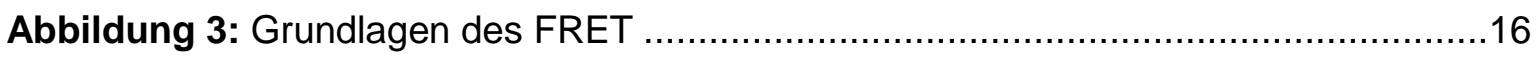

Abbildung 4: Schematische Darstellung der Funktionsweise des Epac1-cAMP-FRET-

Sensors

Abbildung 5: Schematische Darstellung des Epac1-PLN-Biosensors .........................19

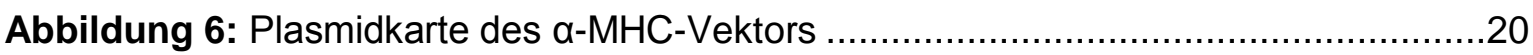

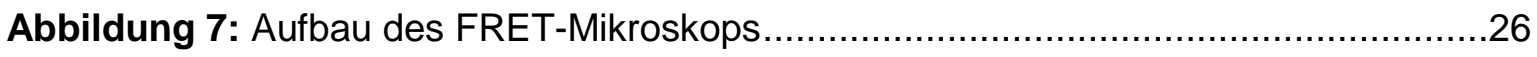

Abbildung 8: Farbkodierungsskala der Streudiagramme .....................................30

Abbildung 9: Größenzunahme der 12pMI-Kardiomyozyten im Vergleich zur Sham-

Gruppe. .38

Abbildung 10: Konfokalaufnahmen lebender di-8-ANEPPS-gefärbter Epac1-PLNtransgener Kardiomyozyten 39

Abbildung 11: Skelettbilder des TATS (ohne Oberflächen-Zellmembran) als Grundlage der Netzwerkanalyse.

Abbildung 12: Zunahme der Dichte und Verzweigungen des TATS nach MI .41

Abbildung 13: Veränderung der Orientierung bestimmter TATS-Elemente nach MI .42

Abbildung 14: Veränderung axialer und transversaler Netzwerkkomponenten 12pMI ....42

Abbildung 15: Konfokale Bilder transgener Kardiomyozyten nach Cav3Immunfluoreszenzfärbung .43

Abbildung 16: Aufnahme einer Epac1PLN-transgenen 12pMI-Kardiomyozyte nach SERCA2a-Immunfärbung. .45

Abbildung 17: Streudiagramme zeigen Kolokalisation von YFP mit SERCA2a durch Häufigkeitsverteilung entlang der Diagonale .46 
Abbildung 18: Korrelationskoeffizienten bestätigen die Kolokalisation von YFP mit SERCA2a in Sham- und 12pMI-Kardiomyozyten

Abbildung 19: Repräsentative Western Blots relevanter Proteine der SERCA2a-

Mikrodomäne 49

Abbildung 20: PLN- und SERCA2a-Expression in Sham- und 12pMI-Kardiomyozyten.. 50 Abbildung 21: PDE4-Beitrag zur Beendigung des $\beta$-Rezeptor-vermittelten cAMP-Signals in der SERCA2a-Mikrodomäne ist 12pMI signifikant reduziert .52

Abbildung 22: PDE4-Aktivität in der SERCA2a-Mikrodomäne ist unter basalen Bedingungen 12pMl signifikant reduziert. .54 


\section{Tabellenverzeichnis}

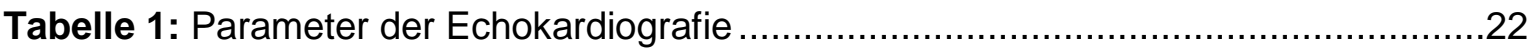

Tabelle 2: Lösungen und Puffer für die Kardiomyozytenisolation ................................24

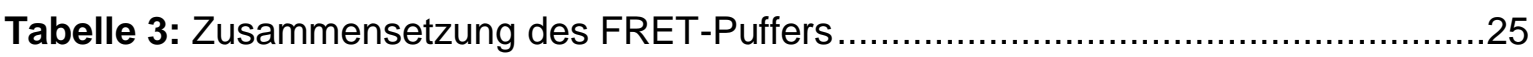

Tabelle 4: Einstellungen für die Konfokalaufnahmen lebender Zellen ..........................28

Tabelle 5: Einstellungen für die Konfokalaufnahmen immungefärbter Präparate............29

Tabelle 6: Zusammensetzung der für den Western Blot verwendeten Substanzen .........34

Tabelle 7: Echokardiografische Phänotypisierung Epac1-PLN-transgener Mäuse 12pMI vs. Sham-Intervention. 


\section{Abkürzungsverzeichnis}

\begin{tabular}{|c|c|}
\hline 12pMl & 12 Wochen nach Myokardinfarkt \\
\hline$A C$ & Adenylatzyklase \\
\hline ACE & Angiotensin-Converting-Enzym \\
\hline AKAP & A-Kinase-Ankerprotein \\
\hline a-MHC & a-Myosin-schwere-Kette \\
\hline ATP & Adenosin-5'triphosphat \\
\hline$\beta-A R$ & $\beta$-Adrenorezeptoren (Subtypen: $\beta_{1}-A R, \beta_{2}-A R, \beta_{3}-A R$ ) \\
\hline Bay & Bay 60-7550 (PDE2-Inhibitor) \\
\hline $\mathrm{Ca}^{2+}$ & Calcium \\
\hline $\mathrm{CaM}$ & Calmodulin \\
\hline CaMKII & Calcium/Calmodulin-abhängige Proteinkinase-II \\
\hline CAMP & zyklisches Adenosin-3',5'-monophophat \\
\hline cGMP & zyklisches Guanosin-3',5'-monophosphat \\
\hline Cav3 & Caveolin 3 \\
\hline CFP & cyan fluoreszierendes Protein \\
\hline Cilo & Cilostamid (PDE3-Inhibitor) \\
\hline CSQ & Calsequestrin \\
\hline EF & Ejektionsfraktion \\
\hline Epac & exchange protein activated by $c A M P$ \\
\hline FAC & fraktionelle Flächenänderungsrate (fractional area shortening) \\
\hline FS & Verkürzungsfraktion (fractional shortening) \\
\hline FRET & Fluoreszenz-Resonanz-Energie-Transfer \\
\hline $\mathrm{G}_{\mathrm{i}}$ & inhibitorisches G-Protein \\
\hline $\mathrm{G}_{\mathrm{s}}$ & stimulatorisches G-Protein \\
\hline GPCR & G-Protein-gekoppelte Rezeptoren \\
\hline $\mathrm{HCN}$ & Hyperpolarisations-aktiviert und Zyklonukleotid-gesteuert \\
\hline Hsp20 & Hitzeschockprotein 20 \\
\hline IBMX & 3-Isobutyl-1-Methylxanthin (nicht-selektiver PDE-Inhibitor) \\
\hline ICD-10 & Internationale Klassifikation von Krankheiten 10. Version \\
\hline Iso & Isoprenalin (nicht-selektives $\beta$-Sympathomimetikum) \\
\hline KHK & koronare Herzkrankheit \\
\hline $\mathrm{KO}$ & Knock-Out \\
\hline LTCC & L-Typ Calcium-Kanal \\
\hline LVEDD & linksventrikulärer enddiastolischer Durchmesser \\
\hline
\end{tabular}


LVESD linksventrikulärer endsystolischer Durchmesser

MBPC Myosinbindeprotein C

$\mathrm{Ml}$

Myokardinfarkt

$\mathrm{Na}^{+}$

Natrium

NCX

Natrium-Calcium-Austauscher

NOS

Nitritoxid-Synthase

PDE

Phosphodiesterase

$\mathrm{PGE}_{1}$

Prostaglandin $\mathrm{E}_{1}$

PKA

cAMP-abhängige Proteinkinase (Proteinkinase A)

PKC

Proteinkinase $\mathrm{C}$

PLN

Phospholamban

PP1

Protein-Phosphatase 1

RIVA

Ramus interventricularis anterior (=left anterior descending $=L A D$ )

$\mathrm{ROI}$

region of interest

Roli

Rolipram (PDE4-Inhibitor)

RyR2

Ryanodin-Rezeptor2

SERCA2a

$\mathrm{Ca}^{2+}$-ATPase 2a des sarko-/endoplasmatischen Retikulums

SICM

Raster-Ionenstrom-Mikroskopie (scanning ion-conductance-

microscopy)

SR

sarkoplasmatisches Retikulum

STED

stimulated emission depletion

TAC

Konstriktion der transversen Aorta (transverse aortic constriction)

TATS

tansversal-axiales Tubulus-System

Tnl

Troponin I

T-Tubuli

transversale Tubuli

YFP

gelb fluoreszierendes Protein 


\section{Einleitung}

\subsection{Bedeutung und Entstehung der Herzinsuffizienz}

In den westlichen Industrienationen ist die Herzinsuffizienz heutzutage eine der häufigsten chronischen Erkrankungen und Todesursachen. Lässt man gesunde Neugeborene außer Acht, so war 2013 die ICD-10-Diagnose Herzinsuffizienz (150) in Deutschland die häufigste Hauptdiagnose stationärer Behandlungsfälle (Statistisches Bundesamt 2015). Die zunehmende Relevanz des Krankheitsbildes zeigt sich durch den Anstieg der Fallzahlen um 2,5\% im Vergleich zum Vorjahr. Langfristig gesehen ist die Zahl der Herzinsuffizienz-Diagnosen seit der Jahrtausendwende von 239.694 (Statistisches Bundesamt 2004) auf 396.380 Fälle im Jahr 2013 um 40 \% gestiegen. Da die Erkrankung vor allem in älteren Bevölkerungsschichten stark vertreten ist, ist eine Abnahme der Bedeutung auf Grund des demografischen Wandels nicht zu erwarten.

Als Herzinsuffizienz wird das Unvermögen des Herzens bezeichnet, bei normalem enddiastolischen Ventrikeldruck die Blutmenge zu befördern, die vom Organismus zur Aufrechterhaltung metabolischer Prozesse benötigt wird. Die Ätiologie des Syndroms ist in einer Vielzahl von strukturellen und funktionellen Herzerkrankungen und Risikofaktoren zu finden. Laut der Framingham-Herz-Studie ist neben der arteriellen Hypertonie auch die koronare Herzerkrankung (KHK) mit der Komplikation des akuten Myokardinfarktes (MI) als eine der häufigsten Ursachen besonders hervorzuheben (Ho et al. 1993). Da das Herz durch ein Endarteriensystem versorgt wird, kommt es bei Einengungen (KHK) oder Verschlüssen (MI) in einer der Koronararterien zu einer Minderversorgung bzw. Ischämie des Herzmuskelgewebes distal der Engstelle. Die daraus resultierenden Kontraktionsstörungen des Myokards führen bei relevanter Größe zu einer Abnahme der Auswurfleistung und somit zu einer Reduktion des Herzzeitvolumens. Um die resultierende Minderperfusion aller Organe auszugleichen und den Kreislauf zu stabilisieren, treten verschiedene Kompensationsmechanismen in Kraft. Hierbei steht vor allem die vermehrte Aktivierung des sympathischen Nervensystems im Vordergrund (Brodde et al. 2006): Durch die hiermit verbundene Katecholaminausschüttung wird über kardiale $\beta$-Rezeptoren der cAMP-Signalweg aktiviert (s. a. 1.2), was unter anderem zu einer Zunahme der Schlagkraft (Inotropie) und der Herzfrequenz (Chronotropie) führt. Außerdem wird eine generalisierte Engstellung der Gefäße über $\alpha$-Rezeptoren bewirkt. Dieser Effekt wird zusätzlich noch durch andere neurohormonale Systeme wie das ReninAngiotensin-Aldosteron-System unterstützt, welches zudem auch zu einer vermehrten Volumenretention beiträgt. Das verbleibende funktionsfähige Myokard versucht durch 
Größenzunahme der einzelnen Kardiomyozyten (Hypertrophie) die vermehrt anfallende Arbeit auszugleichen. Zusammengefasst führen all diese Effekte zu einem vermehrten Sauerstoffbedarf des bereits vorgeschädigten Herzens, wodurch bei chronischem Bestehen ein Teufelskreis entsteht, der den progredienten Verlauf der Erkrankung bewirkt. Nach den Leitlinien der European Society of Cardiology (ESC) wird therapeutisch die Anwendung von Diuretika (Volumenreduktion) sowie die neuroendokrine Blockade durch $\quad \beta$-Blocker, Angiotensin-Converting-Enzym(ACE)-Hemmer bzw. AT ${ }_{1}$ Angiotensinrezeptor-Antagonisten und Mineralkortikoid-Rezeptor-Antagonisten empfohlen (McMurray et al. 2012). Bei Indikation können außerdem Ivabradin (Senkung der Herzfrequenz) oder Herzglykoside (Verbesserung der Effizienz der elektromechanischen Kopplung und inotrope Wirkung) eingesetzt werden.

Trotz aller Therapiemöglichkeiten ist die Prognose der manifesten Herzinsuffizienz nach wie vor ungünstig. Die 5-Jahres-Überlebensrate liegt unter $50 \%$ und ist somit schlechter als die vieler karzinomatöser Erkrankungen (Go et al. 2013). Dementsprechend stand die Herzinsuffizienz in der Statistik zur Häufigkeit von Todesursachen 2013 deutschlandweit an dritter Stelle (Statistisches Bundesamt 2014). Bei Betrachtung lediglich des weiblichen Bevölkerungsanteils war sie sogar als zweithäufigster Grund der Sterbefälle identifizierbar. Um ein besseres Verständnis aufbauen zu können, ist die Aufklärung molekularer Mechanismen im Rahmen des Krankheitsbildes somit dringend notwendig.

\section{2 cAMP und seine Rolle im Herzen}

Zyklisches Adenosin-3',5'-monophosphat (cAMP) ist ein ubiquitär vorkommender sekundärer Botenstoff, der ein von außen kommendes Signal intrazellulär weiterleitet. Hierzu wird zunächst ein primäres Signal, z.B. ein hydrophiler Botenstoff, der die Zellmembran nicht passieren kann, benötigt. Bindet dieser an G-Protein-gekoppelte Rezeptoren (GPCR) der äußeren Membran, werden je nach Art des Rezeptors inhibitorische $\left(\mathrm{G}_{\mathrm{i}}\right)$ oder stimulatorische $\left(\mathrm{G}_{\mathrm{s}}\right)$ G-Proteine aktiviert. Diese hemmen bzw. fördern wiederum die enzymatische Bildung von cAMP aus Adenosin-5"-triphosphat (ATP) durch sogenannte Adenylatzyklasen (ACs). Die durch cAMP erzielten Wirkungen variieren stark je nach Zelltyp und sind oft durch nachgeschaltete Effektormoleküle vermittelt. Sie reichen von der Regulierung des Glukose- und Fettstoffwechsels (Altarejos und Montminy 2011, Qi et al. 2009) über die Immunregulation von T-Zellen (Guereschi et al. 2013, Brudvik und Taskén 2012) bis hin zur Gedächtnisbildung (Florian et al. 2006, Morozov et al. 2003) und auch weit über diese Beispiele hinaus. Zur Terminierung und lokalen 
Beschränkung von cAMP-Signalen kommen Phosphodiesterasen (PDEs) zum Einsatz, welche in Kapitel 1.3 noch näher besprochen werden.

Im Herzen wird der cAMP-Spiegel vor allem durch die G-Protein-gekoppelten $\beta$ Adrenorezeptoren ( $\beta$-ARs) beeinflusst. Sie stehen unter Kontrolle des sympathischen Nervensystems und werden im Körper durch Adrenalin und Noradrenalin aktiviert. Durch die ergotrope Wirkung erzielen sie kardial eine Zunahme von Inotropie und Chronotropie (s. oben) sowie auch von Bathmotropie (Senkung der Reizschwelle) und Lusitropie (Relaxationsfähigkeit des Myokards) und haben zudem einen positiv dromotropen Einfluss auf das Reizleitungssystem (beschleunigte Überleitung am Atrioventrikularknoten). Diese Effekte werden vor allem in Verbindung mit $\mathrm{G}_{\mathrm{s}}$-Aktivierung hervorgerufen, die sowohl durch $\beta_{1}$-ARs als auch durch $\beta_{2}$-ARs erfolgt. Funktionell dominiert jedoch der $\beta_{1}$-AR, der auch einen Anteil von 70-80\% der $\beta$-ARs am gesunden Herzen einnimmt (Lohse et al. 2003). Ein wichtiger Effekt der $\mathrm{G}_{\mathrm{s}}$-induzierten cAMP-Erhöhung ist die Aktivierung der cAMP-abhängigen Proteinkinase (PKA). Diese phosphoryliert unter anderem verschiedene Proteine, die eine entscheidende Rolle bei der elektromechanischen Kopplung spielen, wodurch der Kontraktionsablauf in Kardiomyozyten beeinflusst wird: Durch Phosphorylierung von L-Typ Calcium-Kanälen (LTCC), Ryanodin-Rezeptor 2 (RyR2) und Phospholamban (PLN), welches die ATPabhängige Calciumpumpe $2 a$ des sarkoplasmatischen und endoplasmatischen Retikulums (SERCA2a) reguliert (s. 1.4), wird der $\mathrm{Ca}^{2+}$-Kreislauf in den Herzmuskelzellen hochreguliert (inotrope Wirkung). Zusätzlich wirkt auch die Phosphorylierung kontraktiler Proteine wie Troponin I (Tnl) oder Myosinbindeprotein C (MBPC) unterstützend (Lompré et al. 2010, Soto et al. 2009, Xiang und Kobilka 2003). Neben vielen weiteren PKAvermittelten Effekten ist cAMP auch in der Lage, über direkte Aktivierung des Austauschproteins Epac (exchange protein directly activated by $c A M P$ ) weitere Proteine zu regulieren. Dieses wirkt nach Aktivierung durch das zyklische Nukleotid als Guaninnukleotid-Austauschfaktor der kleinen GTPase Rap1 (de Rooij et al. 1998) und kann über diese Signalkette zahlreiche biologische Funktionen in verschiedensten Geweben regulieren (Schmidt et al. 2013). In Kardiomyozyten ist vor allem die Isoform Epac1 relevant, welche maßgeblich an der Induzierung der Myokardhypertrophie beteiligt ist (Morel et al. 2005). Außerdem wurde gezeigt, dass Epac1, ähnlich wie die PKA, an der Phosphorylierung von PLN und RyR2 beteiligt ist und somit auch an der Regulierung des $\mathrm{Ca}^{2+}$-Haushaltes unter kardialem Stress (Okumura et al. 2014). Der vergleichsweise geringe Einfluss von Epac1 auf die Herzfunktion unter basalen Bedingungen (RuizHurtado et al. 2013) lässt eine besondere Relevanz des Epac-Signalweges unter pathologischen Bedingungen vermuten. Eine weitere Wirkung von cAMP ist die Öffnung 
Zyklonukleotid-aktivierter lonenkanäle (Craven und Zagotta 2006), von denen im Herzen der den Schrittmacherstrom (l funny $)$ erzeugende Hyperpolarisations-aktivierte Zyklonukleotid-gesteuerte Kationenkanal (HCN-Kanal) eine herausragende Stellung einnimmt (DiFrancesco 2010). Wie eine Studie an HCN4-Mutationsträgern zeigt, scheint der Einfluss von cAMP auf die Herzfrequenz aber nur unter Ruhebedingungen relevant zu sein (Schweizer et al. 2010) und nicht, wie lange angenommen, bei der belastungsbedingten Frequenzanpassung durch $\beta$-AR (Bucchi et al. 2007, DiFrancesco und Tortora 1991). Eine zusammenfassende Übersicht des cAMP-Signalweges findet sich in Abbildung 1.

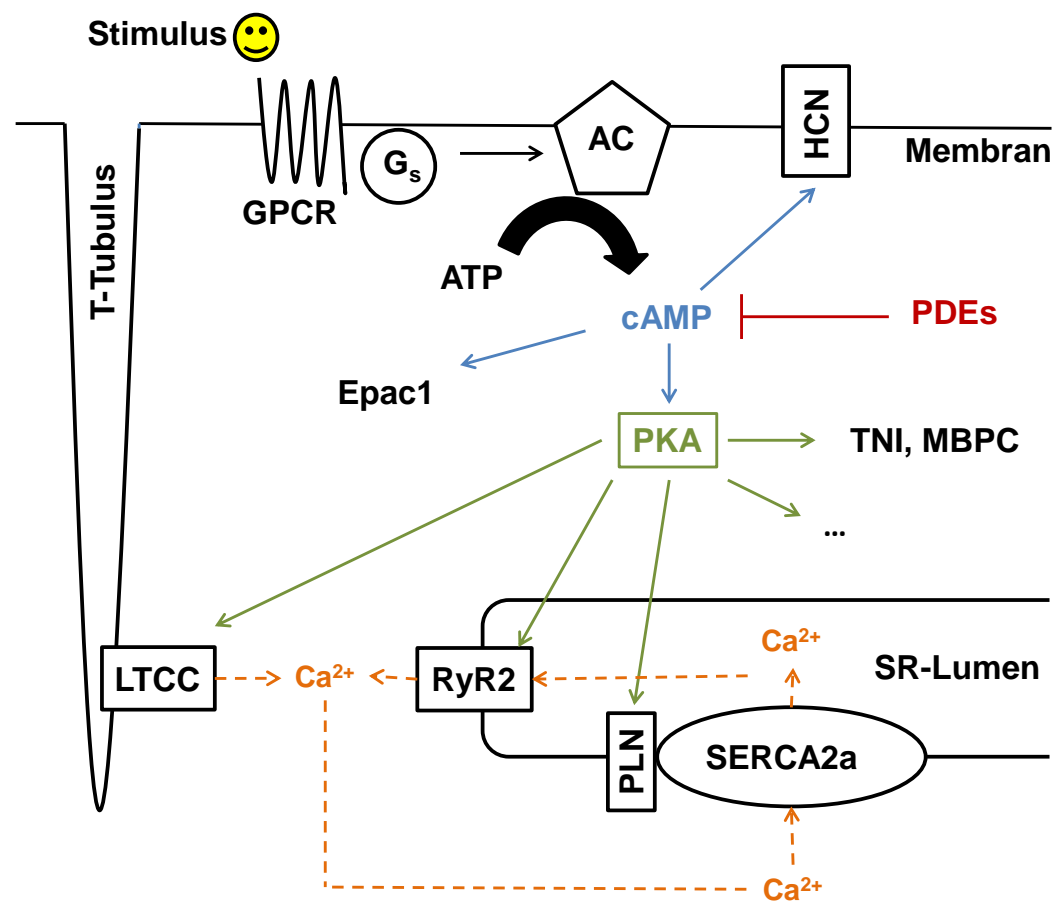

Abbildung 1: Schematische Darstellung der cAMP-Signalkaskade im Herzen. Nach Aktivierung des $\mathrm{G}_{\mathrm{s}} \mathrm{PCR}$ durch einen adäquaten Stimulus (z.B. Adrenalin, Noradrenalin) kommt es

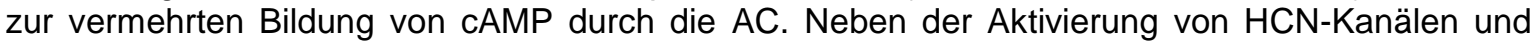
Epac1 aktiviert cAMP die PKA, welche wiederum zahlreiche Effekte vermittelt. Hierzu gehört beispielsweise die Phosphorylierung von den $\mathrm{Ca}^{2+}-K$ reislauf regulierenden Strukturen, wie LTCC, RyR2 und PLN, aber auch die Phosphorylierung kontraktiler Proteine wie Tnl und MBPC. PDEs hemmen durch die Hydrolyse des sekundären Botenstoffes all diese Effekte.

Trotz der Kopplung sowohl des $\beta_{1}$-AR als auch des $\beta_{2}-A R$ mit $G_{s}$ sind die vermittelten Effekte verschieden. Während das $\beta_{1}$-Signal eher auf globaler Zellebene wirkt, sind die Signale des $\beta_{2}$-AR räumlich und funktionell kompartimentiert (Nikolaev et al. 2006, Zheng et al. 2004). Im Gegensatz zum $\beta_{1}-A R$, besitzt der $\beta_{2}$-AR außerdem die Eigenschaft, nach Phosphorylierung durch die PKA von $\mathrm{G}_{\mathrm{s}^{-}}$auf $\mathrm{G}_{\mathrm{i}}-$ Kopplung zu wechseln (Daaka et al. 1997). Das erklärt auch die teils kontroversen Eigenschaften der beiden Rezeptoren: So zeigte sich beispielsweise, dass $\beta_{1}$-AR-Stimulation pro-apoptotisch wirkt, während die 
Stimulation von $\beta_{2}-A R$ die Apoptose hemmt (Communal et al. 1999). Die eher schädlichen Effekte chronischer $\beta_{1}$-AR-Anregung zeigen sich auch in der hierdurch vermittelten Entwicklung von Hypertrophie und Herzinsuffizienz (Engelhardt et al. 1999). Dem gegenüber wurde gezeigt, dass eine Überexpression von $\beta 2-A R$ in transgenen Mäusen sogar zu eine Verbesserung der Herzfunktion führt (Milano et al. 1994). Des Weiteren findet sich im Herzen auch der $\beta_{3}-A R$, welcher jedoch mit einem Anteil von 2-3\% an den kardialen $\beta$-ARs unter physiologischen Bedingungen nur geringere Relevanz hat (Lymperopoulos 2013). Seine antagonistische Wirkung zu $\beta_{1}$ - und $\beta_{2}$-ARs entfaltet er erst bei sehr hohen Katecholamin-Mengen vor allem über den StickstoffmonooxidSynthase(NOS)-Signalweg, weshalb er wohl eher zur Begrenzung überschießender Sympathikusaktivität dient (Belge et al. 2014, Moens et al. 2010).

Darüber hinaus gibt es auch noch weitere $\mathrm{G}_{\mathrm{s}} \mathrm{PCR}$, die den cAMP-Spiegel im Herzen erhöhen. Hierzu gehören beispielsweise Prostaglandin-, Histamin- und Glukagon-likepeptid-1-Rezeptoren, wobei allen gemeinsam ist, dass sie im Gegensatz zu den $\beta$-ARs keine ergotrope Wirkung vermitteln (Vila Petroff et al. 2001, Bers und Ziolo 2001). Die Tatsache, dass sich trotz gleichartiger cAMP-Erhöhung konträre Effekte ergeben, lässt sich mit dem Modell der intrazellulären cAMP-Kompartimentierung erklären.

\subsection{Kompartimentierung von cAMP in Kardiomyozyten}

Schon Ende der 70er Jahre wurde festgestellt, dass die durch cAMP vermittelten Effekte abhängig vom stimulierenden Hormon und somit angeregtem Rezeptor sind: Zwar bewirkte die Stimulation isolierter Rattenherzen sowohl mit Isoprenalin (Iso) als auch mit Prostaglandin $E_{1}\left(P_{G}\right)$ einen vergleichbaren Anstieg der cAMP-Level und der PKAAktivierung, jedoch hatte lediglich die Stimulation mit Iso eine Zunahme der Inotropie und die Aktivierung verschiedener Enzyme des Glykogen-Stoffwechsels zur Folge (Hayes et al. 1979). Im weiteren Verlauf zeigte sich dann, dass die Stimulation mit Iso die cAMPSpiegel sowohl im Bereich der Zellmembran als auch im Zytosol beeinflusst, wohingegen $\mathrm{PGE}_{1}$ lediglich Auswirkungen auf cAMP in zytosolischen Bereiche hat (Brunton et al. 1981, Buxton und Brunton 1983). Auf Basis derartiger Beobachtungen entwickelte sich diese Idee der zellulären Kompartimentierung von cAMP über Jahrzehnte hinweg zu einem heute anerkannten Modell (Perera und Nikolaev 2013). In Kardiomyozyten sind derartige cAMP-Mikrodomänen beispielsweise um die verschiedenen $\mathrm{Ca}^{2+}$-regulierenden Untereinheiten wie den LTCC, RyR2 oder die SERCA2a angeordnet. Der lokale CAMPPool wird durch die spezifische Zusammensetzung des Signalkomplexes - unter anderem 
aus cAMP-hydrolysierenden PDEs und strukturgebenden A-Kinase-Ankerproteinen (AKAPs) - sowie der genauen Lokalisation der GPCRs begrenzt.

Einer der Mechanismen, die zur cAMP-Kompartimentierung beitragen, ist die Anreicherung der GPCRs - wie $\beta$-ARs oder PGE-Rezeptoren - in spezifischen Membranbereichen und der nach deren Stimulation dort resultierenden lokalisierten cAMP-Produktion. Zu solchen Bereichen gehören lipidreiche Domänen, sogenannte Lipid Rafts, aber auch deren abgrenzbare Untereinheiten, die cholesterinreichen Caveolae, in denen sich das strukturverleihende Protein Caveolin anreichert (Patel et al. 2008). Es konnte gezeigt werden, dass $\beta$-ARs in neonatalen Rattenkardiomyozyten in Caveolinreichen Domänen zu finden sind, wohingegen der ebenfalls $\mathrm{G}_{\mathrm{s}}$-assoziierte Prostaglandin$E_{2}$-Rezeptor in diesen Regionen nicht vorkommt (Head et al. 2005, Ostrom et al. 2001). Eine andere Studie zeigte, dass die Anordnung einzelner Rezeptoren sogar dynamisch sein kann: Nach agonistischer Rezeptor-Stimulation nahm die $\beta_{2}$-AR-Präsenz in den Caveolae deutlich $a b$, während ein Einfluss auf die Lokalisation der $\beta_{1}$-ARs nicht festgestellt werden konnte (Rybin et al. 2000). Die spezifische Verteilung von $\beta$-ARs wurde außerdem durch eine Kombination aus Fluoreszenz-Resonanz-Energie-Transfers (FRET) und Raster-lonenstrom-Mikroskopie (scanning ion-conductance microscopy, SICM) gezeigt (Nikolaev et al. 2010). In dieser Studie wurde nachgewiesen, dass funktionelle $\beta_{2}$-ARs in adulten Rattenkardiomyozyten nur in Einstülpungen der Zellmembran, den sogenannten transversalen Tubuli (T-Tubuli) lokalisiert sind, wohingegen $\beta_{1}$-ARs über die gesamte Plasmamembran verteilt vorliegen.

Die wesentliche Rolle bei der Abgrenzung verschiedener cAMP-Pools voneinander spielen jedoch die PDEs, die durch Hydrolysierung des sekundären Botenstoffes in der Lage sind, das Signal zu beenden. Bisher sind 11 PDE-Familien mit zahlreichen Isoformen bekannt, die durch permanente oder transiente Anordnung in subzellulären Domänen eine cAMP-Kompartimentierung ermöglichen (Ahmad et al. 2015). Im Herzen sind vor allem die Familien 1,2,3,4 und 8 für den cAMP-Abbau relevant, wobei die PDEs13 zusätzlich auch zyklisches Guanosin-3',5'-monophosphat (cGMP), den Sekundärbotenstoff des NOS-Signalweges, hydrolysieren (Keravis und Lugnier 2012, Zaccolo und Movsesian 2007, Fischmeister et al. 2006). Abgesehen von unterschiedlicher Substratspezifität haben PDEs auch verschiedene Regulationsmechanismen, weshalb die Anordnung ausgewählter Subtypen vielseitigen Einfluss auf die Eigenschaften der jeweiligen Mikrodomäne hat.

Die PDE1 ist dadurch gekennzeichnet, dass die Enzymaktivität durch Bindung von Calmodulin (CaM) in Abhängigkeit von $\mathrm{Ca}^{2+}$ signifikant erhöht werden kann (Sonnenburg 
et al. 1993), weshalb sie auch als $\mathrm{Ca}^{2+} / \mathrm{CaM}$-stimulierte PDE bezeichnet wird. Die Expression verschiedener Isoformen ist bei zahlreichen Säugetieren bekannt, wobei die PDE1A dominant in Mäusen ist und eine höhere Affinität zu cGMP aufweist, während die PDE1C mit gleicher Substratspezifität in humanen Kardiomyozyten überwiegt (Lee und Kass 2012, Vandeput et al. 2007).

Eine besondere Eigenschaft der PDE2 ist, dass ihre Aktivität über die allosterische Bindung von cGMP gesteigert werden kann (Martinez et al. 2002). Der Einfluss von cGMP auf den cAMP-Spiegel scheint auch wesentlicher Bestandteil bei der $\beta_{3}$-AR-vermittelten Antagonisierung der Sympathikusaktivität im Herzen zu sein (Mongillo et al. 2006), welche auch schon unter 1.2 angesprochen wurde.

Die PDE3 als dritte Familie mit dualer Substratspezifität wird - im Gegensatz zur PDE2 durch cGMP gehemmt. Sie ist die häufigste PDE-Familie im menschlichen Herzen (Eschenhagen 2013) und scheint vor allem über die Isoform PDE3A maßgeblichen Einfluss auf die Kontraktion von Kardiomyozyten zu besitzen (Sun et al. 2007). PDE3Inhibitoren wie Milrinon wurden eine Zeit lang klinisch zur Behandlung der Herzinsuffizienz eingesetzt. Heute kommen sie jedoch auf Grund der arrhythmogenen Nebenwirkungen und Zunahme der Mortalität bei langfristiger Behandlung nur noch bei Therapieversagen anderer positiv inotrop wirkender Substanzen im Akutfall parenteral zum Einsatz (Allen et al. 2014, Miller und Yan 2010).

Die PDE4-Familie ist substratspezifisch für cAMP, wobei ihre Aktivität in Form einer negativen Rückkopplungschleife über Phosphorylierung durch die PKA zum Abbau des sekundären Botenstoffes angeregt werden kann (Beard et al. 2000). Die PDE4-Familie hat bei Nagetieren den größten Anteil an der cAMP-Hydrolyse und wird durch vier Gene codiert, die durch alternatives Splicing mehr als 20 Isoformen bilden können (Richter et al. 2011). Diese besitzen jeweils spezifische N-terminale Regionen, die durch Bindung an intrazelluläre Strukturen wie AKAPs oder Arrestine eine Kompartimentierung ermöglichen (Houslay und Adams 2003). So wird beispielsweise der unter 1.2 beschriebene Wechsel des $\beta_{2}$-AR von $G_{s}$ auf $G_{i}$ durch Rekrutierung der an $\beta$-Arrestin gebundenen PDE4D5 beeinflusst (Lynch et al. 2005). Des Weiteren wurde die Bildung eines sich gegenseitig beeinflussenden Signalkomplexes aus PKA und PDE4D3 beschrieben, welche über eine Muskel-spezifische AKAP (mAKAP) gebunden sind und vermutlich den basalen cAMPSpiegel aufrecht erhalten (Dodge et al. 2001). Ein gleich aufgebauter Signalkomplex ist mit dem RyR2-Rezeptor assoziiert (Marx et al. 2000), wo er eine wichtige Rolle in der Regulation der $\mathrm{Ca}^{2+}$-Freisetzung aus dem sarkoplasmatischen Retikulum (SR) über 
RyR2-Kanäle einnimmt und eine protektive Wirkung bezüglich der Entwicklung von Herzinsuffizienz und Arrhythmien hat (Lehnart et al. 2005).

Die PDE8 hydrolysiert spezifsch cAMP mit der höchsten Affinität (Keravis und Lugnier 2012) und kann wie auch die PDE4 durch die PKA reguliert werden (Brown et al. 2012). In Kardiomyozyten wird vor allem die Isoform PDE8A exprimiert, welche an der Regulation des $\mathrm{Ca}^{2+}$-Haushaltes beteiligt ist (Patrucco et al. 2010). Interessanterweise spricht die PDE8 im Gegensatz zu anderen PDEs nicht auf den nicht-selektiven PDE-Hemmer 3Isobutyl-1-Methylxanthin (IBMX) an.

Wie das Beispiel des mAKAP-Signalkomplexes zeigt, leisten auch Gerüstproteine einen wichtigen Beitrag zur Formierung spezieller Mikrodomänen. Gerade die Familie der AKAPs nimmt hierbei eine herausragende Stellung ein. Aktuell sind bereits über 70 verschiedene AKAPs bekannt, von denen mehr als $14 \mathrm{im}$ Herzen exprimiert werden (Rababa'h et al. 2015). Neben der Verankerung der PKA sind sie in der Lage, viele weitere Proteine der cAMP-Signalkaskade, wie PDEs, Phosphatasen und zahlreiche Signalproteine zu binden und so spezifische funktionelle Komplexe zu bilden (Lee et al. 2013, Scott und Santana 2010, Mauban et al. 2009). Dass dies eine unverzichtbare Aufgabe für die Aufrechterhaltung der Funktion der jeweiligen Mikrodomäne ist, zeigt sich am Beispiel des LTCC: In Folge der Aktivierung von $\beta$-ARs wird über AKAP79/150 (humane/murine Form) die PKA-abhängige Phosphorylierung des lonenkanals vermittelt (Gao et al. 1997) und so der $\mathrm{Ca}^{2+}$-Einstrom in die Kardiomyozyte erhöht. AKAP79/150 hat hierbei die wichtige Aufgabe, AC, PKA, Calcineurin und LTCC an Caveolin-reichen Domänen zu einer funktionellen Einheit zusammenzuführen. Durch Experimente an AKAP150-Knock-Out(KO)-Mäusen konnte gezeigt werden, dass ein Fehlen von AKAP79/150 die Beeinflussbarkeit des LTCC nach $\beta$-AR-Stimulation aufhebt (Nichols et al. 2010). Darüber hinaus sind noch zahlreiche weitere AKAPs und andere strukturgebende Proteine mit unterschiedlichsten Funktionen bekannt, die an der individuellen Gestaltung von cAMP-Kompartimenten beteiligt sind.

\subsection{Funktion der SERCA2a und Bestandteile ihrer Mikrodomäne}

Die SERCA-Familie ist eine Gruppe von $\mathrm{Ca}^{2+}$-ATPasen, die durch drei Gene (ATP2A1, ATP2A2 und ATP2A3) codiert wird, welche durch alternatives Splicing verschiedene Isoformen bilden können (Frank et al. 2003, Arai 2000, Anger et al. 1994). Im Herzen ist vor allem die Isoform SERCA2a relevant und dort maßgeblich an der Regulation des $\mathrm{Ca}^{2+}$-Haushaltes beteiligt (s.a. Abb. 1). 
Nach Depolarisation der äußeren Zellmembran kommt es zur Öffnung der LTCC und somit zum $\mathrm{Ca}^{2+}$-Einstrom in die Zelle. Hierdurch wird die $\mathrm{Ca}^{2+}$-Freisetzung über den RyR2 aus dem sarkoplasmatischen Retikulum (SR), einem intrazellulären Netzwerk zur $\mathrm{Ca}^{2+}$ Speicherung, getriggert (Fabiato und Fabiato 1975, Fabiato 1983). Die Erhöhung des intrazellulären $\mathrm{Ca}^{2+}$-Spiegels resultiert schließlich in der Kontraktion der Herzmuskelzelle. Für die folgende Relaxation des Herzens ist es nun notwendig, dass der $\mathrm{Ca}^{2+}$-Spiegel wieder gesenkt wird. Unter Hydrolyse von ATP ist die SERCA2a in der Lage, 70 \% des $\mathrm{Ca}^{2+}$ in humanen Kardiomyozyten und sogar 90\% in murinen, aktiv aus dem Zytosol in das SR zurück zu pumpen (Vangheluwe et al. 2006). Hierdurch werden die $\mathrm{Ca}^{2+}$-Speicher des SR in der Diastole wieder aufgefüllt und stehen somit für weitere Kontraktionszyklen zur Verfügung. Zu einem geringeren Anteil ist auch der Natrium $\left(\mathrm{Na}^{+}\right)-\mathrm{Ca}^{2+}$-Austauscher (NCX) und die $\mathrm{Ca}^{2+}$-ATPase der Plasmamembran an der Extraktion von $\mathrm{Ca}^{2+}$ nach extrazellulär beteiligt, was vom Anteil her dem LTCC-Einstrom entspricht. Die Relevanz der SERCA2a im $\mathrm{Ca}^{2+}$-Kreislauf wurde auch in Experimenten mit SERCA2a-KO-Mäusen gezeigt: Obwohl das Fehlen der SERCA2a durch die Isoform SERCA2b teilweise kompensiert wurde, ließ sich bei den KO-Mäusen eine konzentrische Hypertrophie des Herzens mit Beeinträchtigung von Kontraktion und Relaxation nachweisen (Heyen et al. 2001). Der Knock-out von SERCA2 im Mausherz, und somit das Fehlen der SERCA2aund SERCA2b-Isoform, ist zwar überlebensfähig, geht jedoch mit einem extremen Volumenverlust des SR und seiner $\mathrm{Ca}^{2+}$-Speicher einher (Swift et al. 2012).

Die Regulierung der SERCA2a erfolgt über verschiedene Mechanismen, von denen vor allem die direkte Interaktion mit PLN physiologisch relevant ist. PLN ist ein aus 52 Aminosäuren bestehendes Transmembranprotein, welches aus einer hydrophilen, zytosolischen Region (Domäne I) und einer lipophilen, im SR verankerten Region (Domäne II) besteht (Fujii et al. 1987). Als negativer Regulator ist PLN in der Lage, die SERCA2a zu inhibieren. Diese hemmende Wirkung besteht vor allem im dephosphorylierten Zustand (Kranias 1985), wohingegen die Phosphorylierung von PLN die SERCA2a-Affinität für $\mathrm{Ca}^{2+}$ steigert (Brittsan et al. 2003, Kim et al. 1990). Die Phosphorylierung erfolgt hierbei je nach Enzym an verschiedenen Epitopen: Während die Phosphorylierungstelle der PKA Serin-16 ist, erfolgt die Phosphorylierung von PLN durch die $\mathrm{Ca}^{2+} / \mathrm{CaM}$-abhängige Proteinkinase-II (CamKII) an Threonin-17 (Simmerman et al. 1986). Eine Phosphorylierung beider Stellen konnte auch nach $\beta$-adrenerger Stimulation nachgewiesen werden (Wegener et al. 1989), wobei jedoch die Phosphorylierung von Serin-16 für eine maximale Sympathikus-Antwort ausreichend ist (Chu et al. 2000). Die Threonin-17 Phosphorylierung kann auch unabhängig von $\beta$-ARs frequenzabhängig erfolgen und ist dann mit einer verminderten Relaxationszeit assoziiert (Hagemann et al. 
2000). Außerdem können auch die ProteinkinaseC (PKC) (Movsesian et al. 1984) und die cGMP-abhängige Proteinkinase-I (Frantz et al. 2013) PLN phosphorylieren. Neuste Untersuchungen zeigen, dass die Interaktion von SERCA2a und PLN auf allosterische Effekte im Rahmen verschiedener Konformationszustände von PLN zurückzuführen ist (Gustavsson et al. 2013). Demnach ist vor allem die zytosolische Domäne la besonders metamorph und kann beispielsweise in Folge der Phosphorylierung an Serin-16 ihre Konformation ändern und so das Gleichgewicht der verschiedenen Zustände zur SERCAaktivierenden Form verschieben. Des Weiteren ist bekannt, dass PLN als Monomer und als Pentamer vorliegen kann (Periasamy et al. 2008). Allerdings ist bisher unklar ob diese Anordnung Einfluss auf die Hemmung der SERCA2a hat. Einerseits zeigen Untersuchungen an transgenen Mäusen, dass eine Überexpression der Monomere die inhibitorische Wirkung auf die SERCA2a verstärkt (Zvaritch et al. 2000), andererseits sind ähnliche Studien bekannt, in denen eine Pentamer-Überexpression selbigen Effekt zeigt (Zhai et al. 2000). Die Dephosphorylierung von PLN, und somit Wiederherstellung der SERCA2a-Inhibition, erfolgt hauptsächlich durch die Proteinphosphatase 1 (PP1) (Vafiadaki et al. 2013, Berrebi-Bertrand et al. 1998). Der Regulationsmechanismus der SERCA2a ist auch in Abbildung 2 dargestellt.

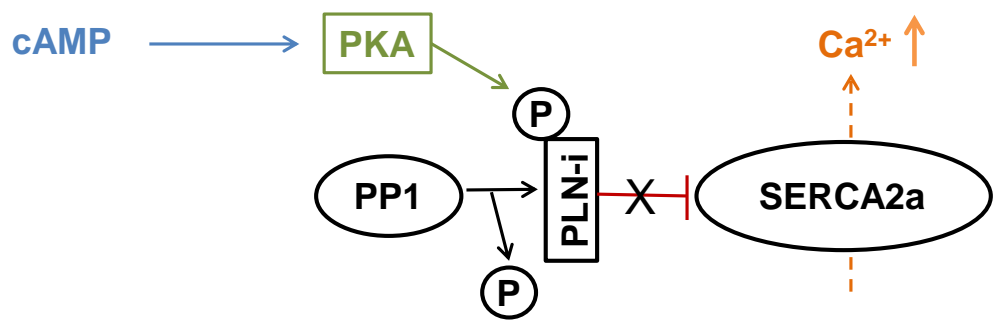

Abbildung 2: Regulation der SERCA2a. Nach cAMP-abhängiger Aktivierung der PKA bewirkt diese eine Phosphorylierung von PLN, wodurch dieses einen inaktiven Zustand einnimmt (PLN-i) und somit seine inhibitorische Wirkung auf die SERCA2a verliert. Dies bewirkt eine Steigerung der SERCA2a-Pumpaktivität und somit den vermehrten Transport von $\mathrm{Ca}^{2+}$ ins SR. Die Wiederherstellung der Hemmung der SERCA2a durch PLN erfolgt über seine Dephophorylierung vor allem durch die PP1.

Wie in anderen Zellkompartimenten leisten auch in der SERCA2a-Mikrodomäne PDEs einen wesentlichen Beitrag zur räumlichen Abgrenzung des cAMP-Signales. Studien an PDE3-KO-Mäusen zeigten, dass die PDE3A-Aktivität im Bereich der SERCA2a dazu beiträgt, unter basalen Bedingungen den $\mathrm{Ca}^{2+}$-Transport und somit die Myokardkontraktion zu beschränken (Beca et al. 2013). Eine andere Studie zeigte, dass auch die PDE4D einen relevanten Einfluss auf die SERCA2a-Aktivität unter basalen Bedingungen hat und durch lokale Beschränkung des CAMP-Pools die Phosphorylierung von PLN reguliert (Beca et al. 2011). Auch in aktuellen Untersuchungen unserer 
Arbeitsgruppe konnte - unter Verwendung derselben transgenen Mauslinie wie in dieser Arbeit - nachgewiesen werden, dass unter physiologischen Bedingungen bei basaler Aktivität die PDE3 und die PDE4 den wesentlichen Beitrag an der Regulation des CAMPPools der SERCA2a-Mikrodomäne leisten (Sprenger et al. 2015).

Als Strukturprotein ist AKAP18ס in der SERCA2a-Mikrodomände besonders relevant. Nach $\beta$-AR-Stimulation vermittelt AKAP18ס durch seine Scaffold-Funktion die Phosphorylierung von PLN durch die PKA und hebt so seine hemmende Wirkung auf die SERCA2a auf (Lygren et al. 2007). Des Weiteren wird auch die PKA-Phosphorylierung von I-1, einem Inhibitor der PP1, durch AKAP18ס vermittelt (Singh et al. 2011). Durch die daraus resultierende Hemmung der PP1 wird PLN vermindert dephosphoryliert, was ebenfalls seine inhibitorischen Wirkung auf die SERCA2a reduziert.

\subsection{Relevante pathologische Veränderungen im Rahmen der Herzinsuffizienz}

Im Rahmen der Manifestation und des Voranschreitens des Krankheitsbildes der Herzinsuffizienz sind verschiedenste molekulare, zelluläre und interstitielle Veränderungen bekannt, die sich auf Struktur, Größe und Funktion des Herzens auswirken und als „kardiales Remodeling“ bezeichnet werden (Cohn et al. 2000, Mann 1999). Als Ursache hierfür werden beispielsweise Veränderungen der neurohormonalen Stimulation, Zytokine und Stress gesehen, die zunächst kompensatorisch erfolgen, jedoch chronisch eine kardilale Fehlfunktion durch zusätzliches Remodeling verstärken. In diesem Kapitel werden bekannte, bei Herzinsuffizienz auftretende Remodelingvorgänge mit Bezug zu dieser Arbeit vorgestellt.

\subsubsection{Das transversal-axiale Tubulus-System (TATS) und sein pathologisches}

\section{Remodeling}

Transversale Tubuli (T-Tubuli) sind Einstülpungen der äußeren Zellmembran von Myozyten, die vor allem im Bereich von Sarkomer Z-Scheiben vorkommen. Sie verzweigen sich im Zellinneren zu einem komplexen Netzwerk aus transversalen und axialen Komponenten, welches die ganze Zelle durchzieht und auch als transversalaxiales Tubulus-System (TATS) bezeichnet wird (Soeller und Cannell 1999, Forbes und van Neil 1988). Das TATS ermöglicht, dass ein an der Membran ankommendes, erregendes Aktionspotential elektrisch schnell durch die ganze Muskelzelle weitergeleitet wird und bewirkt so die räumliche und zeitliche Synchronisierung der $\mathrm{Ca}^{2+}$-Freisetzung (Brette und Orchard 2003). Dies ist möglich, da das TATS viele für die Regulation des $\mathrm{Ca}^{2+}$-Haushaltes wichtige Strukturen in deutlich höherer Konzentration als die 
Oberflächenmembran enthält, hierunter der LTCC (Gu et al. 2002) und der NCX (Despa et al. 2003). Außerdem bringen T-Tubuli die LTCCs in räumliche Nähe zu den RyR2 (Song et al. 2005) und ermöglichen so die in Kapitel 1.4 beschriebene $\mathrm{Ca}^{2+}$-getriggerte $\mathrm{Ca}^{2+}$-Freisetzung aus dem SR (Fabiato und Fabiato 1975, Fabiato 1983). Folglich ist die reguläre Anordnung der TATS-Elemente entscheidend für eine effiziente Kontraktion des Myokards. Pathologische Veränderungen des $\mathrm{Ca}^{2+}-\mathrm{Kreislaufs}$ bei Herzinsuffizienz werden dementsprechend mit Remodeling-Vorgänge des TATS in Verbindung gebracht (Heinzel et al. 2008, Song et al. 2006, Louch et al. 2006). In zahlreichen Untersuchungen am Menschen und am Tiermodell konnten diesbezüglich unterschiedliche Veränderungen nachgewiesen werden, die wohl auf die jeweils verschiedenen Modelle und Bedingungen zurückzuführen sind:

Ein häufig beschriebenes Phänomen ist die Reduktion der TATS-Dichte in herzinsuffizienten Kardiomyozyten. Konfokalmikroskopische Untersuchungen von Hundeherzen zeigten, dass es nach Tachykardie-induzierter Herzinsuffizienz zu einer Abnahme der Dichte des TATS kommt (Balijepalli et al. 2003, He et al. 2001). Eine andere Studie, die zusätzlich zur Konfokalmikroskopie auch SICM anwendete wies zudem nach, dass auch in menschlichen und in Rattenkardiomyozyten ein pathologischer „Verlust von T-Tubuli“ erfolgt (Lyon et al. 2009). Zu selbigem Ergebnis führten auch Untersuchungen an einem post-MI Rattenmodell, wobei hier festgestellt wurde, dass dem Dichte-Verlust durch körperliche Betätigung teilweise entgegengewirkt werden kann (Kemi et al. 2011).

Des Weiteren wurden mehrfach räumliche Umstrukturierungen des TATS festgestellt: Nach Entwicklung einer Herzinsuffizienz in spontan hypertensiven Ratten zeigte sich, dass die T-Tubuli nicht mehr regulär entlang der Z-Linien angeordnet waren. Hierbei konnte im weniger strukturiert erscheinenden Netzwerk eine Zunahme axialer Elemente bei gleichzeitiger Reduktion der transversalen Elemente durch zellweite Fourier-Analyse des Streifensignals festgestellt werden (Song et al. 2006). Der Studie zu Folge führt das TATS-Remodeling zur Verwaisung der RyR2 von TATS-Membranen, was mit einem Verlust an physiologisch regulierter $\mathrm{Ca}^{2+}$-Freisetzung aus dem $\mathrm{SR}$ korreliert. Eine Zunahme der axialen Elemente wurde auch in einer anderen Studie an herzinsuffizienten Hunden bestätigt (Sachse et al. 2012). Mittels höchstauflösender STED (stimulated emission depletion)-Mikroskopie konnte an lebenden Maus-Kardiomyozten eine Zunahme der TATS-Dichte zu einem frühen Zeitpunkt der Herzinsuffizienz (4 Wochen nach Infarkt) dargestellt werden, die mit einer signifikanten Zunahme axialer und auch schräg verlaufender Elemente einhergeht (Wagner et al. 2012). In dieser Studie wurde erstmals direkt quantitativ gezeigt, dass das TATS-Remodeling progredient abläuft, wobei das 
Netzwerk zu einem späteren Zeitpunkt zunehmend unstrukturierter erscheint und mit einem Verlust transversaler Elemente - bei signifikanter Zunahme der axial und schräg verlaufenden Anteile - einhergeht. Demzufolge scheint also das Ausmaß des TATSUmbaus mit dem Krankheitsstadium zu korrelieren. Dies wird auch durch eine Studie unterstützt, die Remodeling-Vorgänge beim Übergang von Herzhypertrophie zu Herzinsuffizienz untersucht und eine Korrelation des Remodeling-Grades mit dem Hypertrophiestatus und der linksventrikulären Pumpfunktion nachweisen konnte (Wei et al. 2010).

\subsubsection{Veränderungen der SERCA2a-Mikrodomäne im Rahmen des cAMP- Signalweges}

Es ist bekannt, dass es bei Herzinsuffizienz unter anderem zu Veränderungen der cAMPKompartimentierung und auch zum Remodeling bestimmter Mikrodomänen kommt. So kommt es durch die chronische Sympathikusaktivität im insuffizienten Herzen (s. a. Kapitel 1.1) auch zur Desensibilisierung der $\beta$-ARs (Marks 2013) und zu einer Herabregulierung der $\beta_{1}$-AR-Expression (Bristow et al. 1982, Miyamoto et al. 2014). Dies führt schließlich zu einer Verschiebung des Verhältnisses der $\beta_{1}$ - und $\beta_{2}$-ARs zueinander, von 75\%: 20\% unter normalen Bedingungen auf 50\%:50\% im Krankheitsfall (Lymperopoulos 2013). Allerdings scheint sich das vom $\beta_{2}$-AR vermittelte cAMP-Signal bei Herzinsuffizienz stark von dem an gesunden Herzen zu unterscheiden. Untersuchungen mit Hilfe der bereits erwähnten SICM/FRET-Technologie zeigten, dass unter pathologischen Bedingungen eine Umverteilung der $\beta_{2}$-ARs aus den T-Tubuli hin zu Bereichen der äußeren Membran erfolgt (Nikolaev et al. 2010). Im Rahmen dieser Studie wurde außerdem nachgewiesen, dass das cAMP-Signal der $\beta_{2}$-ARs nun eher dem diffusen Signal der $\beta_{1}$-ARs gleicht und nicht mehr, wie unter 1.2 beschrieben, kompartimentiert ist. Dementsprechend scheinen auch die erwähnten protektiven Effekte des $\beta_{2}$-AR, wie die Hemmung der Apoptose oder Verbesserung der Herzfunktion (s. 1.2), aufgehoben zu sein: In einer Studie an herzinsuffizienten Meerschweinchen wurde beispielsweise gezeigt, dass die Aktivierung von $\beta_{2}$-AR im Krankheitsfall die Entstehung ventrikulärer Arrhythmien begünstigt, was eine erhöhte Sterblichkeit durch plötzlichen Herztod zur Folge hat (Wang et al. 2015).

Darüber hinaus ist im Rahmen der Herzinsuffizienz eine verminderte Aktivität der SERCA2a bekannt (Meyer und Dillmann 1998, Schwinger et al. 1995). Die Ursachen hierfür werden kontrovers diskutiert. Eine Vielzahl von Studien an Menschen und an Tiermodellen zeigen, dass die SERCA2a-Expression bei Herzinsuffizienz reduziert ist 
bzw. dass eine Herabregulierung ihrer mRNA vorliegt (Zarain-Herzberg et al. 1996, Hasenfuss et al. 1994). Eine pathologische Bedeutung der SERCA-Abnahme bei Herzinsuffizienz wird auch in Experimenten an herzinsuffizienten Ratten gezeigt, bei denen durch Gentransfer-vermittelter SERCA2a-Überexpression eine Normalisierung des intrazellulären $\mathrm{Ca}^{2+}$-Handlings erzielt werden konnte (Lyon et al. 2011). Ebenso zeigte eine Phase 2 Studie an Patienten mit fortgeschrittener Herzinsuffizienz einen positiven Einfluss des SERCA2a-Gentransfers auf die Herzfunktion (Jessup et al. 2011). Für den wichtigsten Regulator der SERCA2a, PLN, konnte zwar eine Verminderung der mRNAKonzentration bei Herzinsuffizienz nachgewiesen werden, jedoch ging diese Beobachtung nicht mit einer veränderten Proteinexpression einher (Linck et al. 1996). Die Meinung, dass die PLN-Expression bei Herzinsuffizienz unverändert bleibt ist auch generell in der Literatur weit verbreitet (Park und Oh 2013, Kranias und Hajjar 2012). Wie in Kapitel 1.4 aufgezeigt, ist die inhibitorische Wirkung von PLN auf die SERCA2a jedoch nicht vorrangig von seiner Proteinmenge, sondern von seinem Phosphorylierungszustand abhängig. Studien an humanen Kardiomyozyten zeigten, dass die PKA-Phosphorylierung von PLN bei Herzinsuffizienz reduziert ist, was die $\mathrm{Ca}^{2+}$-Sensitivität der SERCA2a vermindert (Schwinger et al. 1999). Im Rahmen dessen wird vermutet, dass der reduzierte Phosphorylierungsstatus von PLN wesentlich durch eine vermehrte Aktivität der PLNdephosphorylierenden PP1 im Krankheitsfall beeinflusst wird (Sande et al. 2002, Huang et al. 1999). Eine Studie an Ratten zeigte, dass eine lang anhaltende $\beta$-AR-Stimulation, die auch bei Herzinsuffizienz gegeben ist (s. 1.1), eine erhöhte Aktivität der PP1 induzieren kann (Bokník et al. 2000). Eine spätere Studie am gleichen Tiermodell brachte verminderte mRNA-Level des PP1-Inhibitors I-1 hiermit in Zusammenhang (El-Armouche et al. 2007). Darüber hinaus konnten Untersuchungen an menschlichen Herzen sowohl die verminderte Expression als auch die verminderte Phosphorylierung von I-1 durch die PKA im Endstadium der Herzinsuffizienz nachweisen (El-Armouche et al. 2004). Bei Experimenten an hypertensiven Ratten, konnte nach Entwicklung von Herzinsuffizienz nicht nur eine Aktivitätsminderung von I-1, sondern auch von I-2, einem weiteren PP1Inhibitor, gezeigt werden (Gupta et al. 2005). Dem gegenüber konnte gezeigt werden, dass das kleine Hitzeschockprotein 20 (Hsp20), welches ebenfalls in der SERCA2aMikrodomäne vorkommt, bei Herzinsuffizienz vermehrt exprimiert und durch die PKA phosphoryliert wird (Qian et al. 2009, Fan et al. 2005). Die Ursache hierfür wird ebenfalls in der chronischen $\beta$-AR-Stimulation vermutet, unter welcher experimentell eben diese Effekte nachgewiesen werden konnten (Chu et al. 2004). Es wird davon ausgegangen, dass Hsp20 im Krankheitsfall eine eher kompensierende Rolle hat, da inm zahlreiche kardioprotektive Effekte, wie der Schutz vor Hypertrophie (Sin et al. 2011), die Hemmung von Apoptose (Fan et al. 2004), die Abschwächung kardialer Remodelingvorgänge (Fan 
et al. 2006) und der Schutz vor Ischämie- bzw. Reperfusions-Schäden (Fan et al. 2005) nachgewiesen wurden. Bezüglich der Aktivität und Expression der verschiedenen PDEFamilien in der SERCA2a-Mikrodomäne unter pathologischen Bedingungen ist bisher nur wenig bekannt. In der bereits erwähnten Vorläuferstudie unserer Arbeitsgruppe wurden bereits PDE-Aktivitäts-Profile an einem Herzhypertrophiemodell (TAC), welches das Vorstadium der Herzinsuffizienz beschreibt, bestimmt (Sprenger et al. 2015). Bei Untersuchung dieses frühen Pathomechanismus zeigte sich eine gesteigerte Aktivität der PDE2 nach $\beta$-AR-Stimulation und eine verminderte Aktivität der PDE4 unter basalen Bedingungen. Abgesehen hiervon wurden bisher nur PDE-Veränderungen an verschiedenen Krankheitsmodellen auf globalem Zellniveau beschrieben (Mehel et al. 2013, Mokni et al. 2010, Abi-Gerges et al. 2009). Über die PDE-Aktivitäten in der SERCA2a-Mikrodomäne bei Herzinsuffizienz ist bisher nichts bekannt. Der lokale CAMPPool und die davon abhängige PKA-Aktivität hat wie aufgezeigt jedoch einen entscheidenden Einfluss auf die veränderte Regulation des $\mathrm{Ca}^{2+}$-Haushaltes und trägt so zur Entstehung und dem Fortschreiten der Pathologie bei. Um ein besseres Verständnis zu entwickeln, wurden im Rahmen dieser Arbeit die Aktivitäten der verschiedenen PDEFamilien in der Mikrodomäne am Modell der Myokardinfarkt-induzierten Herzinsuffizienz zu einem späteren Krankheitszeitpunkt untersucht.

\subsection{FRET-basierte Messung von cAMP}

Eine etablierte Methode, um die Dynamik sekundärer Botenstoffe in lebenden Zellen zu untersuchen, ist die Verwendung von auf Fluoreszenz-Resonanz-Energietransfer (FRET)basierenden Biosensoren. FRET ist ein distanzabhängiger fotophysikalischer Prozess, bei dem es zum strahlenfreien Energieaustausch zwischen fluoreszierenden Molekülen kommt (Förster 1948). Wie im Jablonski-Schema in Abbildung 3A dargestellt, wird ein Donor-Fluorophor durch Anregung mit Licht spezifischer Wellenlänge von seinem Grundzustand $S_{0}$ auf ein höheres Erregungsniveau $S_{1}$ gebracht. Beim Rückfall in den Grundzustand, wird Energie frei, die zum einen als Fluoreszenz erkennbar wird, zum anderen aber auch in Form von FRET auf ein geeignetes Akzeptor-Fluorophor übergeht. Hierdurch wird auch das Akzeptor-Fluorophor zum Übergang auf $S_{1}$ angeregt und setzt bei Wiederkehr in $\mathrm{S}_{0}$ ebenfalls seine Energie in Form von Fluoreszenz frei. 
A

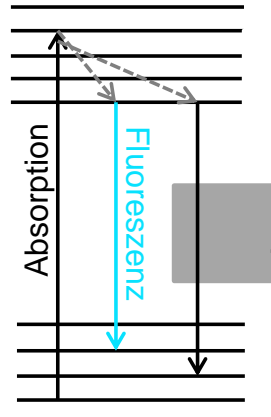

Donor

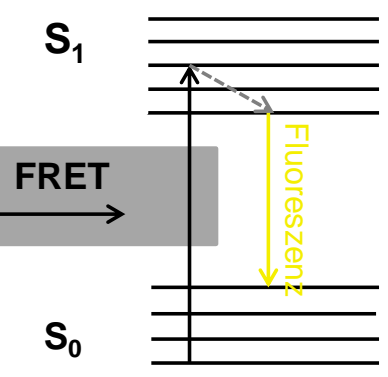

Akzeptor
B

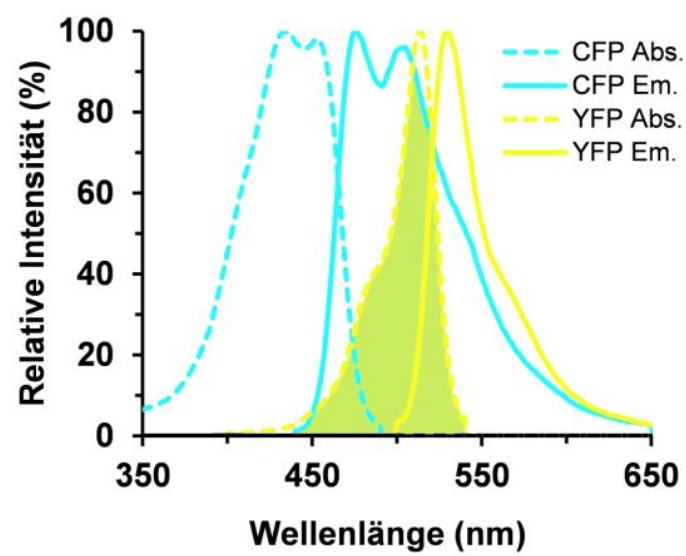

Abbildung 3: Grundlagen des FRET. A Das Jablonski-Schema zeigt den Mechanismus des Fluoreszenz-Resonanz-Energie-Transfers. Durch Photonen-Absorption werden die Elektronen des Donors vom Grundzustand $S_{0}$ in einen höheren Erregungszustand $S_{1}$ gebracht. Bei Rückkehr in $S_{0}$ wird Energie in Form von Fluoreszenz frei und kann bei räumlicher Nähe $(<10 \mathrm{~nm})$ mittels FRET auf einen geeigneten Akzeptor mit niedrigerem Erregungsspektrum übertragen werden. Hierdurch werden die Elektronen des Akzeptors angeregt und lassen bei Rückfall auf $S_{0}$ ebenfalls Fluoreszenzemission erkennnen. B Wichtige Vorraussetzung für FRET ist neben der räumlichen Nähe der Fluorophore auch die Überlappung des Emissionsspektrums des Donors mit dem Absorptionsspektrum des Akzeptors. Wie durch den grün hinterlegten Bereich dargestellt, ist diese Bedingung für das FRET-Paar mit CFP als Donor und YFP als Akzeptor erfüllt.

Wichtige Bedingung für FRET ist, dass die beiden Fluoreszenzmoleküle einen Abstand zwischen 1-10 nm zueinander haben (Sun et al. 2011). Außerdem ist entscheidend, dass sich das Emissionsspektrum des Donors mit dem Absorptionsspektrum des Akzeptors wesentlich überschneidet. Diese Vorrausetzung erfüllt das auch in dieser Arbeit verwendete FRET-Paar aus cyan fluoreszierendem Protein (CFP) und gelb fluoreszierendem Protein (YFP), wobei CFP, dessen Anregung bei einer kürzeren Wellenlänge erfolgt, als Donor und YFP als Akzeptor fungiert (s. Abb. 3 B). Das Ausmaß des Energietransfers lässt sich dann am einfachsten durch Verhältnissetzung der Emissionsintensitäten von Donor und Akzeptor ermitteln. Auf Grundlage von FRET wurden in den letzten Jahrzehnten bereits zahlreiche Biosensoren zur Messung intrazellulärer cAMP-Konzentrationen entwickelt, die nach unterschiedlichen Prinzipien arbeiten (Sprenger und Nikolaev 2013). Ein Mechanismus ist beispielsweise die Verwendung von A-Kinase-Aktivitäts-Reportern (AKAR), welche eine Phosphorylierungsstelle für die PKA besitzen und so, gekoppelt mit FRET-fähigen Fluoreszenzprotein-Paaren, indirekt Auskunft über den cAMP-Spiegel geben (Depry et al. 2011, Allen und Zhang 2006). Dieser Mechanismus wurde auch verwendet, um einen PLN-gekoppelten FRET-Sensor, SR-AKAR3, zu entwickeln und so die spezifisch PLNlokalisierte PKA-Aktivität in der SERCA2a-Mikrodomäne zu messen (Liu et al. 2011). Die transiente Expression des Sensors in neonatalen Rattenkardiomyozyten wurde hier wie 
weitgehend üblich mittels Adenovirus-Infektion erzielt (Kirshenbaum et al. 1993). Nachteil dieser Methode ist, dass für den Gentransfer eine Zellkultur von mindestens 48 Stunden nötig ist, was vor allem bei empfindlichen Mauskardiomyozyten ohne die Zugabe von Zusatzstoffen problematisch ist (Kabaeva et al. 2008). Um dieses Problem zu umgehen, wurden transgene Mauslinien entwickelt, welche derartige Biosensoren direkt in vivo exprimieren, ohne dabei Einfluss auf die physiologische Herzfunktion zu nehmen (Calebiro et al. 2009, Nikolaev et al. 2006). Hierzu gehört auch die in dieser Arbeit verwendete neue Linie der Epac1-PLN-transgenen FVB/N-Mäuse (Sprenger et al. 2015), die einen Epac1-cAMP-Biosensor durch feste Kopplung an PLN in der SERCA2aMikrodomäne tragen (zur Kreation dieser Mauslinie s. a. Kapitel $2.1 \mathrm{im}$ Methodenteil). Das Prinzip dieses Sensors basiert auf der Kopplung der FRET-fähigen Fluoreszenzprotein CFP und YFP an CAMP-bindendes Epac1, ein Konzept, welches bereits im Vorfeld mehrfach zur Anwendung kam (Nikolaev et al. 2004, Ponsioen et al. 2004, DiPilato et al. 2004). Wie in Abbildung 4 dargestellt kommt es bei Bindung von cAMP an Epac1 zu einer Konformationsänderung, die mit einem verminderten Energietransfer mittels FRET einhergeht. Auf diese Weise ist es möglich, an frisch isolierten lebenden Kardiomyozyten, durch Messung des Verhältnisses von Donor- und Akzeptor-FluoreszenzemissionsIntensitäten, Aussagen über die lokale cAMP-Dynamik unter möglichst physiologischen Bedingungen zu treffen.

A

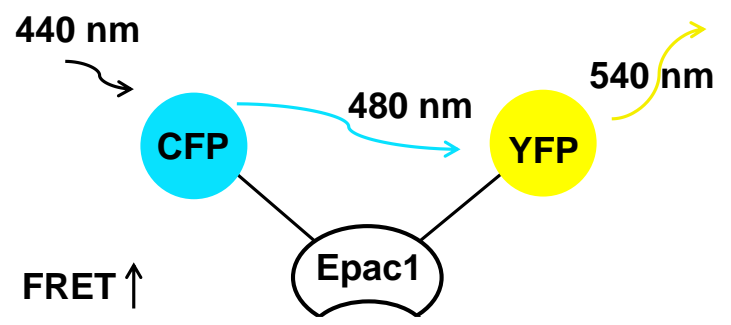

B

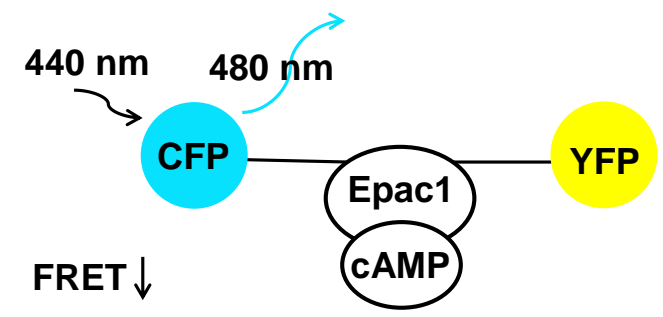

Abbildung 4: Schematische Darstellung der Funktionsweise des Epac1-cAMP-FRETSensors. A In Abwesenheit von cAMP kommt es nach Anregung des Donors CFP zum Energietransfer mittels FRET auf den sich in unmittelbarer Nähe befindenden Akzeptor YFP, welcher daraufhin vermehrt Licht der Wellenlänge $540 \mathrm{~nm}$ emittiert, das dann gemessen wird. B Nach Bindung von cAMP an Epac1 kommt es zur Konformationsänderung, die in einem „Auseinanderdriften“ der Fluoreszenzproteine resultiert. Der Energietransfer mittels FRET wird so cAMP-abhängig vermindert, was sich in einer vermehrten CFP-Fluoreszenzemission bei vermindert detektierbarer YFP-Emissionsintensität zeigt. 


\subsection{Ziel dieser Arbeit}

Ziel dieser Studie war es, Veränderungen im lokalen cAMP-Pool der SERCA2aMikrodomäne in kardialer Myozyten unter den pathologischen Rahmenbedingungen der Herzinsuffizienz zu untersuchen. Hierfür sollten Experimente an einer transgenen Mauslinie durchgeführt werden, welche einen FRET-cAMP-Biosenser - Epac1-PLN lokalisiert in der SERCA2a-Mikrodomäne exprimiert. Zur Kranheitsinduktion wurde eine Myokardinfarkt-induzierende Operation gewählt, deren Erfolg und regelhafte Ausbildung des Krankheitsbildes mittels verschiedener Verfahren validiert werden sollte. Im Zuge dessen sollten auch Remodelingvorgänge des TATS untersucht werden, da diese eng mit pathologischer Dysfunktion in Zusammenhang stehen und Hinweise auf das Ausmaß des Krankheitsbildes geben können. Des Weiteren sollte die regelhafte Expression und Lokalisation des transgenen Sensors im Krankheitsfall überprüft werden, um die angestrebte Messung kompartimentierter Signale zu bestätigen. Mit Hilfe von EchtzeitFRET-Messungen an frisch isolierten, lebenden Kardiomyozyten sollten dann die Beiträge verschiedener PDE-Familien zur Begrenzung des lokalen cAMP-Pools in der SERCA2aDomäne unter pathologischen Bedingungen gemessen und mit einer Kontrollgruppe verglichen werden. Da die SERCA2a ein wichtige Stellung in der Regulation des intrazellulären $\mathrm{Ca}^{2+}$-Haushaltes unter physiologischen und pathologischen Bedingungen einnimmt und durch lokale cAMP-Spiegel beeinflussbar ist, können die hierbei gewonnenen Erkenntnisse ein besseres Verständnis für molekulare Mechanismen sowie Krankheitsfortschreiten und Pathophysiologie schaffen. 


\section{Methoden}

Alle Tierversuche wurden vom Tierschutzbüro der Universitätsmedizin Göttingen und dem Niedersächsischen Landesamt für Verbraucherschutz und Lebensmittelsicherheit (LAVES) geprüft und genehmigt. Eine Auflistung der Verbrauchsgegenstände, Chemikalien und Antikörper sowie der verwendeten Geräte und Software befindet sich im Anhang (6.1-6.6).

\subsection{Epac1-PLN-transgene Mauslinie}

Zur Untersuchung der cAMP Signaldynamik in der SERCA2a-Mikrodomäne hatte Dr. Julia Sprenger bereits im Zuge ihrer Promotion die Linie der Epac1-PLN-transgenen FVB/NMäuse generiert (Sprenger 2014), an der alle Experimente dieser Studie erfolgten. Diese Mauslinie exprimiert herzspezifisch einen SERCA2a-gekoppelten, auf FluoreszenzResonanz-Energie-Transfer (FRET) basierenden Sensor (s.a. 1.6), welcher durch zyklisches Adenosin-Monophosphat (cAMP) stimuliert wird. Wie in Abbildung 5 dargestellt, ist der Epac1-PLN-cAMP-Sensor über CFP permanent an Phospholamban (PLN) gekoppelt und somit fest in der SERCA2a-Domäne verankert.
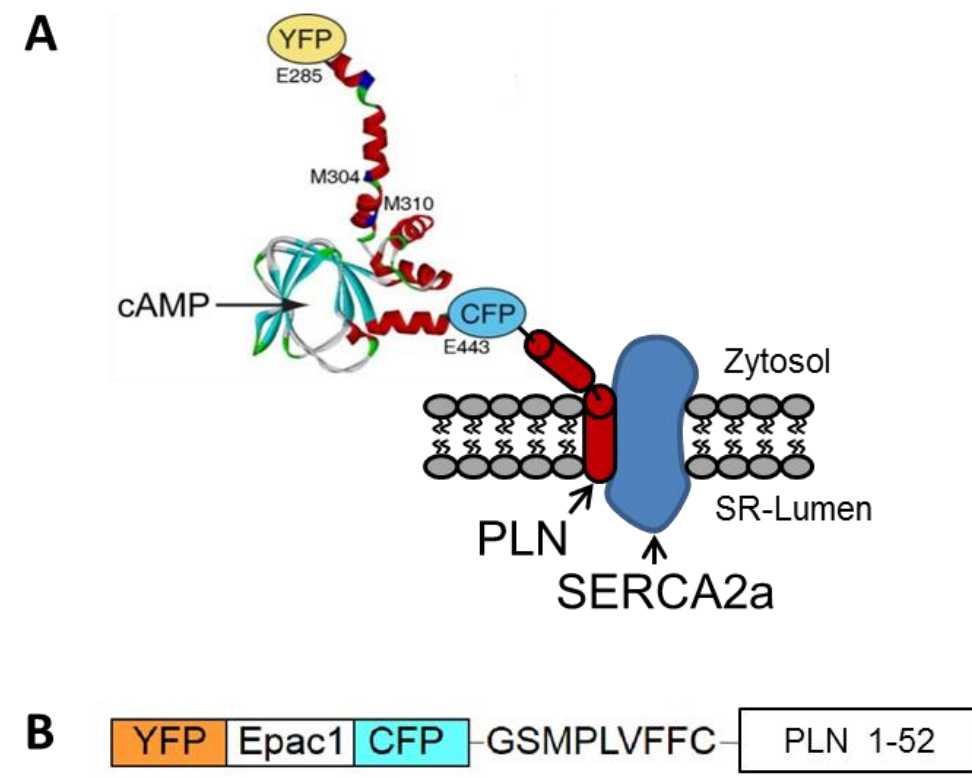

Abbildung 5: Schematische Darstellung des Epac1-PLN-Biosensors.* Grafik A zeigt die angenommene Lokalisation zur SERCA2a-Mikrodomäne innerhalb transgener Kardiomyozyten. Die Bindungsstelle von cAMP an humanes Epac1 ist mit einem Pfeil gekennzeichnet. In B ist der Sensor in linearer Anordnung und seine Kopplung über CFP an PLN dargestellt.

* Beide Zeichnungen sind mit freundlicher Genehmigung der Dissertation von Dr. Julia Sprenger entnommen (Sprenger 2014). 
Um die Sensorexpression zu ermöglichen, wurde ein Vektor erstellt, welcher den $\alpha$ Myosin-schwere-Kette( $\alpha-\mathrm{MHC})$-Promotor für herzspezifische Expression enthält (Nikolaev et al. 2006). Grundlage hierfür war die Subklonierung des vollständigen Epac1-PLNVektors (pcDNA3.1), welcher bereits 2010 durch Dr. Viacheslav Nikolaev in Würzburg erstellt wurde. Der Aufbau des a-MHC-Vektors ist in Abbildung 6 dargestellt.

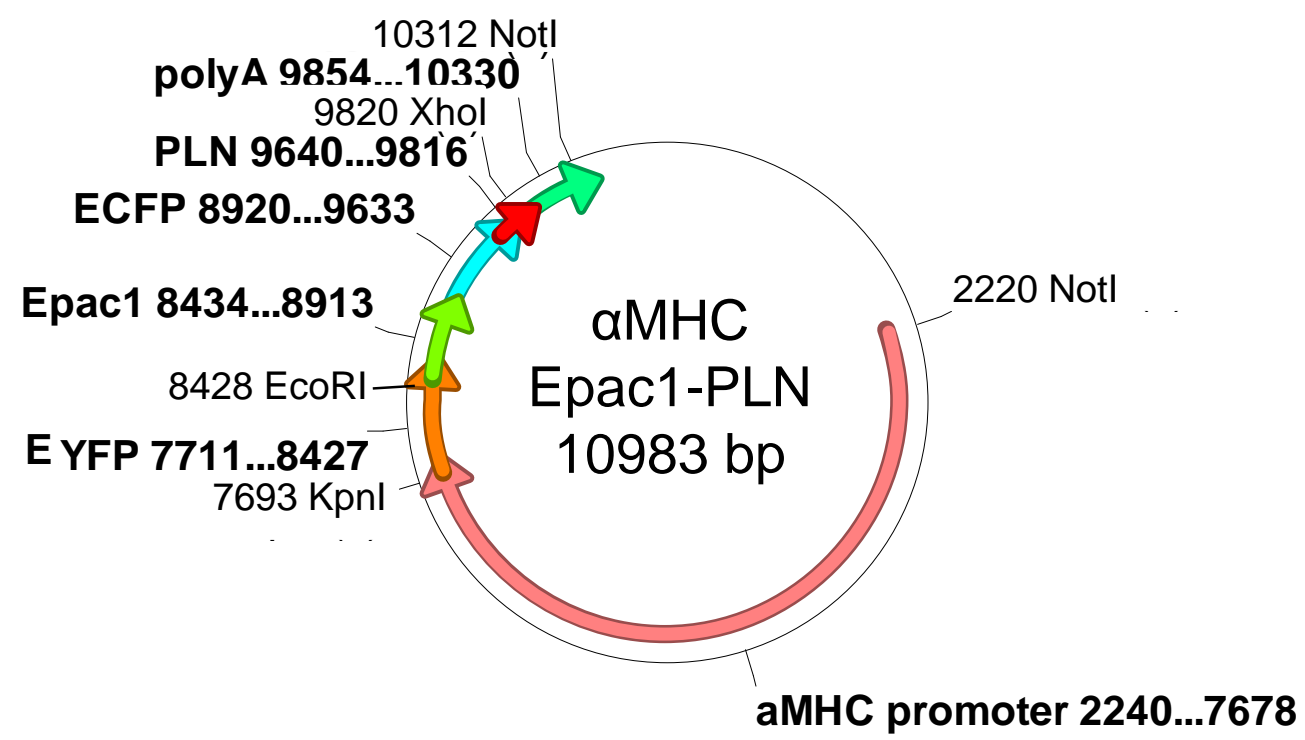

Abbildung 6: Plasmidkarte des a-MHC-Vektors. Neben den fettgedruckten Kodierungssequenzen sind auch die Schnittstellen der Restriktionsenzyme angegeben. Durch den a-MHCPromoter wird die kardiale Expression gewährleistet.

Nach der Linearisierung des Epac1-PLN-Konstruktes wurde dieses in den Vorkern von FVB/N-Mäusen eingebracht. Die Mikroinjektion wurde durch das Max-Planck-Institut für Experimentelle Medizin in Göttingen nach bereits beschriebener Vorgehensweise durchgeführt (Buitrago et al. 2005). Eine Gründermaus, welche den Sensor in nahezu allen Kardiomyozyten exprimierte, wurde schließlich mit einem Wildtyp-FVB/NRjWeibchen verpaart. Die heterogenen Folgegenerationen wurden dann über ein Schwanzspitzenbiopsat mittels Standard-PCR durch Tobias Goldak der AG Nikolaev (Abteilung Kardiologie und Pneumologie der Universitätsmedizin Göttingen) genotypisiert. Die den Epac1-PLN-cAMP-Sensor tragenden Mäuse konnten so anhand positiver Banden bei 340 bp identifiziert werden. 


\subsection{Krankheitsmodell}

Für diese Studie wurden Epac1-PLN-transgene weibliche Mäuse im Alter von 8-12 Wochen randomisiert der Kontroll- (Sham) oder Myokardinfarkt(MI)-Gruppe zugeteilt und der jeweiligen Operation unterzogen. Zur Ausbildung des Krankheitsbildes der Herzinsuffizienz wurden 12 Wochen nach Intervention gewährt. Erst dann erfolgte die echokardiografische Phänotypisierung und anschließend die Umsetzung der Experimente.

\subsubsection{Ligatur des RIVA zur Induktion eines Myokardinfarktes}

Der operative Eingriff und das perioperative Management, wurde von Dr. Daniela Hübscher (Abteilung Kardiologie und Pneumologie der Universitätsmedizin Göttingen) wie in ihrer Dissertation beschrieben durchgeführt (Hübscher 2012).

Zur Schmerztherapie erfolgte 3 Tage vor dem Eingriff die Gabe von Metamizol (Novaminsulfon $500 \mathrm{mg}$ Lichtenstein, Zentiva) über das Trinkwasser (1 Tropfen pro $10 \mathrm{ml}$ ) sowie eine Stunde präoperativ die intraperitoneale Verabreichung von $0,1 \mathrm{mg} / \mathrm{kg}$ Buprenorphin (Temgesic $\AA$, Essex Pharma $\mathrm{GmbH}$ ). Während der Operation befand sich die Maus intubiert in Inhalationsanästhesie unter $2 \%$ Isofluran (Florene ${ }^{\circledR}$, Abbott) - gelöst in Sauerstoff - bei einem Atemzugvolumen von ca. 0,15 ml und einer Frequenz von 150/min. Der operative Zugang erfolgte durch linksseitige laterale Thorakotomie. Nach Eröffnung des Perikards wurde der Myokardinfarkt mittels Ligatur des Ramus interventricularis anterior (RIVA) mit einer nicht-resorbierbaren 9-0-Polyamidnaht (Ethilon, Ethicon) herbeigeführt. Der Erfolg der Intervention konnte durch die Entfärbung des distal gelegenen Gewebes auf Grund der Unterbindung der Blutzufuhr direkt beobachtet werden. Nach Verschluss der Thoraxwand mit einer 6-0-Naht (Prolene, Ethicon) wurde die Isofluranzufuhr beendet und die Maus nach Einsetzen der regelhaften Spontanatmung extubiert. Während der postoperativen Regenerationsphase erfolgte weiter die Schmerztherapie mit Metamizol für 7 Tage, wobei der Gesundheitszustand der operierten Tiere täglich überprüft wurde.

Die Operation und Behandlung der Sham-Mäuse erfolgte nach demselben Schema, jedoch mit der Ausnahme, dass in dieser Gruppe die Unterbindung der linken Koronaraterie ausblieb. 


\subsubsection{Echokardiografie}

Die Herzfunktion der Sham- und MI-operierten Mäuse wurde 12 Wochen nach dem Eingriff (12pMl) mittels Echokardiografie (Vevo 2100, VisualSonics) unter Verwendung eines $30 \mathrm{~Hz}$ Schallkopfes (MS400 MicroScan ${ }^{\mathrm{TM}}$ Transducer) charakterisiert. Unter Sedierung mit 1.5\% Isofluran wurden die in Tabelle 1 genannten morphologischen und funktionellen Herzparameter bestimmt.

Tabelle 1: Parameter der Echokardiografie

\begin{tabular}{ll}
\hline Parameter & Abkürzung \\
\hline Vorderwanddicke in der Diastole & AWThd \\
Vorderwanddicke in der Systole & AWThs \\
Linksventrikulärer enddiastolischer Durchmesser & LVEDD \\
Linksventrikulärer endsystolischer Durchmesser & LVESD \\
Enddiastolisches Volumen & EDV \\
Endsystolisches Volumen & ESV \\
Kammerquerschnittsfläche in der Diastole & EDA \\
Kammerquerschnittsfläche in der Systole & ESA \\
Systolische epikardiale Fläche & Epis \\
Lange Achse (Aortenklappe bis Herzspitze) in der Systole & LS \\
Herzfrequenz & HF \\
\hline
\end{tabular}

Aus den ermittelten Werten wurden dann weitere charakteristische Kenngrößen berechnet: Die Ejektionsfraktion (EF) ist die Menge des ausgeworfenen Blutes während der Systole und entspricht dem Quotienten aus Schlagvolumen (SV) und enddiastolischem Volumen (EDV). Das Schlagvolumen wiederum berechnet sich aus der Differenz zwischen EDV und ESV. Somit ergibt sich folgende Formel:

$\mathrm{EF}=\frac{\mathrm{SV}}{\mathrm{EDV}}=\frac{\mathrm{EDV}-\mathrm{ESV}}{\mathrm{EDV}} \times 100$

Die Verkürzungsfraktion (FS) ist ein Parameter für die Pumpfunktion des linken Ventrikels und beschreibt die Verkürzung des Herzens während der Systole. Sie berechnet sich wie folgt:

$\mathrm{FS}=\frac{\text { LVEDD }- \text { LVESD }}{\text { LVEDD }} \times 100$ 
Ähnliche Aussagekraft hat die fraktionelle Flächenänderungsrate (FAC), in die die Differenz der enddiastolischen (EDA) und endsystolischen Kammerquerschnittsfläche (ESA) einfließt:

$\mathrm{FAC}=\frac{\mathrm{EDA}-\mathrm{ESA}}{\mathrm{EDA}} \times 100$

Darüber hinaus wurde das Herzgewicht $(\mathrm{HW})$ mit folgender Formel näherungsweise ermittelt:

$\mathrm{HW}=1,05 \times \frac{5}{6} \times\left\{\left[\right.\right.$ Epis $\times\left(\right.$ Ls $\left.\left.+\frac{\text { AWThs }+ \text { AWThd }}{2}\right)\right]-($ ESA $\times$ Ls $\left.)\right\}$

Die echokardiografischen Untersuchungen wurden von Roland Blume und Marcel Zoremba der SFB-Service-Unit der Abteilung Kardiologie und Pneumologie der Universitätsmedizin Göttingen durchgeführt. Die Analyse der Daten erfolgte durch Beate Knocke in derselben Abteilung. Sowohl die Echokardiografie als auch die Auswertung fand als Blindversuch statt.

\subsection{Isolation ventrikulärer Kardiomyozten}

Die Isolation ventrikulärer Kardiomyozyten erfolgte mittels Langendorff Perfusion, wie bereits beschrieben (Götz und Nikolaev 2013). Dazu wurden die Mäuse mit Isofluran narkotisiert und der Tod durch Genickbruch herbeigeführt. Nach Eröffnung des Brustkorbs wurde das Herz zügig entnommen und direkt in eine mit eiskalter phosphatgepufferter Saline (PBS) gefüllte Petrischale überführt. Dort wurde das Herz über die Aorta auf eine stumpf geschliffene 21G Kanüle gezogen und befestigt. Die Perfusion des Herzens nach Langendorff erfolgte bei $37^{\circ} \mathrm{C}$ mit einer Flussrate von $3,5 \mathrm{ml} / \mathrm{min}$. Das Herz wurde hierzu zunächst für $3 \mathrm{~min}$ mit Perfusionspuffer und anschließend mit $30 \mathrm{ml}$ Verdaupuffer perfundiert. Im Anschluss an den Verdau wurden die Atrien sowie durch den Infarkt entstandenes Narbengewebe entfernt und die Ventrikel in 2,5 ml Verdaupuffer für $30 \mathrm{~s}$ grob zerkleinert. Durch Zugabe des Stopppuffers 1 wurde der Verdau beendet und die Zellsuspension für $3 \mathrm{~min}$ mit einer $1 \mathrm{ml}$ Spritze homogenisiert. Bevor das Pellet im Stopppuffer 2 resuspendiert wurde, wurden die Zellen zur Sedimentation 10 min bei Raumtemperatur belassen. Das weitere Vorgehen unterschied sich je nach Art des Versuches und wird an entsprechender Stelle beschrieben. Zur Zusammensetzung der verwendeten Substanzen siehe Tabelle 2. 
Tabelle 2: Lösungen und Puffer für die Kardiomyozytenisolation

\begin{tabular}{|c|c|c|}
\hline Substanz & Zusammensetzung & \\
\hline $\begin{array}{l}\text { Stock-Perfusionspuffer 10x } \\
\text { (steril filtriert) }\end{array}$ & $\begin{array}{l}\mathrm{NaCl} \\
\mathrm{KCl} \\
\mathrm{KH}_{2} \mathrm{PO}_{4} \\
\mathrm{Na}_{2} \mathrm{HPO}_{4} \times 2 \mathrm{H}_{2} \mathrm{O} \\
\mathrm{MgSO}_{4} \times 7 \mathrm{H}_{2} \mathrm{O} \\
\mathrm{Phenolrot} \\
\mathrm{NaHCO}_{3} \\
\mathrm{KHCO}_{3} \\
\mathrm{HEPES} \\
\text { Taurin }\end{array}$ & $\begin{array}{r}1,13 \mathrm{M} \\
47 \mathrm{mM} \\
6 \mathrm{mM} \\
6 \mathrm{mM} \\
12 \mathrm{mM} \\
0,32 \mathrm{mM} \\
120 \mathrm{mM} \\
100 \mathrm{mM} \\
100 \mathrm{mM} \\
300 \mathrm{mM}\end{array}$ \\
\hline $\begin{array}{l}\text { Perfusionspuffer } \mathbf{1 x} \\
\text { (steril filtriert) }\end{array}$ & $\begin{array}{l}\text { Stock-Perfusionspuffer 10x } \\
\text { BDM-Lösung } \\
\text { Glukose } \\
\text { Aqua dest. }\end{array}$ & $\begin{array}{r}10 \mathrm{ml} \\
2 \mathrm{ml} \\
100 \mathrm{mg} \\
\text { ad } 100 \mathrm{ml}\end{array}$ \\
\hline BDM-Lösung & BDM & $500 \mathrm{mM}$ \\
\hline BSA-Lösung (steril filtriert) & BSA & $10 \%$ \\
\hline $\mathrm{CaCl}_{2}$-Lösung $100 \mathrm{mM}$ (steril filtriert) & $\mathrm{CaCl}_{2}$ & $100 \mathrm{mM}$ \\
\hline $\mathrm{CaCl}_{2}$-Lösung $10 \mathrm{mM}$ (steril filtriert) & $\mathrm{CaCl}_{2}$ & $10 \mathrm{mM}$ \\
\hline $\begin{array}{l}\text { Liberase-Lösung } \\
\text { (sterile Bedingungen) }\end{array}$ & $\begin{array}{l}\text { Liberase } \mathrm{DH} \\
\text { Aqua dest. }\end{array}$ & $\begin{array}{l}50 \mathrm{mg} \\
12 \mathrm{ml}\end{array}$ \\
\hline Verdaupuffer & $\begin{array}{l}\text { Perfusionspuffer } 1 \mathrm{x} \\
\mathrm{CaCl}_{2} \text {-Lösung } 100 \mathrm{mM} \\
\text { Trypsin 2,5\% } \\
\text { Liberase-Lösung }\end{array}$ & $\begin{array}{r}2,6 \mathrm{ml} \\
3,75 \mu \mathrm{l} \\
200 \mu \mathrm{l} \\
450 \mu \mathrm{l}\end{array}$ \\
\hline Stopppuffer 1 & $\begin{array}{l}\text { Perfusionspuffer } 1 \mathrm{x} \\
\text { BSA-Lösung } \\
\mathrm{CaCl}_{2} \text {-Lösung } 100 \mathrm{mM}\end{array}$ & $\begin{array}{l}2,25 \mathrm{ml} \\
250 \mu \mathrm{l} \\
1,25 \mu \mathrm{l}\end{array}$ \\
\hline Stopppuffer 2 & $\begin{array}{l}\text { Perfusionspuffer } 1 \mathrm{x} \\
\text { BSA-Lösung } \\
\mathrm{CaCl}_{2} \text {-Lösung } 100 \mathrm{mM}\end{array}$ & $\begin{array}{l}9,5 \mathrm{ml} \\
500 \mu \mathrm{l} \\
3,75 \mu \mathrm{l}\end{array}$ \\
\hline
\end{tabular}




\subsection{Epifluoreszenzmikroskopie und FRET-Messungen}

\subsubsection{Vorbereitung der Zellen}

Um den isolierten Kardiomyozyten eine möglichst physiologische Umgebung zu schaffen, erfolgte vor den FRET-Experimenten ein $\mathrm{Ca}^{2+}$-Aufbau mit den oben genannten $\mathrm{CaCl}_{2}{ }^{-}$ Lösungen im Stopppuffer 2. Hierbei wurden folgende Mengen der entsprechenden Lösung zur Zellsuspension gegeben und zwischen jedem Schritt 4 min zur Adaptation gegeben:

$$
\begin{array}{rrr}
50 \mu \mathrm{CaCl}_{2} 10 \mathrm{mM} & \text { Endkonzentration } & 62 \mu \mathrm{M} \\
50 \mu \mathrm{CaCl}_{2} 10 \mathrm{mM} & \text { Endkonzentration } 112 \mu \mathrm{M} \\
100 \mu \mathrm{l} \mathrm{CaCl}_{2} 10 \mathrm{mM} & \text { Endkonzentration } 212 \mu \mathrm{M} \\
30 \mu \mathrm{CaCl}_{2} 100 \mathrm{mM} & \text { Endkonzentration } 500 \mu \mathrm{M} \\
50 \mu \mathrm{CaCl}_{2} 100 \mathrm{mM} & \text { Endkonzentration } 1000 \mu \mathrm{M}
\end{array}
$$

Nach der Rekalzifizierung wurden die Kardiomyozyten zur Sedimentation 10 min bei $37^{\circ} \mathrm{C}$ und $5 \% \mathrm{CO}_{2}$ in den Inkubator gestellt. Dort wurden die Zellen nach Ausplattierung auf Laminin-beschichtete Deckgläser ( $\varnothing 24 \mathrm{~mm}$ ) auch wieder bis zu ihrer Verwendung aufbewahrt.

\subsubsection{FRET-Messungen und Datenanalyse}

Sowohl Messungen als auch Mikroskopaufbau und Datenanalyse wurden entsprechend dem bereits veröffentlichten Video-Artikel durchgeführt, dem auch weitere Details entnommen werden können (Sprenger et al. 2012).

Tabelle 3: Zusammensetzung des FRET-Puffers

\begin{tabular}{l|lc}
\hline & Zusammensetzung \\
\hline FRET-Puffer & $\mathrm{NaCl}$ & $144 \mathrm{mM}$ \\
& $\mathrm{KCl}$ & $5,4 \mathrm{mM}$ \\
& $\mathrm{MgCl}_{2}$ & $1 \mathrm{mM}$ \\
& $\mathrm{CaCl}_{2}$ & $1 \mathrm{mM}$ \\
& $\mathrm{HEPES}$ & $10 \mathrm{mM}$ \\
& $\mathrm{NaOH}$ & bis pH 7,3 \\
\hline
\end{tabular}

Frühestens 30 min nach Ausplattierung der Kardiomyozyten wurden die besäten Deckgläser in der Messkammer befestigt, die Zellen einmal mit $400 \mu$ FRET-Puffer 
gewaschen und anschließend mit $400 \mu$ FRET-Puffer bedeckt (Zusammensetzung s. Tab. 3).

Die Messungen erfolgten an einem inversen Epifluoreszenz-Mikroskop mit einem 40x ÖlObjektiv, welches durch die MicroManager Freeware gesteuert wurde. Der schematische Aufbau ist in Abbildung 7 dargestellt. Durch eine CoolLED, welche Licht der Wellenlänge $440 \mathrm{~nm}$ ausstrahlt, wurde der FRET-Sensor-Donor CFP angeregt. Das daraufhin aus der Probe emittierte Licht wurde durch einen DualView-Filter in ein CFP- und ein YFP-Signal aufgeteilt, welche dann mit Hilfe einer CCD-Kamera detektiert wurden.
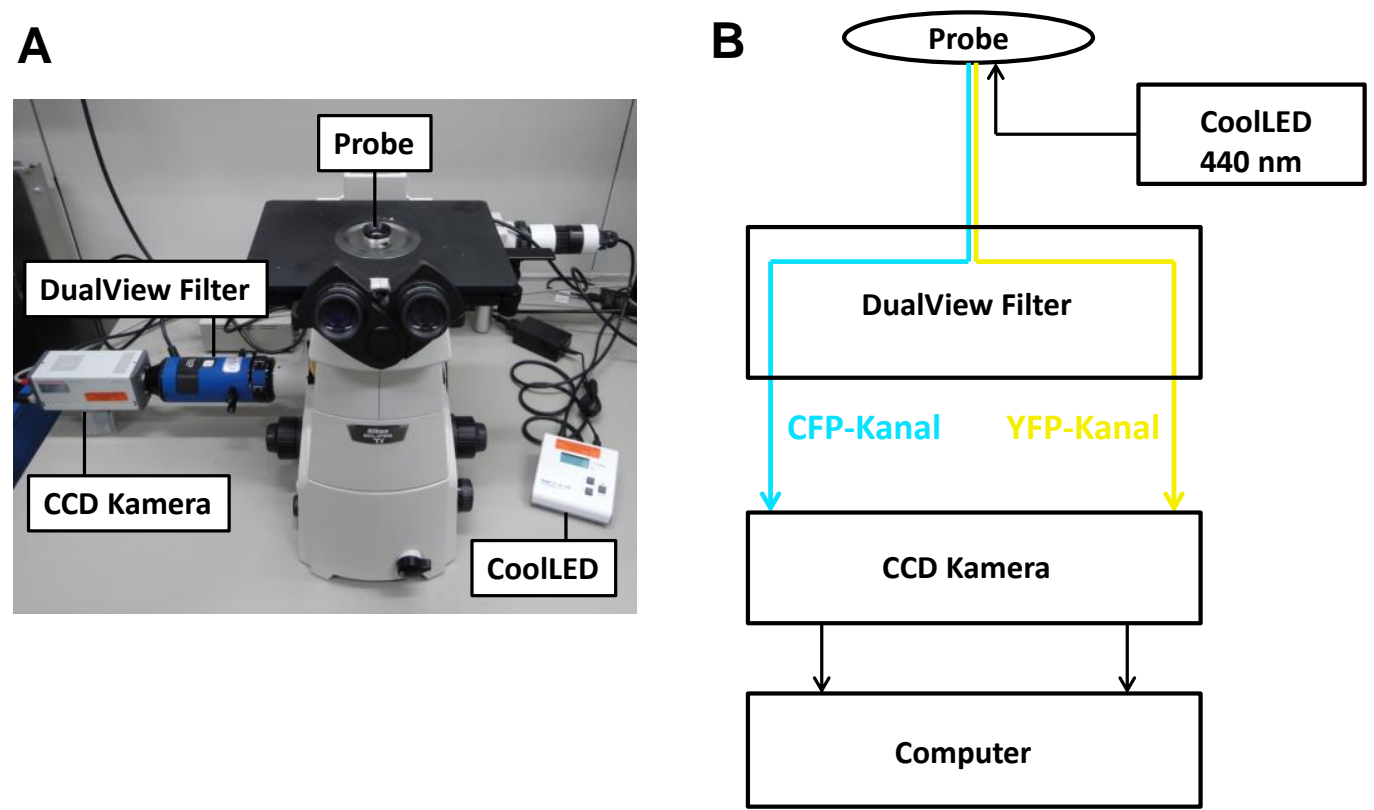

Abbildung 7: Aufbau des FRET-Mikroskops. A Foto des Mikroskopaufbaus B Die Anregung der transgenen Kardiomyozyten in der Probe erfolgte bei $440 \mathrm{~nm}$ mittels einer CoolLED. Das emittierte Licht wurde dann durch den DualView-Filter in den Donor(CFP)- und Akzeptor(YFP)-Kanal gespalten und beide Kanäle durch die CCD-Kamera aufgenommen. Am Computer wurden die jeweiligen Intensitäten dann mit Hilfe von ImageJ gemessen und die FRET-Ratio ermittelt.

Für die bei Raumtemperatur erfolgten Experimente wurden Kardiomyozten ausgewählt, welche den Sensor so exprimierten, dass sich unter dem Mikroskop eine mittelstarke Fluoreszenz erkennen ließ. Um Photobleichung zu vermeiden, wurde die Bestrahlung mit Fluoreszenzlicht möglichst kurz gehalten. Die Aufnahmen des CFP- und YFP-Kanals erfolgten alle $5 \mathrm{~s}$, wobei die optimale Belichtungszeit in der Regel um die $10 \mathrm{~ms}$ lag. Vor und zwischen der Stimulation der Zellen mit in FRET-Puffer verdünnten Pharmaka, wurde jeweils das Erreichen einer stabilen Grundlinie der YFP/CFP-Ratio abgewartet.

Die Datenanalyse erfolgte nach Beendigung der Experimente offline. Die Intensitäten der Aufnahmen im Donor(CFP)- und Akzeptor(YFP)-Kanal wurden mit Hilfe der ImageJ 
Software in ausgewählten Bildregionen (ROIs) gemessen und die Werte anschließend in Excel kopiert. Die korrekte YFP/CFP- oder auch FRET-Ratio errechnete sich dann, unter Berücksichtigung des Durchblutens der CFP-Emission in den YFP-Kanal, mit folgender Formel:

FRET Ratio $=\frac{\text { YFP }-0,63 \times \text { CFP }}{\text { CFP }}$

Der Faktor 0,63 entspricht dem Anteil der Donorfluoreszenz im Akzeptorkanal (YFP/CFP) und wurde bereits an Zellen, welche mit einem CFP-Plasmid transfiziert worden waren, ermittelt. Die so erhaltenen Daten konnte dann grafisch dargestellt und das Ausmaß der FRET-Antwort auf die verschiedenen Stimulantien ermittelt werden.

\subsection{Konfokalmikroskopie}

Die Bildgebung zur Beantwortung strukturanalytischer Fragestellungen erfolgte mit einem konfokalen Laser-Scanning-Mikroskop (LSM710, Carl Zeiss) unter Verwendung eines 63x 1.4 NA Öl-Objektives. Zur Aufnahme der Bilder wurde die zugehörige Software des Herstellers (ZEN 2009) verwendet, welche die Bilder als proprietäres „.Ism“ Dateiformat speichert. Die Pixelgröße wurde auf $0,1 \mu \mathrm{m} \times 0,1 \mu \mathrm{m}$ bei einer Verweildauer von 0,5-0,6 $\mu \mathrm{s}$ pro Bildpunkt festgelegt. Bei allen Aufnahmen wurden zusätzlich zu den gefärbten Proteinen, jeweils das CFP- und das YFP-Signal des Epac1-PLN-cAMP-Sensors detektiert. Die Mikroskopeinstellungen, Farbstoffe und Antikörper wurden so gewählt, dass alle Signale getrennt voneinander ohne Durchbluten dargestellt werden konnten. Außerdem wurde von jeder Zelle ein Durchlichtbild zur Beurteilung der Zellqualität und Bestimmung der Zellgröße erstellt, für welches die Pixelgröße bei hypertrophen Zellen gegebenenfalls auf $0,38 \mu \mathrm{m} \times 0,38 \mu \mathrm{m}$ erhöht wurde.

\subsubsection{Vorbereitung der Zellen}

Die Isolation der ventrikulären Kardiomyozyten erfolgte wie unter 2.3 beschrieben, jedoch wurde im Stopppuffer 2 sowie in dem im weiteren Verlauf verwendeten Perfusionspuffer auf die Zugabe von Phenolrot verzichtet, um bei der Bildgebung die Detektion des roten Farbstoffes zu vermeiden. Im Anschluss an die Überführung der Zellen in Stopppuffer 2 wurden ca. 10 min bei Raumtemperatur zur Sedimentation der Kardiomyozyten gewährt. Das Zellpellet wurde in Perfusionspuffer resuspendiert und nach weiteren $5 \mathrm{~min}$ Sedimentationszeit für Membranfärbungen (s. 2.5.2) verwendet oder für Immunfärbungen direkt fixiert (s. 2.5.3). 


\subsubsection{Membranfärbung mit di-8-ANEPPS und Lebendaufnahmen}

Die Plasmamembran der lebenden Kardiomyozyten - einschließlich des TATS - wurde mit dem lipophilen Farbstoff di-8-ANEPPS gefärbt. Hierzu wurden zunächst Deckgläser ( $\varnothing 42$ $\mathrm{mm})$ in einer Messkammer befestigt und mit Laminin beschichtet $(1 \mathrm{mg} / \mathrm{ml}, 1: 5$ in Perfusionspuffer verdünnt). Anschließend wurde das gewonnene Zellpellet in $800 \mu \mathrm{l}$ Perfusionspuffer, welcher mit $50 \mu \mathrm{M}$ di-8-ANEPPS versetzt worden war, resuspendiert. Das Gemisch wurde sofort auf die lamininbeschichteten Deckgläser gegeben, sodass sich die Kardiomyozyten bereits während des Färbevorgangs absetzen konnten. Nach 15 minütiger Inkubation bei Raumtemperatur im Dunklen wurden die Zellen einmal mit Perfusionspuffer gewaschen und mit $1 \mathrm{ml}$ Puffer bedeckt. Direkt im Anschluss wurde mit den Aufnahmen der lebenden Zellen begonnen. Neben dem di-8-ANEPPS-Signal wurde außerdem der CFP-Kanal des Epac1-PLN-cAMP-Sensors detektiert. Die gewählten Mikroskopeinstellungen können Tabelle 4 entnommen werden.

Tabelle 4: Einstellungen für die Konfokalaufnahmen lebender Zellen

\begin{tabular}{l|l|l}
\hline Kanal & Anregung & Detektion \\
\hline di-8-ANEPPS $(50 \mu \mathrm{M})$ & $458 \mathrm{~nm}$ & $600-740 \mathrm{~nm}$ \\
& $($ Laserleistung 3 - 5,5\%) & (gain 800 - 950) \\
\hline Sensor-CFP & $405 \mathrm{~nm}$ & $450-501 \mathrm{~nm}$ \\
& $($ Laserleistung 4\%) & (gain 900) \\
\hline
\end{tabular}

Da ein Durchbluten von di-8-ANEPPS in den Kanal des Sensor-YFPs bei der Negativkontrolle an Wildtypzellen nicht verhindert werden konnte, wurde auf dessen Darstellung bei den Lebendaufnahmen verzichtet.

\subsubsection{Immunfärbungen fixierter Kardiomyozyten und deren Aufnahmen}

Für die Immunfluoreszenzfärbungen mussten die wie unter 2.5 .1 beschrieben vorbereiteten Kardiomyozyten zunächst fixiert werden. Hierzu wurden Deckgläser ( $\varnothing 18$ $\mathrm{mm})$ in einer 12-Well-Platte zunächst mit Laminin beschichtet $(1 \mathrm{mg} / \mathrm{ml}, \quad 1: 5$ in Perfusionspuffer verdünnt). Die frisch isolierten, gewaschenen Zellen wurden dann in Perfusionspuffer resuspendiert und pro Deckglas $200 \mu \mathrm{l}$ der Zellsuspension aufgetragen. Nach einer Stunde Inkubation bei Raumtemperatur wurden die Zellen mit $4 \%$ Paraformaldehyd (PFA) 5 min bei Raumtemperatur fixiert. Die Verdünnung des PFA erfolgte hierbei in PBS $\left(\mathrm{pH} 7,4\right.$, ohne $\mathrm{Ca}^{2+}$ und $\mathrm{Mg}^{2+}$ ). Anschließend wurden die fixierten Zellen einmal mit Blockingpuffer, bestehend aus 0,2 \% Triton X-100 und $10 \%$ bovinem Kälberserum (BCS) in PBS, gewaschen. Die Permeabilisierung der Kardiomyozyten 
erfolgte ebenfalls in Blockingpuffer für $1 \mathrm{~h}$ bei Raumtemperatur. Im Anschluss wurden die Zellen über Nacht bei $4^{\circ} \mathrm{C}$ mit den in Blockingpuffer verdünnten Primärantikörpern inkubiert.

Am nächsten Tag wurden die Zellen dreimal mit Blockingpuffer gewaschen und dann mit den hierin verdünnten Sekundärantikörpern für $4 \mathrm{~h}$ bei Raumtemperatur im Dunkeln inkubiert. Daraufhin wurden die Kardiomyozyten noch dreimal mit PBS gewaschen und die Deckgläser in Einbettungsmedium auf Objektträger gebracht. Nach 12-48 h waren die Präparate ausgehärtet und wurden mit Nagellack versiegelt.

Die verwendeten Primär- und Sekundärantikörper einschließlich ihrer Verdünnung sind im Anhang unter Kapitel 6.2 aufgelistet.

Immunfluoreszenzgefärbte Strukturen sowie die Sensor-Fluoreszenzproteine wurden mit den in Tabelle 5 genannten Einstellungen am Konfokalmikroskop aufgenommen.

Tabelle 5: Einstellungen für die Konfokalaufnahmen immungefärbter Präparate

\begin{tabular}{|c|c|c|}
\hline Kanal & Anregung & Detektion \\
\hline AlexaFluor ${ }^{\circledR} 568$ & $\begin{array}{l}561 \mathrm{~nm} \\
\text { (Laserleistung 1\%) }\end{array}$ & $\begin{array}{l}570-620 \mathrm{~nm} \\
\text { (gain 750) }\end{array}$ \\
\hline AlexaFluor ${ }^{\circledR} 633$ & $\begin{array}{l}633 \mathrm{~nm} \\
\text { (Laserleistung 1\%) }\end{array}$ & $\begin{array}{l}640-740 \mathrm{~nm} \\
\text { (gain } 800 \text { ) }\end{array}$ \\
\hline Sensor-YFP & $\begin{array}{l}514 \mathrm{~nm} \\
\text { (Laserleistung } 5 \%)\end{array}$ & $\begin{array}{l}519-560 \mathrm{~nm} \\
\text { (gain 770) }\end{array}$ \\
\hline Sensor-CFP & $\begin{array}{l}405 \mathrm{~nm} \\
\text { (Laserleistung } 3 \% \text { ) }\end{array}$ & $\begin{array}{l}454-550 \mathrm{~nm} \\
\text { (gain } 700 \text { ) }\end{array}$ \\
\hline
\end{tabular}

\subsection{Analyse der Konfokalbilder}

Die Auswertung der Konfokalbilder erfolgte mit Hilfe der Fiji-Software, einer frei erhältlichen Variante von ImageJ mit zusätzlichen Analyse Plugins. Vor ihrer Bearbeitung und Analyse wurden die als „.Ism“-Datei gespeicherten Aufnahmen zunächst in „.tif“Dateien umgewandelt. Zur Datenorganisation und für weitere Auswertungsschritte, wurden die ermittelten Werte am Ende der Analyse in Excel importiert.

\subsubsection{Kolokalisationsanalyse des Epac1-PLN-Sensors mit SERCA2a}

Die Kolokalisation des Epac1-PLN-Sensors mit dem funktionell relevanten SERCA2aKompartiment wurde mit Hilfe von Fiji durch Ermittlung von Kolokalisationskoeffizienten 
und der Erstellung von Streudiagrammen entsprechend etablierter Vorgehensweisen überprüft (Zinchuk et al. 2007). Als Grundlage hierfür dienten die qualitätsgesicherten Konfokalaufnahmen der immungefärbten SERCA2a-Präparate (s. 2.5.3). Zur Lokalisation des Sensors wurde das YFP-Signal gewählt, da YFP im Vergleich zu CFP ein besonders vorteilhaftes Signal-Rausch-Verhalten zeigte. Das für CFP verstärkt hervortretende Hintergrundrauschen wird hierbei vermutlich durch die ebenfalls angeregte Eigenfluoreszenz erzeugt. Für die Analysen wurden zunächst beide Kanäle überlagernde ROls von $20 \mu \mathrm{m} \times 15 \mu \mathrm{m}$ im Zellinneren ausgewählt. Hier wurde darauf geachtet, dass sowohl im SERCA2a- als auch im YFP-Kanal, ein möglichst hintergrundarmes Signal ohne störende Elemente (Zellkerne etc.) sowie eine möglichst planare Sarkomerarchitektur (Durchlichtbild) vorlag. Die ausgewählten ROls wurden dann getrennt durch die folgenden Befehle, mit in Klammern genannten Einstellungen, in ImageJ bearbeitet:

1. Subtract background (rolling ball radius $=100$ )

2. Enhance Contrast... (Saturated pixels 0.1 , normalize)

3. Filters $->$ Mean (Radius $=1.0$ pixels)

Mit Hilfe des Analyse-Plugins Coloc2 (Manders' Correlation, 2D intensity histogram) wurde dann durch die Software automatisch das Streudiagramm erstellt sowie der Pearson-Koeffizient und die Manders-Koeffizienten M1 und M2 berechnet. Im Streudiagramm (s. a. Abb. 17 Ergebnisteil) ist die Intensität des YFP-Signals (Kanal 1) auf der X-Achse und die Intensität des Serca2a-Signals (Kanal 2) auf der Y-Achse dargestellt. Dementsprechend finden sich kolokalisierte Signale gleicher Intensität direkt auf der Diagonalen zwischen den beiden Achsen. Aufgrund der großen Anzahl der untersuchten Pixel wurde die Darstellung der Bildpunkte beider Kanäle entsprechend ihrer Häufigkeiten widergegeben. Dazu wurde das Diagramm farbkodiert, wobei die Farben die Dichte der einzelnen Punkte widerspiegeln. Wie in Abbildung 8 dargestellt, entsprechen hierbei schwarze Bereiche einer niedrigen Dichte und weiße Bereiche einer hohen Dichte an Bildpunkten.

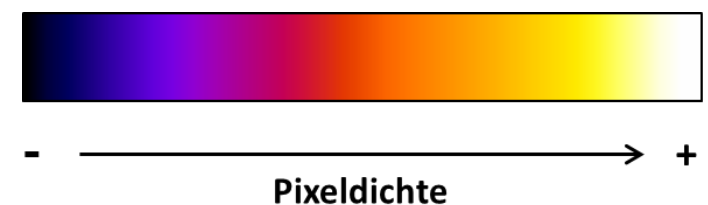

Abbildung 8: Farbkodierungsskala der Streudiagramme. Dunkle Bereiche im Diagramm entsprechen einer geringen Dichte an Bildpunkten. Weiße Bereiche hingegen weisen auf eine hohe Pixeldichte hin. 
Um die Sensorlokalisation zwischen Sham- und 12pMI-Gruppe zu vergleichen, wurden die ermittelten Korrelationskoeffizienten für die jeweilige Gruppe gemittelt.

\subsubsection{Bestimmung der Zellgrößen}

Die Vermessung der Kardiomyozyten erfolgte an den Durchlichtbildern, welche wie in Kapitel 2.5 beschrieben aufgenommen wurden. Eine ausreichende Relaxierung der Zellen zum Zeitpunkt der Aufnahme wurde durch den BDM-haltigen Perfusionspuffer sichergestellt, in dem sich die Kardiomyozyten während der Lebendaufnahmen bzw. während der Fixierung für die Immunfärbungen befanden. Die erfolgreiche Kontraktionshemmung der Herzmuskelzellen durch BDM wurde außerdem durch stichprobenartige Kontrolle der Sarkomerlänge $(>1,8 \mu \mathrm{m})$ überprüft. Mit Hilfe der ImageJSoftware wurden die Umrisse der einzelnen Zellen auf den Aufnahmen zunächst manuell markiert und dem ROI-Manager zugefügt. Querschnittsfläche, Länge und Breite wurde dann durch die Software automatisch vermessen.

\subsubsection{Quantitative Analyse des TATS}

Die Analyse des TATS anhand der di-8-ANEPPS-Zellmembran-Signale erfolgte mit Hilfe des Bildbearbeitungsprogrammes Fiji. Das Vorgehen entspricht hierbei weitgehend standardisierten quantitativen Analyseschritten der AG Lehnart, die nach Qualitätssicherung durch Peer Review sowohl als Open Access Publikation sowie als Protokoll-Dateien frei verfügbar sind (Wagner et al. 2014). Dementsprechend wurden passende intrazelluläre ROls ausgewählt welche das Netzwerk, nicht jedoch die äußere Zellmembran oder die Zellkerne enthielten. Die ausgewählten Bildbereiche wurden dann mit den folgenden Befehlen und den in Klammern genannten Einstellungen bearbeitet:

1. Subtract Background (rolling ball radius=5)

2. Enhance Local Contrast/CLAHE (block size=49, histogram=256, maximum=3, mask=none)

3. Smooth

4. Statistical Region Merging ( $Q=100$, show averages)

5. type $->8$ bit

6. Threshold (40, upper threshold 255) 
Aus den so entstandenen Binärbildern wurden dann durch das Plugin „Skeletonize (2D/3D)“ Skelettbilder des TATS erstellt. Auf Grundlage dieser Bilder erfolgte mittels des Plugins „Analyze Skeleton (2D/3D)“ die automatische Extrahierung quantitativer Eigenschaften wie Astlänge und Anzahl der Knotenpunkte. Die ermittelten Werte wurden für die weitere Datenanalyse in Excel importiert und die Gesamtlänge des Netzwerkes berechnet. Als Bezugsgröße diente die Fläche des jeweiligen ROI, die ebenfalls automatisch mit Hilfe des ROI-Managers durch die Software gemessen wurde.

Die Richtungsanalyse der einzelnen Komponenten des TATS erfolgte ebenfalls auf Basis der erzeugten Skelettbilder. Hierzu wurde das Plugin "Directionality“ (method=Fourier Components, nbins $=180$, histogram start $=-45^{\circ}$, display table) verwendet. So wurde für jedes Skelett ein Histogramm erstellt, welches die Häufgkeit der Elemente in der jeweiligen Richtung mit einer Klassenbreite von $1^{\circ}$ darstellt. Die Winkelgrade werden hierbei in Relation zur longitudinalen Zellachse der Kardiomyozyten angegeben, weshalb axiale Elemente der Tubuli bei $0^{\circ}$ und transversale Anteile bei $90^{\circ}$ liegen. Die Werte bei $0^{\circ}$ wurden als den Werten bei $180^{\circ}$ äquivalent betrachtet. Nachdem alle Bilder analysiert waren, wurden jeweils die Werte der Sham- und der 12pMI-Gruppe gemittelt. Um die beiden Häufigkeitsspitzen bei $0^{\circ}$ und $90^{\circ}$ grafisch besser darzustellen, wurde die Richtungsskala von $-45^{\circ}$ bis $135^{\circ}$ gewählt, wobei Werte von $-45^{\circ}$ bis $-1^{\circ}$ denen von $135^{\circ}$ bis $179^{\circ}$ aufgrund der Richtungssymmetrie entsprechen.

Des Weiteren wurde die absolute Menge an axialen und transversalen Elementen ermittelt und zwischen Sham- und 12pMl-Gruppe verglichen. Dazu wurde mit Hilfe des im Histogramm erzeugten Prozentsatzes bestimmter Richtungselemente, der jeweilige Anteil an der ermittelten Gesamtlänge des Skeletts bestimmt. Als axiale Komponente wurde hierfür jeweils die Summe aller Werte von $0^{\circ} \pm 3^{\circ}$ festgelegt. Entsprechend wurde für die transversale Komponente die Summe aller Werte von $90^{\circ} \pm 3^{\circ}$ angenommen. Auch hier wurden sowohl für die axialen als auch für die transversalen Komponenten jeweils die Werte der Sham- und der 12pMI-Gruppe gemittelt und getrennt dargestellt.

\subsection{Proteinanalysen mittels Western Blot}

Für die Proteinanalysen mittels Western Blot wurden Kardiomyozyten transgener Shamund MI-operierter Mäuse, wie in Kapitel 2.3 beschrieben, isoliert, im Stopppuffer 2 jedoch auf die Zugabe von BSA verzichtet. Die Zusammensetzung aller verwendeten Substanzen sowie der Gele, kann in Tabelle 6 eingesehen werden. 
Direkt nach der Überführung der Zellen in Stopppuffer 2 wurden diese 2 min bei 2.000 rpm zentrifugiert und nach Abnahme des Überstandes sofort in flüssigem Stickstoff schockgefroren. Die Zellpellets wurden in Homogenisierungspuffer mit Hilfe einer Insulinspritze homogenisiert und die Proteinkonzentration, mittels eines BCA ${ }^{\text {TM Protein }}$ Assay Kits entsprechend der Anleitung des Herstellers, bestimmt. Jeweils $20 \mu \mathrm{g}$ des Proteins wurden dann mit Homogenisierungspuffer und 3x SDS Stopp vermischt und die Sham- und MI-Proben sowie der Proteinmarker auf $12 \%$ SDS Gele aufgetragen.

Die Auftrennung der Proteine erfolgte unter Verwendung von Laufpuffer bei $100 \mathrm{~V}$, bis die ersten Banden das untere Ende des Gels erreicht hatten. Anschließend wurden die Proteine auf eine Nitrozellulose Membran übertragen. Das Blotting erfolgte in Transferpuffer bei ca. $4^{\circ} \mathrm{C}$ und einer Spannung von $100 \mathrm{~V}$ für 2 Stunden.

Nach Anfärben der Membranen mit Ponceau S wurden diese mit Aqua dest. gewaschen und mindestens $1 \mathrm{~h}$ bei Raumtemperatur oder über Nacht bei $4{ }^{\circ} \mathrm{C}$ geblockt. Je nach später verwendetem Primärantikörper wurde hierzu TBS-Tween®20 mit 5\% Milchpulver (anti-PLN-AK, anti-SERCA2a-AK) oder 3\% BSA (anti-CSQ-AK) versetzt. Die Primärantikörper wurden dann entsprechend verdünnt und über Nacht bei $4^{\circ} \mathrm{C}$ (anti-PLNAK, anti-SERCA2a-AK) bzw. $1 \mathrm{~h}$ bei Raumtemperatur (anti-CSQ-AK) mit den Membranen inkubiert. Vor der Zugabe der Sekundärantikörper wurden die Membranen jeweils dreimal für 5 min mit TBS-Tween $\AA_{20}$ gewaschen. Die Sekundärantikörper wurden entsprechend den Primärantikörpern im jeweiligen Medium verdünnt und für $1 \mathrm{~h}$ bei Raumtemperatur mit den Membranen inkubiert. Nach erneutem dreimaligem Waschen der Membranen mit TBS-Tween $\AA_{20}$ wurden diese entwickelt. Sowohl Primär- als auch Sekundärantikörper einschließlich ihrer Verdünnungsverhältnisse sind im Anhang unter Kapitel 6.2 aufgelistet. Zur Detektion der Proteinbanden wurden die Membranen 1 min mit einer kommerziellen Entwicklerlösung inkubiert und in der Dunkelkammer mit Hilfe eines Entwicklergerätes entwickelt.

Aufgrund der Laufeigenschaften der hier untersuchten Proteine, wurde der Vorgang zunächst komplett für die Analyse der PLN Banden durchgeführt. Anschließend erfolgte das Antikörper-Stripping der Membranen für 8 min mit 0,2 M Natronlauge bei Raumtemperatur, wobei die Membranen jeweils vorher und nachher 4 min mit $\mathrm{H}_{2} \mathrm{O}$ gewaschen wurden. Zur Detektion der SERCA2a- und CSQ-Banden wurde der Vorgang wie beschrieben ab dem Blocken an der aufgeteilten Membran wiederholt. Die Vermessung der Banden erfolgte mit Hilfe von ImageJ. 
Tabelle 6: Zusammensetzung der für den Western Blot verwendeten Substanzen

\begin{tabular}{|c|c|c|}
\hline Substanz & Zusammensetzung & \\
\hline Homogenisierungspuffer & $\begin{array}{l}\text { HEPES } \\
\text { Saccharose } \\
\mathrm{NaCl} \\
\mathrm{EGTA} \\
\mathrm{CaCl}_{2} \\
\mathrm{pH} \text { einstellen auf } \\
\text { PhosSTOP } \\
\text { Protease Inhibitor Cocktail } \\
\text { Triton X-100 }\end{array}$ & $\begin{array}{c}10 \mathrm{mM} \\
300 \mathrm{mM} \\
150 \mathrm{mM} \\
1 \mathrm{mM} \\
2 \mathrm{mM} \\
7,4 \\
1 \text { Tablette } \\
1 \text { Tablette } \\
10 \%\end{array}$ \\
\hline $3 x$ SDS-Stopp & $\begin{array}{l}\text { TRIS } \\
\mathrm{HCl} \text { bis pH } \\
\text { SDS } \\
\text { Glycerin } \\
\text { Bromphenolblau } \\
\text { 2-Mercaptoethanol }\end{array}$ & $\begin{array}{l}200 \mathrm{mM} \\
6,7 \\
6 \% \\
15 \% \\
10 \%\end{array}$ \\
\hline $\begin{array}{l}\text { Trenngel 12\% } \\
\text { (Ansatz für } 2 \text { Gele, } 12 \text { ml) }\end{array}$ & $\begin{array}{l}\text { Acrylamid } \\
\text { 4xTris/SDS pH 8,8 } \\
\text { Aqua bidest. } \\
\text { 10\% APS-Lösung } \\
\text { TEMED }\end{array}$ & $\begin{array}{r}4,8 \mathrm{ml} \\
3 \mathrm{ml} \\
4,2 \mathrm{ml} \\
48 \mu \mathrm{l} \\
18 \mu \mathrm{l}\end{array}$ \\
\hline $\begin{array}{l}\text { Sammelgel } \\
\text { (Ansatz für } 2 \text { Gele, } 12 \text { ml) }\end{array}$ & $\begin{array}{l}\text { Acrylamid } \\
\text { 4xTris/SDS pH 6,8 } \\
\text { Aqua bidest. } \\
\text { 10\% APS-Lösung } \\
\text { TEMED }\end{array}$ & $\begin{array}{r}500 \mu \mathrm{l} \\
940 \mu \mathrm{l} \\
2,31 \mathrm{ml} \\
18,8 \mu \mathrm{l} \\
7,5 \mu \mathrm{l}\end{array}$ \\
\hline 4x Tris/SDS pH 6,8 & $\begin{array}{l}\text { TRIS } \\
\text { SDS } \\
\mathrm{pH}\end{array}$ & $\begin{array}{l}500 \mathrm{mM} \\
0,4 \% \\
6,8\end{array}$ \\
\hline 4x Tris/SDS pH 8,8 & $\begin{array}{l}\text { TRIS } \\
\text { SDS } \\
\mathrm{pH}\end{array}$ & $\begin{array}{l}1,5 \mathrm{M} \\
0,4 \% \\
6,8\end{array}$ \\
\hline 10\% APS-Lösung & APS & $10 \%$ \\
\hline 10x SDS-Laufpuffer & $\begin{array}{l}\text { TRIS } \\
\text { Glycine }\end{array}$ & $\begin{array}{l}250 \mathrm{mM} \\
1,9 \mathrm{M}\end{array}$ \\
\hline
\end{tabular}




\begin{tabular}{|c|c|c|}
\hline & SDS & $1 \%$ \\
\hline & $\mathrm{pH}$ & 8,3 \\
\hline \multirow[t]{2}{*}{ 10x Transferpuffer } & TRIS & $325 \mathrm{mM}$ \\
\hline & Glycine & $1,9 \mathrm{M}$ \\
\hline \multirow[t]{2}{*}{ 1x Transferpuffer } & 10x Transferpuffer & $10 \%$ \\
\hline & Methanol & $20 \%$ \\
\hline \multirow[t]{2}{*}{ Ponceau S-Solution } & Ponceau S & $0,5 \%$ \\
\hline & in $10 \%$ Essigsäure & \\
\hline \multirow[t]{3}{*}{ 10x TBS-Puffer } & TRIS & $100 \mathrm{mM}$ \\
\hline & $\mathrm{NaCl}$ & $1,5 \mathrm{M}$ \\
\hline & $\mathrm{HCl}$ bis $\mathrm{pH}$ & 7,5 \\
\hline \multirow[t]{2}{*}{ 1x TBS-Tween ${ }^{\circledR 20}(0,1 \%)$} & 10x TBS Puffer & $10 \%$ \\
\hline & Tween®20 & $0,1 \%$ \\
\hline \multirow[t]{2}{*}{$5 \%$ Milchpuffer } & Milchpulver & $5 \%$ \\
\hline & in 1x TBS-Tween $\AA 20$ & \\
\hline \multirow[t]{2}{*}{$3 \%$ BSA } & BSA & $3 \%$ \\
\hline & in 1x TBS-Tween $\circledast 20$ & \\
\hline
\end{tabular}

\subsection{Statistik}

Soweit nicht anders vermerkt, werden alle Daten als Mittelwerte \pm Standardfehler angegeben. Die Unterschiede zwischen Sham- und 12pMI-Gruppe wurden durch Excel (Microsoft Office 2010) mittels eines heteroskedastischen T-Tests mit zweiseitiger Verteilung, auf Signifikanz getestet. Im Falle der Western Blot Analysen wurden hierfür die Werte aus den dreimal wiederholten Versuchen zunächst je Probe gemittelt. 


\section{Ergebnisse}

\subsection{Validierung der Ausbildung des Krankheitsbildes Herzinsuffizienz}

Zur Untersuchung pathophysiologischer Veränderungen der SERCA2a-Mikrodomäne wurde ein bereits beschriebenes post-MI-Mausmodell verwendet (Muthuramu et al. 2014). Die Epac1-PLN-transgenen Weibchen wurden im Alter von 8-12 Wochen einer Myokardinfarkt(MI)-induzierenden Operation unterzogen, bei welcher die permanente Ligatur des RIVA erfolgte (s. 2.2.1). Innerhalb der folgenden Wochen entwickelte sich dann eine systolische Herzinsuffizienz, wobei alle hier beschriebenen Experimente nach Abschluss der 12. postoperativen Woche (12pMl) als Terminalvesuche durchgeführt wurden. Als Kontrolle wurde jeweils auch eine Gruppe Sham-operierter Mäuse (ebenfalls unter 2.2.1 beschrieben) untersucht. Die Wirksamkeit der operativen Intervention wurde dann mittels der im Folgenden beschriebenen Verfahren objektiviert:

\subsubsection{Echokardiografische Untersuchungen}

12 Wochen nach dem operativen Eingriff wurden die Mäuse unter Isofluoran-Sedierung in Blindversuchen echokardiografisch phänotypisiert. Beim Vergleich der ermittelten Herzparameter zwischen Sham- und 12pMI-Gruppe ergaben sich hochsignifikante Unterschiede, welche in Tabelle 7 dargestellt sind. Die Zunahme des linksventrikulären enddiastolischen (LVEDD) sowie des endsystolischen (LVESD) Durchmessers 12pMI bestätigt die erwartete Dilatation des insuffizienten Herzens in der Krankheitsgruppe. Der Verlust der systolischen Pumpfunktion in der 12pMI-Gruppe wird durch die Abnahme der Verkürzungsfraktion (FS) und der fraktionellen Flächenänderungsrate (FAC) deutlich. Wie unter 2.2.2 beschrieben errechnen sich diese Parameter aus Messwerten der Systole und Diastole und lassen somit Rückschlüsse auf die Kontraktionseffizienz des Myokards zu. Die systolische Insuffizienz des Herzens wird vor allem auch durch die verminderte Ejektionsfraktion (EF) 12pMl erkennbar. Die EF gibt das prozentuale Blutvolumen an, das während einer Herzaktion von einer Herzkammer ausgestoßen wird und beschreibt somit die Auswurfleistung des linken Ventrikels. Relativ zur Sham-Gruppe war die EF nach Infarkt um im Schnitt $44 \%$ reduziert. Außerdem wurde das errechnete Herzgewicht in $\mathrm{mg}$ (Formel s. 2.2.2) ins Verhältnis zum gewogenen Körpergewicht in g gesetzt. Hierbei zeigte sich ebenfalls eine signifikante Zunahme der Herzgewicht-zu-Körpergewicht-Ratio (HW/BW) in der Krankheitsgruppe, was eine pathologische Herzmuskelhypertrophie bestätigt. Zusammengefasst zeigen die echokardiografischen Daten also phänotypische Kennzeichen der Herzinsuffizienz mit Hinweis auf Herzhypertrophie, systolische Pumpschwäche und dilatative Komponente. 
Tabelle 7: Echokardiografische Phänotypisierung Epac1-PLN-transgener Mäuse 12pMI vs. Sham-Intervention. Dargestellt sind Mittelwerte \pm Standardfehler. Bezüglich der Herzfrequenz konnten keine signifikanten Unterschiede zwischen den beiden Gruppen festgestellt werden. LVEDD: linksventrikulärer enddiastolischer Durchmesser. LVESD: linksventrikulärer endsystolischer Durchmesser. FAC: fraktionelle Flächenänderungsrate. FS: Verkürzungsfraktion. EF: Ejektionsfraktion. HW/BW: errechnetes Verhältnis von Herz- zu Körpergewicht. n: Anzahl der Tiere in der jeweiligen Gruppe. *: $p<0,001$ im Vergleich zur Sham-Gruppe.

\begin{tabular}{|l|c|c|}
\hline \multirow{2}{*}{ Parameter } & \multicolumn{2}{c|}{ E1-PLN transgen } \\
\cline { 2 - 3 } & Sham & 12pMI \\
\hline LVEDD (mm) & $3,67 \pm 0,06$ & $5,00 \pm 0,14^{*}$ \\
LVESD (mm) & $2,06 \pm 0,04$ & $3,98 \pm 0,24^{*}$ \\
FAC (\%) & $64,46 \pm 1,12$ & $37,37 \pm 5,23^{*}$ \\
FS (\%) & $43,90 \pm 1,19$ & $20,52 \pm 3,58^{*}$ \\
EF (\%) & $71,29 \pm 1,18$ & $40,07 \pm 5,00^{*}$ \\
HW/BW (mg/g) & $4,58 \pm 0,22$ & $6,49 \pm 0,13^{*}$ \\
$\mathrm{n}$ & 10 & 9 \\
\hline
\end{tabular}

\subsubsection{Zellgrößenbestimmung}

Eine Hypertrophie der ventrikulären 12pMI-Kardiomyozyten wurde außerdem durch manuelle Vermessung einzelner Zellen (s. 2.6.2) nachgewiesen. Hierzu wurden Durchlichtbilder lebender und fixierter ventrikulärer Herzmuskelzellen verwendet. Wie in Abbildung 9A dargestellt, konnte nach Infarkt eine hochsignifikante Zunahme der Querschnittsfläche der Kardiomyozyten von durchschnittlich $3291 \mu \mathrm{m}^{2}$ in der ShamGruppe auf im Schnitt $4025 \mu \mathrm{m}^{2}$ 12pMl nachgewiesen werden $(p<0,001)$. Diese Größenzunahme ergibt sich aus einem Wachstum sowohl in der Länge (s. Abb. 9B) (Sham: $145 \mu \mathrm{m}, 12 \mathrm{pMl}: 168 \mu \mathrm{m}, \mathrm{p}<0,001$ ) als auch in der Breite der Herzmuskelzellen (s. Abb. 9C) (Sham: $33 \mu \mathrm{m}, 12 \mathrm{pMl}: 36 \mu \mathrm{m}, \mathrm{p}<0,001$ ). 
A

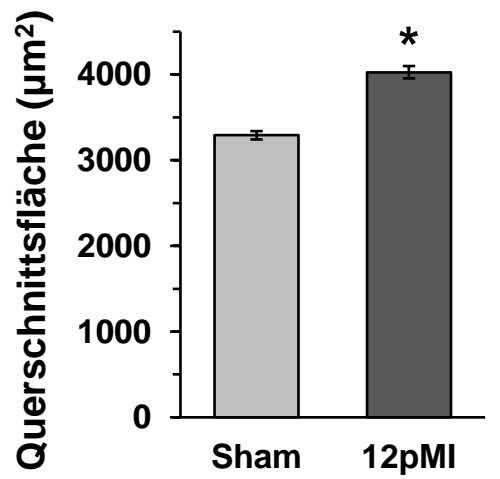

B

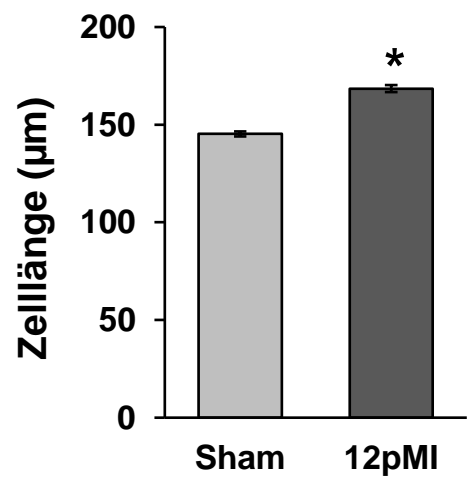

C

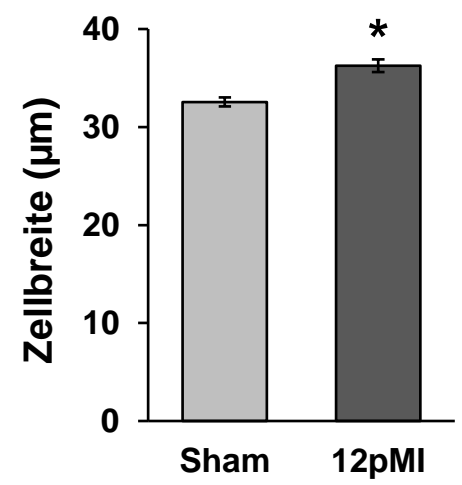

Abbildung 9: Größenzunahme der 12pMI-Kardiomyozyten im Vergleich zur Sham-Gruppe. Die Zellgröße wurde manuell an aufgenommenen Durchlichtbildern ventrikulärer Kardiomyozyten bestimmt. A Querschnittsfläche der Kardiomyozyten. B Länge der Kardiomyozyten. C Breite der Kardiomyozyten. Die dargestellten Daten entsprechen den Mittelwerten \pm Standardfehler, wobei folgende Anzahl an Kardiomyozyten vermessen wurde: 208 Sham, 219 12pMl. *: p<0,001 im Vergleich zur Sham-Gruppe.

\subsubsection{Remodeling des TATS nach MI}

In bereits veröffentlichten Untersuchungen wurde mittels Superresolution-STEDMikroskopie gezeigt, dass es nach Ml zu einem progredientem Remodeling des TATS kommt (Wagner et al. 2012). Zur besseren Einordnung des Krankheitsstadiums auf zellulärer Ebene, wurden in dieser Arbeit Ausmaß und Art des TATS-Remodeling in Epac1-PLN-transgenen FVB/N-Mäuse 12pMl mit Hilfe der Konfokalmikroskopie analysiert, da zuvor weder der Zeitpunkt noch der genetische Hintergrund im Zusammenhang mit möglichen TATS-Veränderungen untersucht worden war.

Zur Darstellung des TATS wurden lebende ventrikuläre Kardiomyozyten mit dem lipophilen Membranfarbstoff di-8-ANEPPS gefärbt und mit einem konfokalen LaserScanning-Mikroskop aufgenommen (s. 2.5.2). Neben dem di-8-ANNEPS-Signal wurde auch das CFP-Signal des Epac1-PLN-Sensors über einen separaten Kanal detektiert sowie pro Zelle ein Durchlichtbild zur Überprüfung der Zellqualität und der morphologischen Aspekte angefertigt. Die Detektion des Sensors im di-8-ANEPPS-Kanal und umgekehrt, wurde an Hand von Negativkontrollen an ungefärbten bzw. Wildtypzellen ausgeschlossen.

Abbildung 10 zeigt ein repräsentatives Beispiel des di-8-ANEPPS- und des CFP-Signals einer Sham- und einer 12pMl-Kardiomyozyte. Beim direkten Vergleich lassen sich bereits Unterschiede in der Netzwerkdichte sowie in der Anordnung einzelner Netzwerkelemente erkennen. Um diese Veränderungen zu quantifizieren, wurden aus den Aufnahmen 
Skelettbilder des intrazellulären TATS über etablierte Bildanalyse-Prototolle extrahiert (s. 2.6.3), was beispielhaft für beide Gruppen in Abbildung 11 dargestellt ist.

A

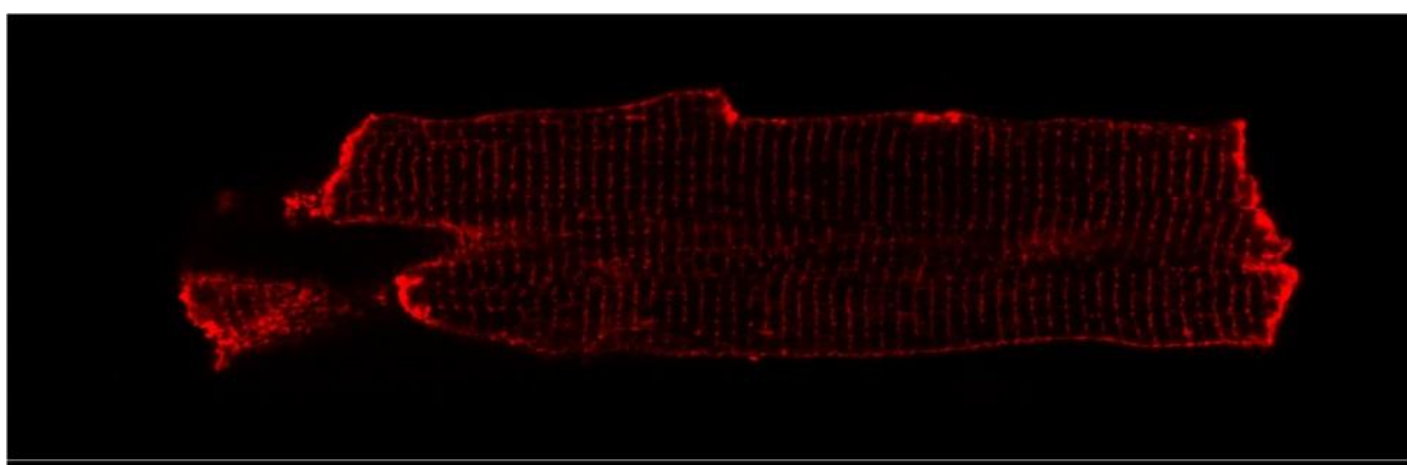

B

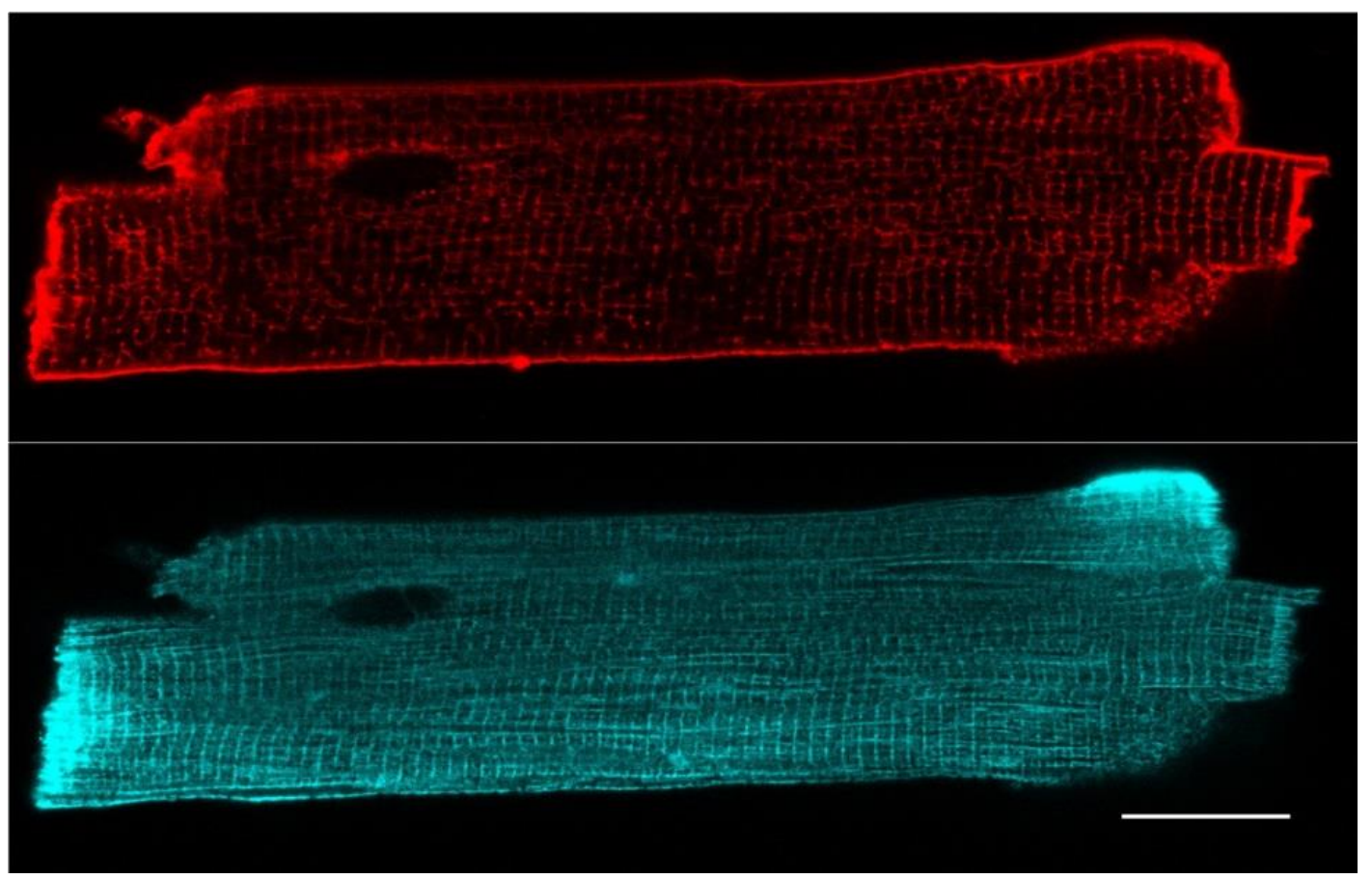

Abbildung 10: Konfokalaufnahmen lebender di-8-ANEPPS-gefärbter Epac1-PLN-transgener Kardiomyozyten. Neben dem rot dargestellten di-8-ANEPPS-Signal wurde auch das CFP-Signal des Epac-PLN-Sensors (blau dargestellt) detektiert. A Abbildung einer Herzmuskelzelle nach Sham-Operation B Abbildung einer 12pMI-Kardiomyozyte. Das durch di-8-ANEPPS dargestellte TATS zeigt sich im Vergleich zur Sham-Zelle deutlich unregelmäßiger und dichter. Die weißen Maßstabskalen entsprechen jeweils einer Länge von $20 \mu \mathrm{m}$. 
A

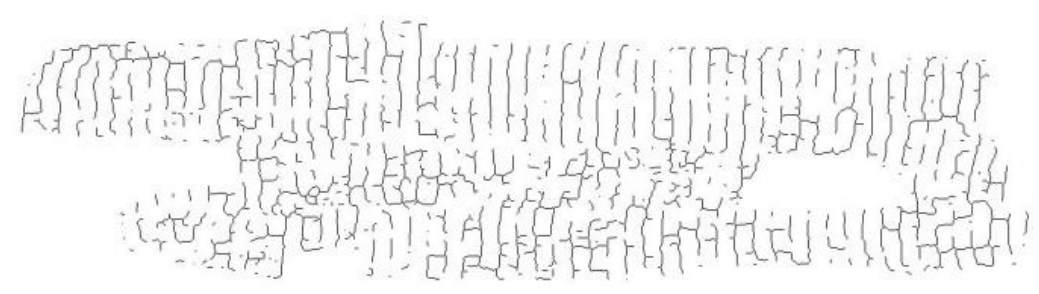

B

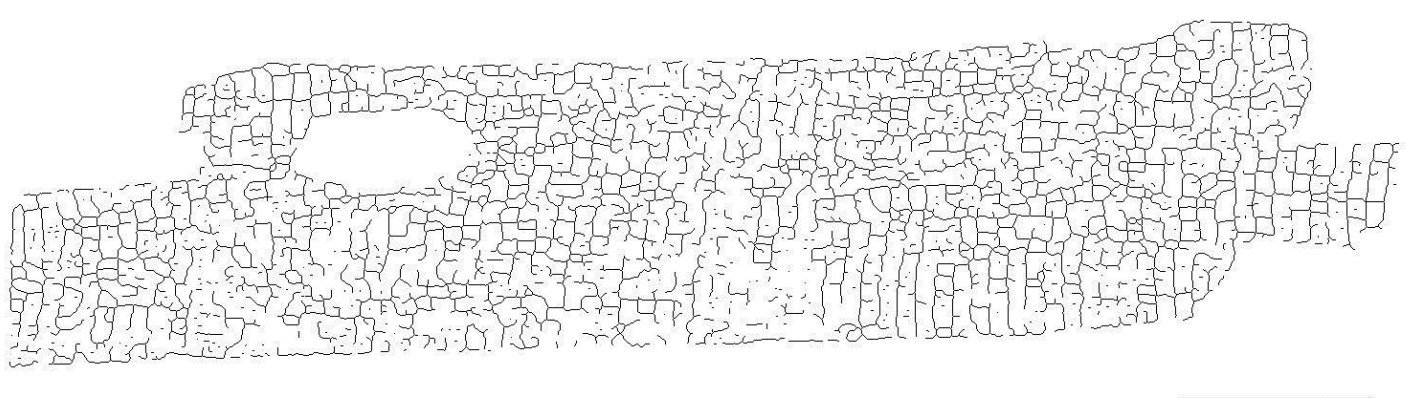

Abbildung 11: Skelettbilder des TATS (ohne Oberflächen-Zellmembran) als Grundlage der Netzwerkanalyse. Die dargestellten Skelettbilder wurden direkt aus den di-8-ANEPPS-Aufnahmen extrahiert (s. 2.6.3). Plasmamembran- und Zellkern-haltige Regionen wurden bereits vor der Skelettierung subtrahiert. A Skelettbild einer Sham-Zelle. B Skelettbild einer 12pMI-Kardiomyozyte. Für die repräsentativen Darstellungen wurden dieselben Kardiomyozyten wie in Abbildung 10 gewählt. Die schwarzen Maßstabskalen entsprechen einer Länge von $20 \mu \mathrm{m}$.

Um die Dichte des TATS zu bestimmen, wurde auf Grundlage der Skelettbilder für jede Zelle zunächst die totale Netzwerklänge der gegebenen Bildebene berechnet und dann auf die entsprechende Fläche normalisiert. Wie in Abbildung 12A dargestellt, zeigte sich im Vergleich der beiden Gruppen eine signifikante Zunahme der Netzwerkdichte 12pMI (Sham: 0,62 $\mu \mathrm{m} / \mu \mathrm{m}^{2}, 12 \mathrm{pMl}: 0,71 \mu \mathrm{m} / \mu \mathrm{m}^{2}, \mathrm{p}<0,001$ ). Im Rahmen dieser Veränderung zeigte sich auch eine stärkere Verzweigung des Netzwerkes in der 12pMI-Gruppe: Als vergleichender Parameter wurde hierzu die Anzahl der Netzwerk-Knotenpunkte pro Fläche bestimmt. Abbildung 12B zeigt die signifikante Zunahme der Verzweigungsstellen von durchschnittlich $0,18 / \mu m^{2}$ in der Sham-Gruppe auf $0,25 / \mu m^{2} 12 p M I(p<0,001)$.

Neben der Analyse der Netzwerkkomplexität wurde auch die zweidimensionale Anordnung der TATS-Elemente untersucht. Hierzu erfolgte, wie in Kapitel 2.6.3 beschrieben, die Richtungsanalyse der Netzwerkkomponenten jeder einzelnen Kardiomyozyte inviduell sowie jeweils für die Sham- und 12pMI-Gruppe. Die Orientierung der einzelnen Elemente wurde hierbei in Winkelgraden, bezogen auf die longitudinale Zellachse, angegeben, weshalb axiale Komponenten bei $0^{\circ}$ liegen. Dementsprechend 
sind die senkrecht dazu stehenden transversalen Komponenten bei $90^{\circ} \mathrm{zu}$ finden. Die Häufigkeit der räumlich orientierten Elemente im jeweiligen Winkelgrad wurde für beide Gruppen gemittelt und mit Hilfe eines Histogramms dargestellt.

A

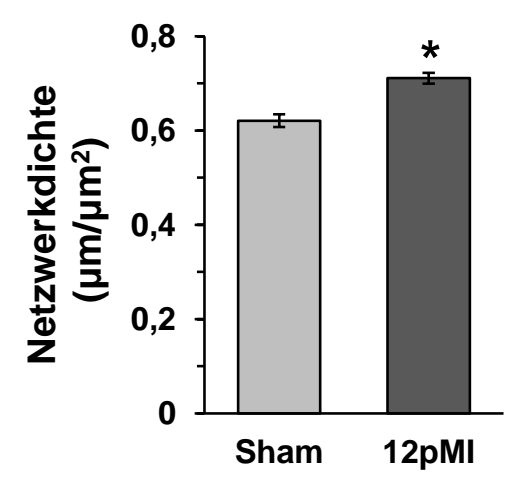

B

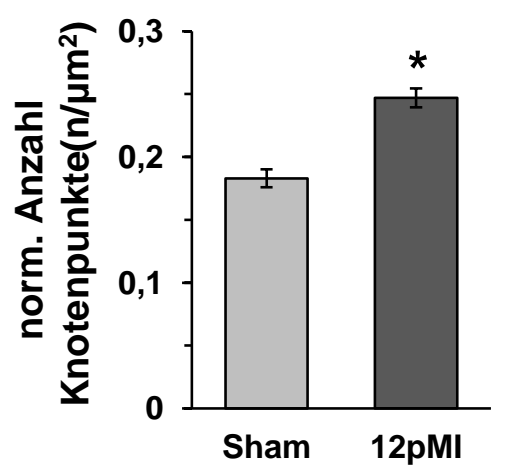

Abbildung 12: Zunahme der Dichte und Verzweigungen des TATS nach MI. Die dargestellten Parameter wurden auf Basis der skelettierten Aufnahmen des TATS für die Sham- und 12pMIGruppe bestimmt. A Netzwerkdichte dargestellt als Netzwerklänge pro Fläche. B Anzahl der Knotenpunkte pro Fläche bezeichnend für die Netzwerkverzweigung. Die dargestellten Daten entsprechen den Mittelwerten \pm Standardfehler, wobei folgende Anzahl an Kardiomyozyten pro Gruppe vermessen wurde: 39 Sham, 54 12pMl. *: p<0,001 im Vergleich zur Sham-Gruppe.

Die Anordnung der einzelnen Netzwerkelemente in der Sham-Gruppe ist in Abbildung $13 \mathrm{~A}$ gezeigt. Bezüglich der Verteilung zeigen sich zwei deutliche Häufigkeitsgipfel um $0^{\circ}$ und $90^{\circ}$. Die höhere Spitze im Bereich transversaler Elemente stimmt auch mit der Abbildung 10A überein und zeigt, dass die regelmäßige Anordnung von TATS-Elementen senkrecht zur Längsachse der Sham-Zelle wie erwartet überwiegt. Wie in Abbildung 13B ersichtlich, sind auch 12pMl zwei Häufigkeitsgipfel zu beobachten. Allerdings zeigt sich hier im Vergleich zur Sham-Gruppe eine signifikante Zunahme im Bereich der axialen Komponenten $\left(0^{\circ}\right)$. Die vermehrte Quervernetzung und dadurch entstandene Unregelmäßigkeit in der Anordnung des TATS ist auch in Abbildung 10B erkennbar. Darüber hinaus ist nach Infarkt auch eine relative Abnahme transversaler Elemente zu verzeichnen. Die Unterschiede zwischen den beiden Gruppen werden in Abbildung 13C verdeutlicht: Bei Abzug der mittleren Häufigkeitsverteilungen der Sham- von der 12pMlGruppe veranschaulicht die positive Differenz (Zunahme) im Bereich axialer Komponenten $\left(0^{\circ}\right)$ und die negative Differenz (Abnahme) im Bereich transversaler Komponenten $\left(90^{\circ}\right)$ die prinzipiell bereits beschriebenen Beobachtungen. 
A

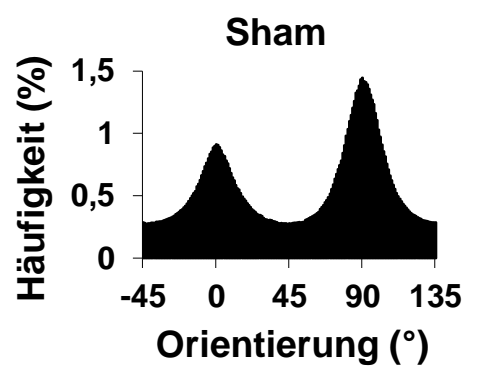

B

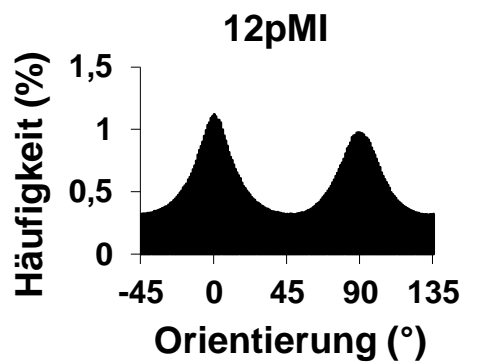

C

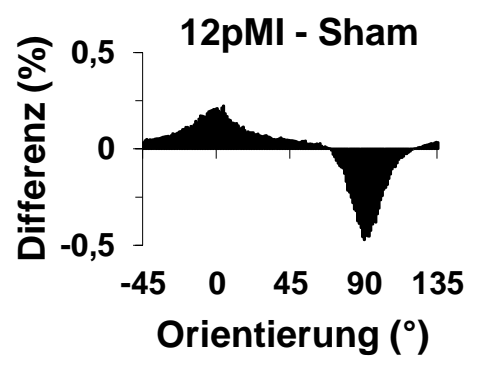

Abbildung 13: Veränderung der Orientierung bestimmter TATS-Elemente nach MI. Die Häufigkeitsverteilung einzelner TATS-Elemente wurde für jede Interventionsgruppe mit Hilfe eines Histogramms dargestellt. Bei $0^{\circ}$ liegen Elemente entlang der longitudinalen Zellachse der Kardiomyozyte. Transversal gerichtete Elemente liegen bei $90^{\circ}$. A Orientierungshistogramm der Sham-Gruppe. B Orientierungshistogramm der 12pMI-Gruppe. C Darstellung der Unterschiede zwischen den Gruppen in der Komponentenverteilung durch Subtraktion der Histogrammintegrale B - A. Zur Datenerhebung wurde folgende Anzahl an Kardiomyozyten vermessen: 39 Sham, 54 $12 \mathrm{pMI}$.

Zusätzlich zu der relativen Häufigkeitsverteilung mittels Histogrammen wurden auch absolute Messwerte axialer und transversaler Komponenten ermittelt und zwischen den Gruppen verglichen. Wie unter 2.6.3 beschrieben, geschah dies indem die Anzahl der relativen Häufigkeiten der axialen und transversalen Winkelgrade für jede Zelle mit deren Netzwerkdichte in $\mu \mathrm{m} / \mu^{2}{ }^{2}$ (s. oben) multipliziert wurde. Als relative Häufigkeit der axialen Komponenten wurden die Werte von $0^{\circ} \pm 3^{\circ}$ addiert. Dementsprechend wurde für die relative Häufigkeit transversaler Komponenten die Summe der Werte von $90^{\circ} \pm 3^{\circ}$ gewählt.
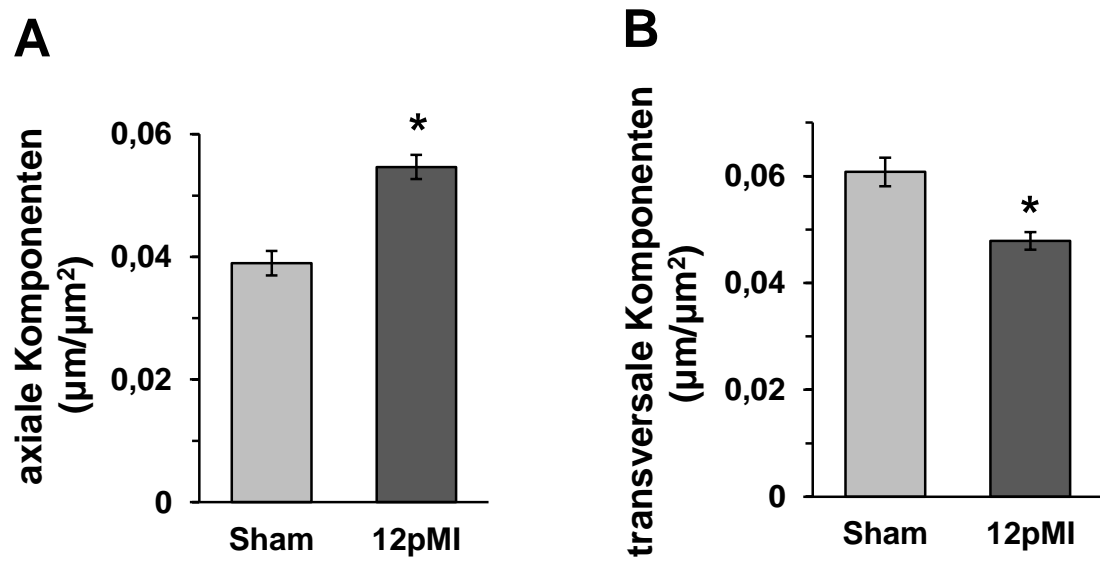

Abbildung 14: Veränderung axialer und transversaler Netzwerkkomponenten 12pMI. Zum Vergleich axialer und transversaler Elemente des TATS zwischen Sham- und 12pMI-Gruppe wurden absolute Werte der jeweiligen Komponenten pro Fläche angegeben. A $0^{\circ} \pm 3^{\circ}$ entsprechen der axialen Komponente. B $90^{\circ} \pm 3^{\circ}$ entsprechen der transversalen Komponente. Die dargestellten Daten entsprechen den Mittelwerten \pm Standardfehler, wobei folgende Anzahl an Kardiomyozyten vermessen wurde: 39 Sham, 54 12pMl. * $p<0,001$ im Vergleich zur Sham-Gruppe. 
Die Ergebnisse des Vergleichs der absoluten Werte zwischen Sham und 12pMI sind in Abbildung 14 dargestellt. Bezüglich der axialen Komponenten zeigt sich eine signifikante Zunahme von $0,039 \mu \mathrm{m} / \mu \mathrm{m}^{2}$ in der Sham-Gruppe auf $0,055 \mu \mathrm{m} / \mu \mathrm{m}^{2} 12 \mathrm{pMl}$. Obwohl die relative Häufigkeitsverteilung in Abbildung 13 einen noch größeren Unterschied im Bereich der transversalen Komponenten zeigt, ist bei Vergleich der absoluten Werte eine etwas geringere, jedoch ebenso signifikante Abnahme der senkrecht zur Zellachse orientierten Elemente nach Ml erkennbar (Sham: 0,061 $\mu \mathrm{m} / \mu \mathrm{m}^{2}, 12 \mathrm{pMl}: 0,048, p<0,001$ ).

Zusammengefasst ließen sich 12pMI signifikante Umbauvorgänge auf Ebene des TATS nachweisen. Im Rahmen dessen wurde ein Zunahme der Netzwerkdichte bei vermehrter Verzweigung sowie eine verstärkte Orientierung einzelner Netzwerkelemente von transversal nach axial festgestellt.
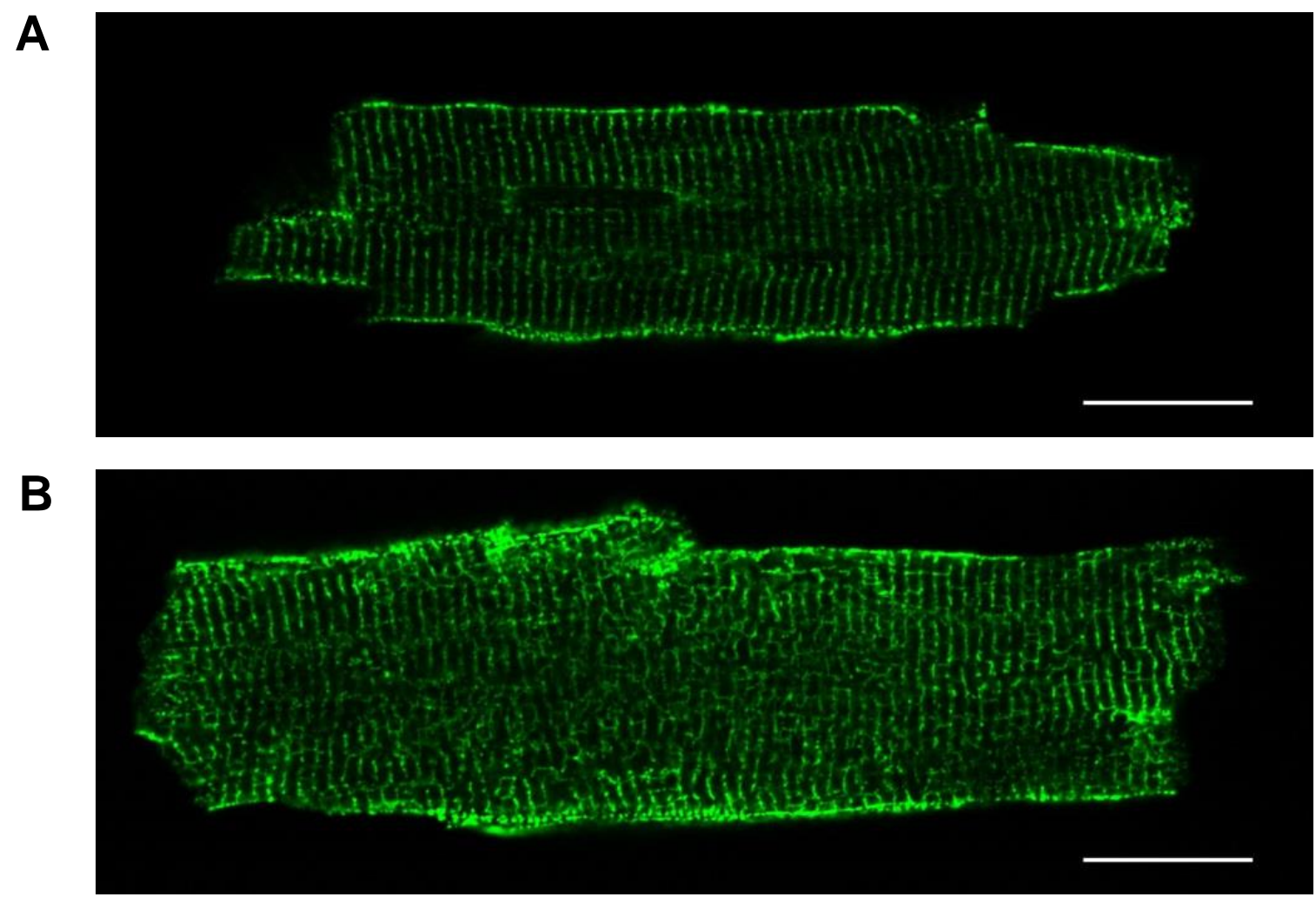

Abbildung 15: Konfokale Bilder transgener Kardiomyozyten nach Cav3Immunfluoreszenzfärbung. Durch indirekte Immunfärbung des Membranproteins Cav3 in fixierten Kardiomyozyten wurden ähnliche Netzwerk-Signale beobachtet wie nach Behandlung lebender Zellen mit di-8-ANEPPS. Das Signal des Epac1-PLN-Sensors ist in den repräsentativen Abbildungen nicht gezeigt. A Cav3 Signal einer Sham-Zelle. B Cav3 Signal einer 12pMlKardiomyozyte. Auch hier werden die Umbauvorgänge des TATS nach Infarkt deutlich. Die weißen Maßstabskalen entsprechen jeweils einer Länge von $20 \mu \mathrm{m}$.

Diese Veränderungen werden auch nach Immunfärbung von Caveolin-3 (Cav3) an transgenen Kardiomyozyten nachvollziehbar (s. 2.5.3). Cav3 ist ein essentielles und 
integrales Strukturprotein der Plasmamembran von Herzmuskelzellen, welches an der Bildung und Stabilisierung cholesterinreicher Mikrodomänen, sogenannter Caveolae, beteiligt ist. Wie in Abbildung 15 erkennbar, lassen sich durch Immunfluoreszenzfärbung von Cav3 vergleichbare TATS-Signale wie durch Färbung der Zellen mit dem lipophilen Membranfarbstoff di-8-ANEPPS erzeugen (vgl. Abb. 10). Dementsprechend können die beschriebenen Remodeling-Vorgänge auch an fixierten Herzmuskelzellen untersucht werden.

\subsection{Unveränderte Lokalisation des Sensors nach MI}

Da sich im Bereich des TATS strukturelle Umbauvorgänge nach MI gezeigt hatten, sollte nun kontrolliert werden, ob der transgene Sensor im Krankheitsmodell nach wie vor in der SERCA2a-Mikrodomäne lokalisiert ist. Um dies zu untersuchen, wurde eine Kolokalisationsanalyse anhand konfokalmikroskopischer Aufnahmen durchgeführt.

Der Epac1-PLN-cAMP-Sensor ist idealerweise über Phospholamban (PLN) in der SERCA2a-Mikrodomäne verankert. Folglich wurde zur Beurteilung der Sensorlokalisation, die Überlagerung der Sensor-Fluoreszenzproteine mit SERCA2a überprüft. Zur Darstellung der Mikrodomäne in transgenen Kardiomyozyten wurden Zellen der Shamund 12pMl-Gruppe fixiert und anschließend mit primären und sekundären Antikörpern zwecks Immunfluoreszenzfarbstoff-Darstellung behandelt (s. 2.5.3). Die Einstellungen zur Aufnahme der Präparate am Konfokalmikroskop (s. Tab. 5) wurden auch hier sogewählt, dass in den Negativkontrollen keine Detektion der Sensorsignale im SERCA2a-Kanal, und umgekehrt, erkennbar war. Da YFP ein deutlich besseres Signal-Rausch-Verhalten als CFP zeigte, wurde YFP prinzipiell für die Lokalisierung des Sensors gewählt. Die beispielhafte Darstellung einer transgenen, SERCA2a gefärbten Kardiomyozyte der 12pMl-Gruppe findet sich in Abbildung 16A. Für die Kolokalisationsanalyse wurde innerhalb jeder Zelle eine region of interest $(\mathrm{ROI})$ gleicher Größe ausgesucht, die sowohl im SERCA2a- als auch im YFP-Kanal ein möglichst deutliches und störfreies Signal zeigte (s. Abb. 16B). Innerhalb dieser ROls wurde dann die Deckung der beiden Signale miteinander ermittelt. Um diesen Schritt besser zu veranschaulichen, wurde YFP grün und SERCA2a rot dargestellt und ein Fusionsbild erzeugt. Bei Überlagerung der Farben rot und grün ergibt sich hierbei ein gelbes Signal, wodurch die Kolokalisation des YFPSignals mit dem SERCA2a-Signal gut erkennbar wird. Wie in Abbildung 16C (12pMI) und 16D (Sham) beispielhaft gezeigt, erscheint die Überlagerung der beiden Signale für die Sham- und 12pMl-Gruppe vergleichbar, was im Folgenden auch durch Kolokalisationsanalysen bestätigt wurde (s. unten). 
A
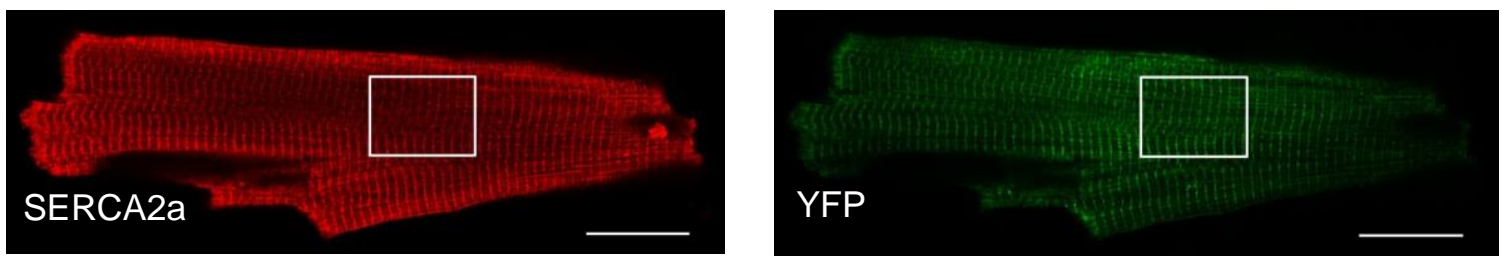

B

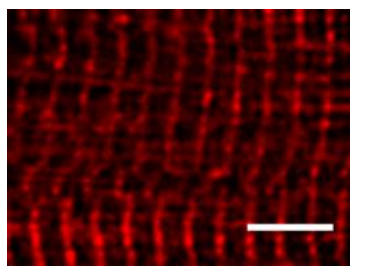

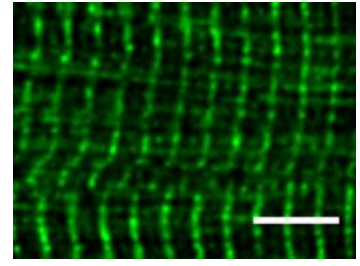

C

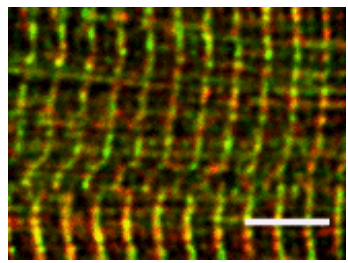

D

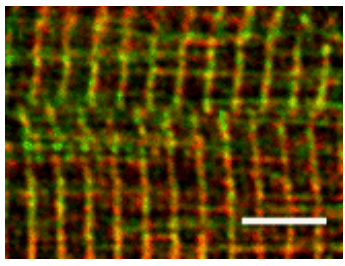

Abbildung 16: Aufnahme einer Epac1PLN-transgenen 12pMI-Kardiomyozyte nach SERCA2aImmunfärbung. Die Zweikanal-Aufnahmen am Konfokalmikroskop bildeten die Grundlage für die Überprüfung der Sensorlokalisation in der SERCA2a-Mikrodomäne. A Beispielhafte Aufnahme von SERCA2a und YFP in einer 12pMI-Kardiomyozyte. Die Rechtecke markieren die in B dargestellten ROls. Die weißen Maßstabskalen entsprechen einer Länge von $20 \mu \mathrm{m}$. B Die ROls der SERCA2a(rot) und der YFP-Aufnahme (grün) bildeten die Grundlage für die Kolokalisationsanalyse. Die hier dargestellten Abbildungen wurden zur Reduzierung des Hintergrundes bereits bearbeitet (s. 2.6.1) und der Kontrast zur besseren Darstellung erhöht. C Fusionsbild der 12pMl ROls aus B. Kolokalisierende Pixel erscheinen gelb. D Beispielhaftes Fusionsbild der ROls einer Sham-Zelle. Die Überlagerung der Signale erscheint vergleichbar mit dem 12pMI Fusionsbild in C. Die weißen Maßstabskalen der ROls entsprechen einer Länge von $5 \mu \mathrm{m}$.

Wie in Kapitel 2.6.1 beschrieben, wurden auf Grundlage der oben dargestellten ROIAuswahl als nächstes Streudiagramme für jede Kardiomyozyte erzeugt sowie bestimmte Korrelationskoeffizienten berechnet. In den Streudiagrammen wurde die Häufigkeitsverteilung der Bildpunkte nach Zusammenführung des YFP- und des SERCA2a-Kanals farbkodiert dargestellt. Reine YFP-Signale lägen hierbei auf der Abszisse, reine SERCA2a-Signale auf der Ordinate. Die Verteilung direkt entlang der Winkelhalbierenden zwischen den beiden Achsen, entspricht einer Deckung zweier Bildpunkte gleicher Intensität. Wie repräsentativ in Abbildung $17 \mathrm{zu}$ sehen ist, sind die Bildpunkte sowohl in der Sham- als auch in der 12pMl-Gruppe relativ häufig um die Diagonale der Diagramme verteilt. Die Pixeldichte ist hierbei zentral am höchsten. Folglich liegt wie erwartet eine Überlagerung der Pixel beider Kanäle vor und somit eine häufige Kolokalisation des Sensor-YFP mit SERCA2a. Details zur Darstellung und Interpretation der Streudiagramme können auch Kapitel 2.6.1 entnommen werden. 
Sham

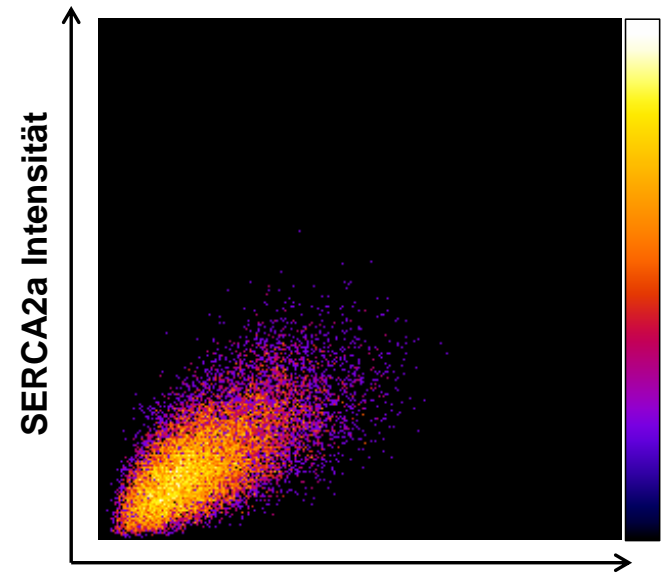

YFP Intensität
$12 \mathrm{pMI}$

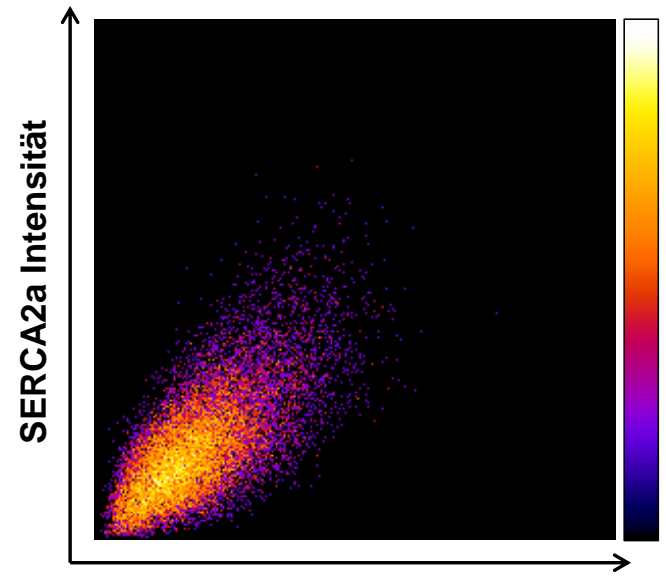

YFP Intensität

Abbildung 17: Streudiagramme zeigen Kolokalisation von YFP mit SERCA2a durch Häufigkeitsverteilung entlang der Diagonale. Dargestellt sind zwei Streudiagramme repräsentativ für die Sham- und die 12pMI-Gruppe. Die Verteilung der Bildpunkte um die Diagonale in beiden Gruppen zeigt die Überlagerung von Pixeln beider Kanäle. Auf Grund der hohen Anzahl an Bildpunkten sind die Diagramme farbkodiert. Eine Farbkodierungsskala befindet sich jeweils an der rechten Seite der Diagramme. Die Helligkeit der Farbe steigt mit der Anzahl an Pixeln in dieser Region (s.a. Kapitel 2.6.1).

Die Kolokalisation von YFP und SERCA2a wurde zudem quantitativ analysiert, indem bestimmte Korrelationskoeffizienten berechnet wurden. Diese wurden für die Sham- und 12pMl-Gruppe jeweils gemittelt um einen Vergleich zwischen den beiden Gruppen zu ermöglichen. Ein standardisiertes Maß um die Überlappung von Pixeln in ZweikanalBildern zu beschreiben ist der Pearson-Koeffizient. Er kann Werte zwischen +1 (vollständig positiver Zusammenhang) und -1 (vollständig negativer Zusammenhang) annehmen und lässt bei 0 auf das Fehlen eines linearen Zusammenhangs rückschließen. Wie in Abbildung 18A grafisch dargestellt, unterscheiden sich die Pearson-Koeffizienten nur geringfügig aber nicht signifikant zwischen beiden Interventionsgruppen (Sham: 0,63, 12pMl: 0,67), was eine wesentliche räumliche Lokalisationsveränderung nach $\mathrm{Ml}$ eher unwahrscheinlich macht. Des Weiteren kann bei Pearson-Werten um 0,65 auch von einem deutlichen Zusammenhang ausgegangen werden, was wiederum für eine weitgehende Kolokalisation von YFP mit SERCA2a in beiden Gruppen spricht. Der Pearson-Koeffizient ist allerdings nicht in der Lage, unterschiedliche Intensitäten der beiden Signale zu berücksichtigen. Methodisch bedingt durch unterschiedliche LabelingDichte, Signalintensität, und Epitop-Lage ist jedoch die Sensorexpression und somit die Intensität im YFP-Kanal nicht in jedem Pixel automatisch identisch mit der Intensität der SERCA2a-Immunfärbung. Dies lässt sich auch bei genauerer Betrachtung der ROls in Abbildung 16 erkennen und ist ein Grund dafür, dass gelb überlagernde Bereiche im Fusionsbild mit grüngelb bzw. orange erscheinenden Pixeln wechselnd erscheinen. Auch 
die Breite der Häufigkeitsverteilung um die Diagonale in den Streudiagrammen (vgl. Abb. 17) lässt sich hierauf zurückführen. Aus diesem Grund wurden zusätzlich die MandersKoeffizienten M1 und M2 untersucht, die dieses Problem eher umgehen und es ermöglichen, Bilder unterschiedlicher Intensitäten miteinander zu vergleichen (Manders et al. 1993). Die Manders-Koeffizienten können Werte von 0 bis 1 annehmen, wobei 0,5 beispielsweise bedeutet, dass 50\% der Bildpunkte kolokalisieren. M1 und M2 beschreiben lediglich wie viele rote Pixel hierbei mit grünen Pixeln überlagern bzw. wie viele grüne Pixel mit roten. Wie aus Abbildung 18B und $\mathrm{C}$ ersichtlich, sind auch für die MandersKoeffizienten keine signifikanten Unterschiede zwischen den Gruppen erkennbar. Der Anteil von überlagernden Bildpunkten wird hier deutlicher als bei der Beschreibung der Pearson-Koeffizienten, da die ermittelten Werte eine prozentuale Aussage über kolokalisierende Pixel zulässt. So zeigt der M1-Koeffizient dass in der Sham-Gruppe $86 \%$ (bzw. $88 \% 12 \mathrm{pMl}$ ) der roten Bildpunkte mit grünen Bildpunkten überlagern. Dementsprechend wird durch den M2-Koeffizienten deutlich, dass nach Sham-Operation 88\% (bzw. 89\% 12pMl) der grünen Pixel auch mit roten Pixeln zur Deckung kommen.
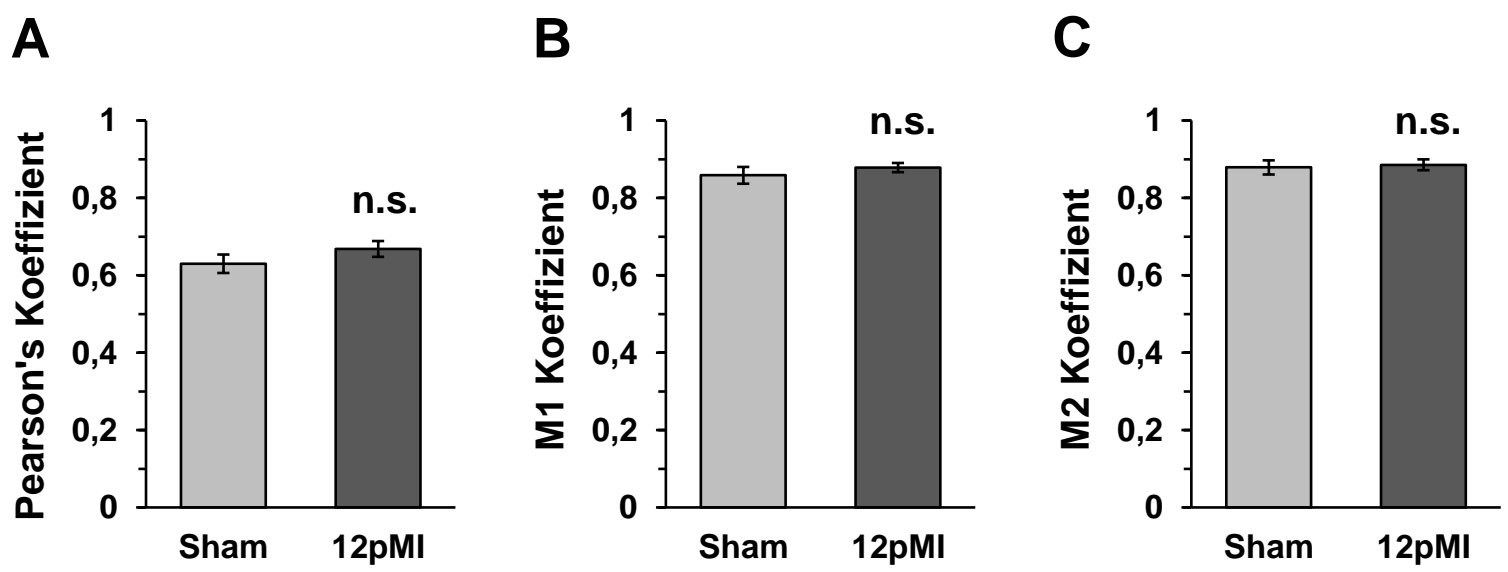

Abbildung 18: Korrelationskoeffizienten bestätigen die Kolokalisation von YFP mit SERCA2a in Sham- und 12pMI-Kardiomyozyten. Die verschiedenen Koeffizienten wurden durch Analyse der ROls für die Sham- und 12pMl-Gruppe berechnet und gemittelt. Bei keinem der drei Korrelationskoeffizienten ist ein signifikanter Unterschied zwischen den beiden Gruppen erkennbar. A Pearson-Koeffizienten. B Manders-Koeffizient M1. C Manders-Koeffizient M2. Die dargestellten Daten entsprechen den Mittelwerten \pm Standardfehler, wobei folgende Anzahl an Kardiomyozyten vermessen wurde: 10 Sham, 10 12pMl. n.s.: nicht signifikant im Vergleich zur Sham-Gruppe.

Zusammenfassend wurde durch verschiedene Kolokalisationsanalysen bei methodisch unterschiedlichen Fluorophor-Markierungen (YFP versus Immunfluoreszenz-Epitop) nachgewiesen, dass bezüglich der Sensorlokalisation keine signifikanten Veränderungen nach MI erkennbar waren. Vor allem die großen Werte der Manders-Koeffizienten in beiden Gruppen sprechen dafür, dass YFP zu einem relativ hohen Anteil tatsächlich mit 
SERCA2a kolokalisiert und der Sensor dementsprechend überwiegend in der gewünschten Mikrodomäne verankert ist.

\subsection{Expression relevanter Proteine in der Mikrodomäne}

Um die Expression relevanter Proteine der Serca2a-Mikrodomäne nach Infarkt beurteilen zu können, wurden, wie in Kapitel 2.7 beschrieben, Western Blots durchgeführt. Zur semiquantitativen Analyse wurde die Dichte der Banden gemessen und die relative Veränderung der Proteine zueinander untersucht. Besonderes Augenmerk lag hierbei auf der Analyse von SERCA2a und PLN, wobei bei letzterem eine getrennte Auswertung des endogenen und des transgenen Sensor-PLN erfolgte. Als Kontrolle wurde die Expression von Calsequestrin (CSQ) bestimmt, da es als Standard-Bezugsprotein für seine konstante Expression auch im Krankheitsmodell bekannt ist.

Für die Experimente wurden Kardiomyozyten aus drei Sham- und drei 12pMI-Mäusen verwendet (s. 2.7). Wie im repräsentativen Blot in Abbildung 19A zu sehen ist, können die PLN-Sensor-Banden der transgenen Mäuse getrennt von den Banden des endogenen PLN analysiert werden. Das Sensor-PLN hat hierbei ein deutlich höheres Molekulargewicht (Monomere bei $70 \mathrm{kDa}$ ) und bildet Oligomere, die bei $250 \mathrm{kDa}$ und $130 \mathrm{kDa}$ liegen. Somit lässt es sich sehr gut von den Banden des endogenen PLN abgrenzen, dessen Monomere bei $5 \mathrm{kDa}$ und Pentamere bei $25 \mathrm{kDa}$ detektiert werden können. SERCA2a und CSQ wurden nach Antikörperstripping auf derselben Membran detektiert. Dabei stellte sich SERCA2a bei $110 \mathrm{kDa}$ (19B) und CSQ bei $55 \mathrm{kDa}$ (19C) dar. Um die statistische Genauigkeit der Ergebnisse zu gewährleisten, wurden die Versuche dreimal mit den gleichen Proben identisch durchgeführt und anschließend Mittelwerte für jede Probe bestimmt. Diese Mittelwerte wurden dann abermals für die Sham- und die 12pMl-Gruppe gemittelt um so einen Vergleich zwischen den beiden Gruppen zu ermöglichen. 
A

PLN-Sensor-Oligomere

PLN-Sensor-Monomere

PLN Pentamere

PLN Monomere

B

C

SERCA2a
kDa Sh1 Ml1 Sh2 MI2 Sh3 MI3

250

70

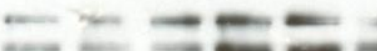

25

5

kDa Sh1 Ml1 Sh2 MI2 Sh3 Ml3

110

kDa Sh1 Ml1 Sh2 MI2 Sh3 Ml3

Calsequestrin

Abbildung 19: Repräsentative Western Blots relevanter Proteine der SERCA2aMikrodomäne. Drei verschiedene Proben der Sham(Sh1-3)- und 12pMl(Ml1-3)-Gruppe wurden jeweils im Wechsel aufgetragen und die Proteine mittels SDS-PAGE aufgetrennt. Ein zusätzlich aufgetragener Proteinmarker ermöglichte die Bestimmung der Molekülgrößen. Dargestellt sind beispielhafte Blots für die jeweiligen Proteine. A Sensor-PLN und endogenes PLN stellen sich in gut voneinander abgrenzbaren Banden dar. SERCA2a (B) und CSQ (C) wurden nach Antikörperstripping auf derselben Membran detektiert.

Von besonderem Interesse für die Versuche mit den transgenen Mäusen war die Expression des Sensor-PLN. Um auszuschließen, dass eine quantitative Veränderung nach MI vorliegt, wurden die Daten der Sensor-Monomere und -Oligomere addiert und im Verhältnis zu CSQ und SERCA2a zwischen der Sham- und 12pMI-Gruppe verglichen (s. Abb. 20A und B). Hierbei konnte bei keinem der beiden Quotienten ein signifikanter Unterschied zwischen den beiden Gruppen festgestellt werden. Vor allem mit dem als konstant anzunehmenden CSQ als Divisor, wichen die Werte der Sensor-PLN-Quotienten zwischen Sham- $(0,64)$ und 12pMI-Gruppe $(0,67)$ kaum voneinander ab.

Der geringfügige Anstieg des Sensor-PLN/Serca2a-Verhälnisses 12pMl (Abb. 20B) ist vermutlich auf eine signifikant verringerte Serca2a-Expression bei Herzinsuffizienz zurückzuführen, welche bereits in der Literatur beschrieben wurde (Hasenfuss et al. 1994). Diese kann tendenziell $(p=0,08)$ auch bei Bildung des SERCA2a/CSQ-Quotienten in den hier durchgeführten Experimenten beobachtet werden (s. Abb. 20C). Des Weiteren 
ist aus früheren Veröffentlichungen ein Anstieg des Verhältnisses von (endogenem) PLN zu SERCA2a bei Herzinsuffizienz bekannt (Chu und Kranias 2006). Wie in Abbildung 20D dargestellt, konnte auch in den hier erfolgten Versuchen für die Epac1-PLN-transgenen Mäuse ein signifikanter Unterschied der 12pMl- gegenüber der Sham-Proben nachgewiesen werden. In Relation zu CSQ bestand für das endogene PLN keine signifikante Zunahme nach $\mathrm{MI}$, auch wenn bei einem $p$-Wert von 0,10 tendenziell der Eindruck entsteht (s. 20E). Als endogenes PLN wurde bei diesen Analysen die Summe aus PLN Monomeren und Pentameren bezeichnet, die Sensor-Monomere und -Oligomere blieben hier unberücksichtigt.

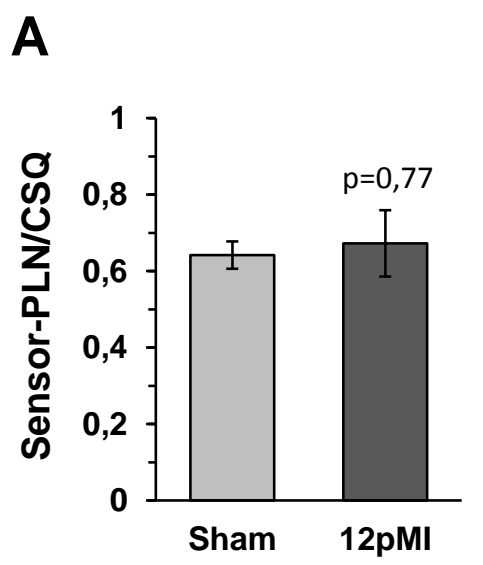

D
B

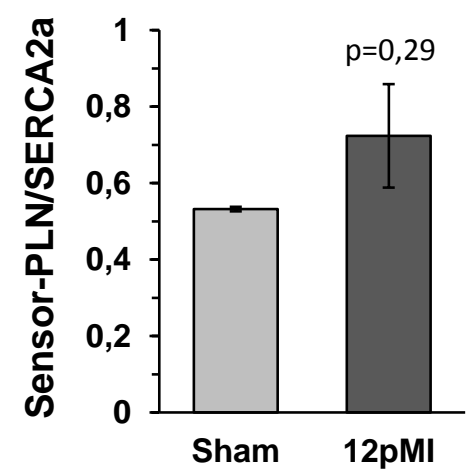

C

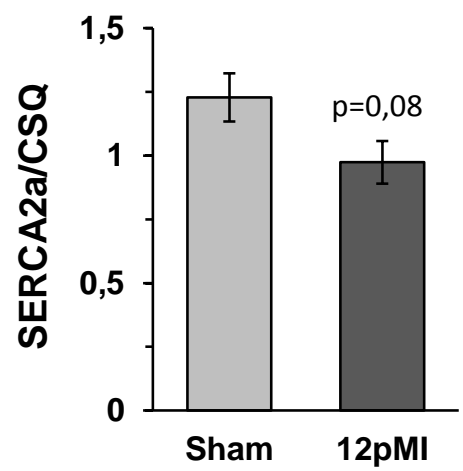

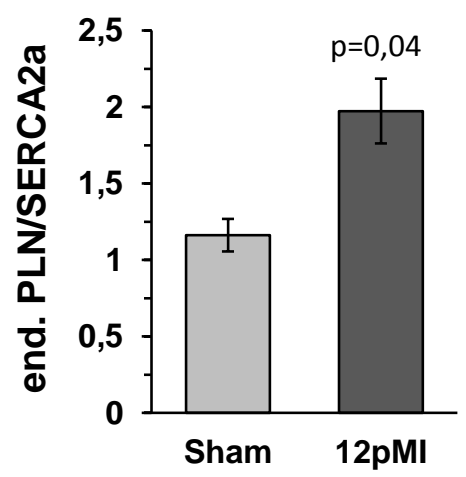

$\mathbf{E}$

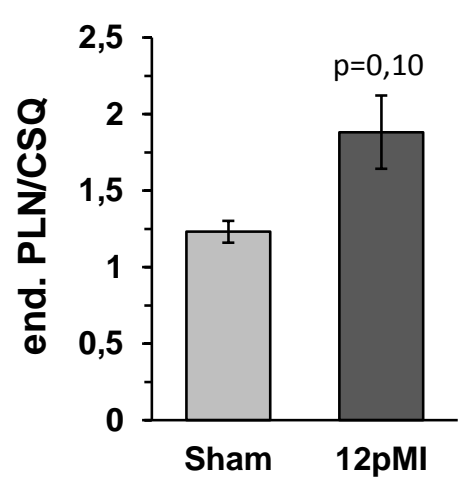

Abbildung 20: PLN- und SERCA2a-Expression in Sham- und 12pMI-Kardiomyozyten. Nach semiquantitativer Analyse der durchgeführten Western Blots (s. Abb. 15) wurden die Verhältnisse verschiedener Proteine zueinander bestimmt und zwischen den beiden Gruppen verglichen. A Verhältnis aus Summe der Sensor-PLN-Monomere und -Oligomere zu SERCA2a. B Verhältnis aus Summe der Sensor-PLN-Monomere und -Oligomere zu CSQ. C SERCA2a/CSQ-Quotient. D Verhältnis aus Summe der endogenen PLN-Monomere und -Pentamere zu SERCA2a. E Verhältnis aus Summe der endogenen PLN-Monomere und -Pentamere zu CSQ. Die dargestellten Daten entsprechen den Mittelwerten \pm Standardfehler, wobei die statistische Genauigkeit der Resultate durch dreifache Wiederholung der Experimente und Mittelung der Ergebnisse erhöht wurde. Untersucht wurden jeweils 3 Proben pro Gruppe. $p=p$-Wert bei T-Test im Vergleich zur Sham-Gruppe. 
Fasst man zusammen, so konnte trotz der bekannten Veränderungen von endogenem PLN und SERCA2a bei Herzinsuffizienz kein signifikanter Unterschied bezüglich der Sensor-PLN-Expression zwischen den Gruppen festgestellt werden. Somit wurden einerseits ergänzend zu Kapitel 3.1 wichtige Hinweise zu erwarteten molekularen Veränderungen des Krankheitsmodells erbracht, andererseits unerwünschte Einflüsse auf die Experimente durch veränderte Sensorexpression nach Ml weitgehend ausgeschlossen.

\subsection{FRET-Messungen an Epac1-PLN-transgenen Kardiomyozyten zeigen Veränderungen im PDE-Profil der Mikrodomäne 12pMI}

Wesentliches Ziel der Arbeit war es, molekulare Mechanismen des $\beta$-Adrenorezeptor ( $\beta$ AR)-vermittelten cAMP-Signalwegs in der SERCA2a-Mikrodomäne bei Herzinsuffizienz zu untersuchen. Phosphodiesterasen (PDEs) leisten durch Hydrolysierung des sekundären Botenstoffes CAMP einen wichtigen Beitrag zur Kompartimentierung der vermittelten Signale. Deshalb wurde der Fokus in den Versuchen auf die Aktivität verschiedener PDESubtypen in der Mikrodomäne gelegt. Im Herzen sind die PDE-Familien 2, 3 und 4 physiologisch relevant und können durch spezifische Inhibitoren jeweils gezielt gehemmt werden. Dank der Expression des SERCA2a-gebundenen Epac1-PLN-cAMP-Sensors in transgenen Kardiomyozyten konnten durch Verwendung dieser Substanzen in FRETExperimenten Aktivitätsprofile der PDEs erzeugt werden. Neben der Aktivität nach $\beta$ Rezeptor-Stimulation wurden auch die anteiligen Beiträge der PDE-Subtypen unter basalen Bedingungen für die Sham- und 12pMI-Gruppe bestimmt und die Daten zwischen den Gruppen verglichen.

\subsubsection{PDE-Profile von Sham- und 12pMI-Kardiomyozyten nach $\beta$-adrenerger Vorstimulation}

Um die Beteiligung der verschiedenen PDEs an der Beendigung des $\beta$-Rezeptor vermittelten cAMP-Signals in der SERCA2a-Mikrodomäne zu beurteilen, wurden gezielt FRET-Experimente (s. 2.4) an frisch isolierten Epac1-PLN-transgenen Kardiomyozyten durchgeführt. Hierzu wurden die Zellen zunächst mit Isoprenalin, einem nicht-selektiven $\beta$ Sympathomimetikum, stimuliert. Zur selektiven Hemmung der PDEs wurde anschließend Bay (PDE2), Cilostamid (PDE3) oder Rolipram (PDE4) zugegeben und die FRET-Antwort in Echtzeit gemessen. IBMX wurde letztlich zur vollständigen Hemmung der PDEabhängigen cAMP-Hydrolyse eingesetzt, um die maximal mögliche Änderung der CFP/YFP-Ratio zu dokumentieren. Anhand dieser FRET-Spuren ließen sich dann die 
relativen Anteile der verschiedenen PDEs an der gesamten PDE-Inhibition ermitteln. Eine repräsentative Darstellung dieser Kurven bei PDE4-Hemmung findet sich in Abbildung 21.

A

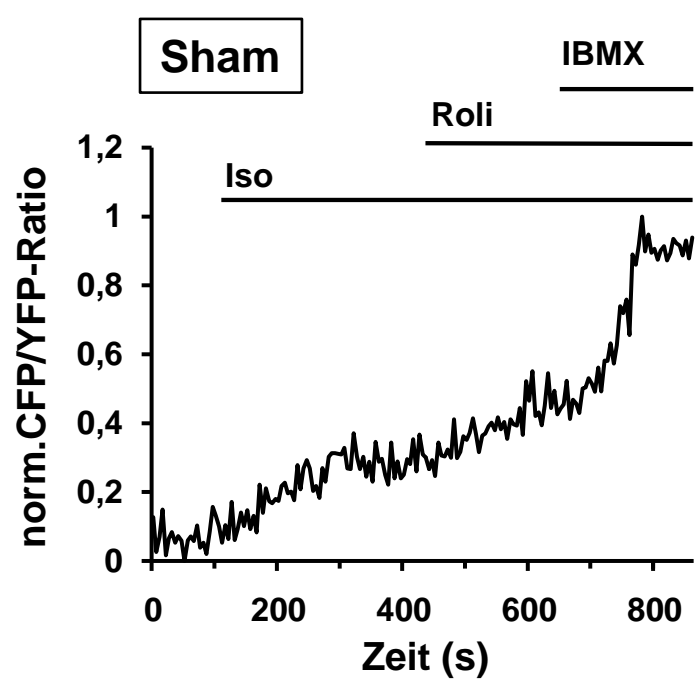

B

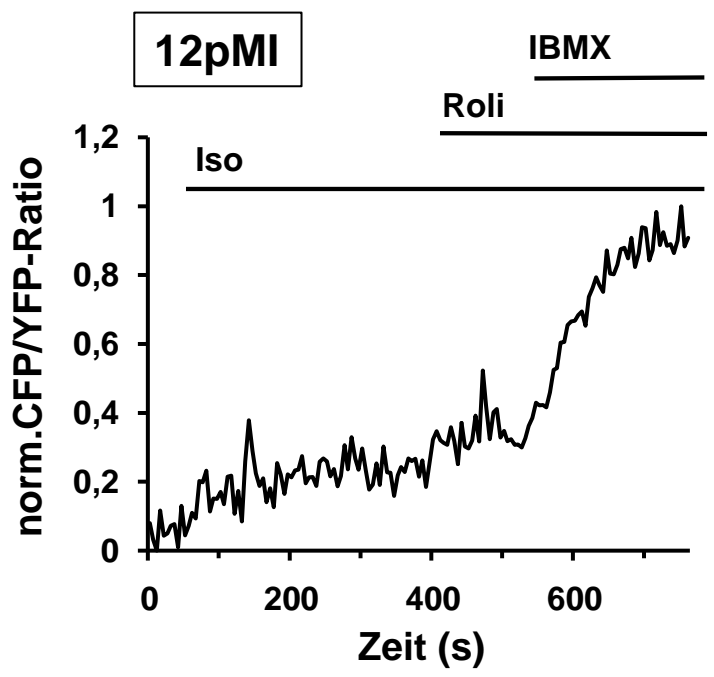

C

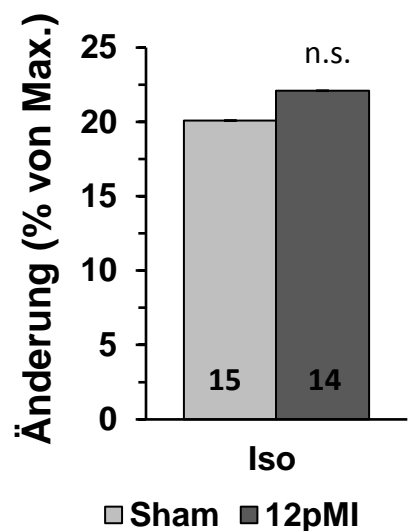

D

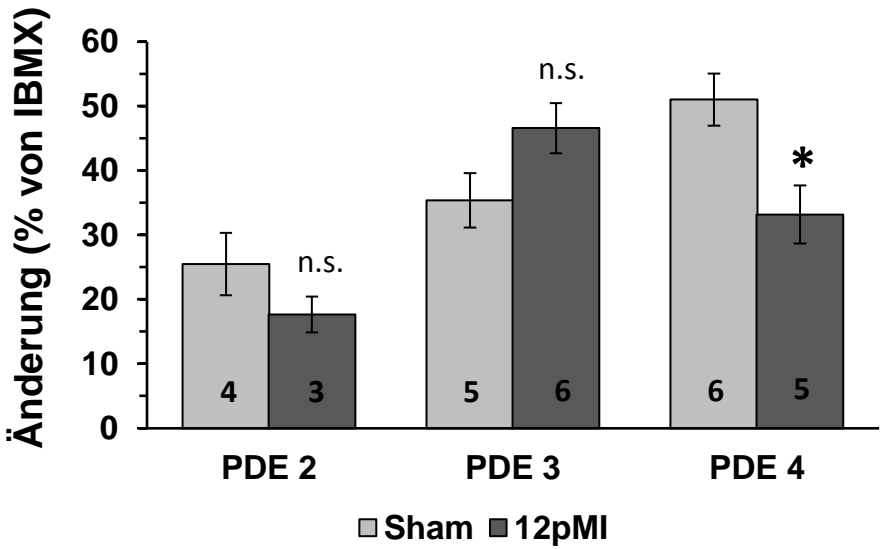

Abbildung 21: PDE4-Beitrag zur Beendigung des $\beta$-Rezeptor-vermittelten cAMP-Signals in der SERCA2a-Mikrodomäne ist 12pMI signifikant reduziert. A und B zeigen repräsentative FRET-Spuren für Sham und 12pMI nach Vorstimulation mit Iso und folgender PDE4-Inhibition. Durch Zugabe von IBMX wurde die vollständige PDE-Hemmung herbeigeführt. C Änderung der FRET-Ratio nach Iso-Stimulation in Prozent der Maximalantwort Sham vs. 12pMI. D Änderung der FRET-Ratio durch isolierte Inhibition der PDE2, 3 und 4 nach Vorstimulation mit Iso, prozentual zur gesamten PDE-Inhibition durch IBMX Sham vs. 12pMI. Der Anteil von PDE4 zeigt sich nach MI signifikant reduziert im Vergleich zur Kontrollgruppe. In den Balkendiagrammen sind Mittelwerten \pm Standardfehler dargestellt. Die jeweilige Anzahl an durchgeführten Experimenten ist in den Balken vermerkt. *: $p<0,05$. n.s.: nicht signifikant im Vergleich zur Sham-Gruppe. Substanzkonzentrationen: Iso $1 \mathrm{nM}$, Bay $100 \mathrm{nM}$, Cilo $10 \mu \mathrm{M}$, Roli $10 \mu \mathrm{M}$, IBMX $100 \mu \mathrm{M}$.

Beim Vergleich von Abbildung 21A und B lässt sich feststellen, dass die Zunahme der CFP/YFP-Ratio nach PDE4-Inhibition mit Roli bis zur Zugabe von IBMX bezogen auf die gesamte PDE-Hemmung in der Sham-Gruppe ausgeprägter ist. Obwohl bezüglich der 
Änderung der FRET-Ratio nach Iso-Stimulation im Mittel kein Unterschied zwischen den Gruppen festzustellen war (s. Abb. 21C), schien diese generell zwischen den Versuchen sehr variabel. Um eine unpräzise Auswertung zu vermeiden, wurden deshalb die PDEAnteile in jedem Versuch prozentual zur jeweils vollständigen PDE-Inhibition (\% von IBMX) angegeben (s. Abb. 21D). Die Änderung der Ratio durch vorhergehende selektive Hemmung wurde hierbei natürlich berücksichtigt. Nach Auswertung aller Experimente, konnte gezeigt werden, dass der Beitrag der PDE4 zur Beendigung des $\beta$-AR vermittelten cAMP-Signals in der SERCA2a-Mikrodomäne nach Ml signifikant verringert ist (Sham: $51 \%$ von IBMX, 12pMI: $33 \%$ von IBMX, $p<0,05)$. Wie ebenfalls aus Abbildung 21D hervorgeht, konnten für die PDE2 und PDE3 12pMI keine signifikanten Unterschiede im Vergleich zur Kontrollgruppe nachgewiesen werden.

\subsubsection{PDE-Profile von Sham- und 12pMI-Kardomyozyten unter basalen Bedingungen}

Um die Beteiligung der PDE-Familien in der SERCA2a-Mikrodomäne nach MI auch unter Ruhebedingungen zu beurteilen, wurden ähnliche FRET-Experimente ohne $\beta$-adrenerge Vorstimulation durchgeführt. Hierfür wurden die transgenen Kardiomyozyten direkt im ersten Schritt mit den verschiedenen selektiven PDE-Inhibitoren stimuliert, und so die FRET-Antwort unter basalen Umständen gemessen. Um die ermittelten Werte in Bezug zur jeweiligen Maximalantwort der Zelle setzen zu können, wurde dann in zwei weiteren Schritten noch IBMX und Iso zugegeben.

Wie aus Abbildung 22 ersichtlich, zeigte sich auch unter Ruhebedingungen 12pMl ein signifikant verringerter Beitrag der PDE4 im Vergleich zur Sham-Gruppe (Sham: 16\% der Maximalantwort, 12pMl: $9 \%$ der Maximalantwort, $p<0,05)$. Genau wie nach $\beta-A R$ Vorstimulation, konnten auch auf basalem Niveau keine relevanten Unterschiede für PDE2 und 3 zwischen den beiden Gruppen beobachtet werden. Des Weiteren bleibt auch die IBMX vermittelte Gesamthemmung der PDEs bei Herzinsuffizienz verglichen mit der Kontrollgruppe unverändert. Es erfolgte ebenfalls eine Berücksichtigung der durch die vorangehende spezifische PDE-Inhibition erzeugten FRET-Antwort. Somit konnten unter Abwesenheit $\beta$-adrenerger Signale 12pMl ähnliche Veränderungen im PDE-Profil der Mikrodomäne wie nach Stimulation mit Iso nachgewiesen werden. 
A

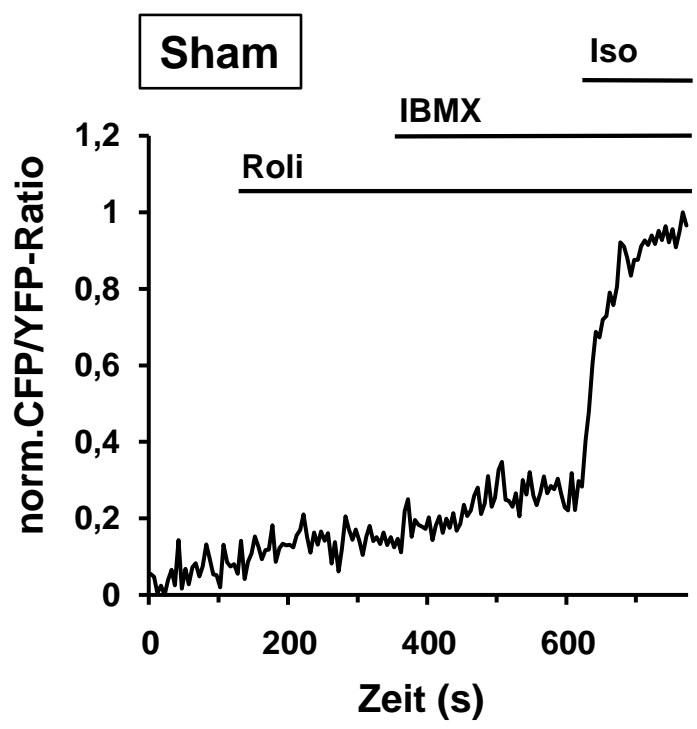

B

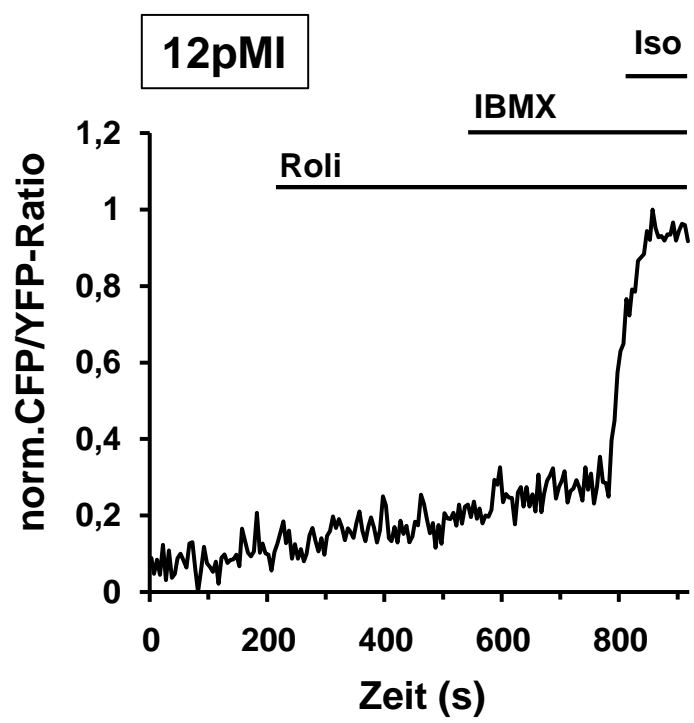

C

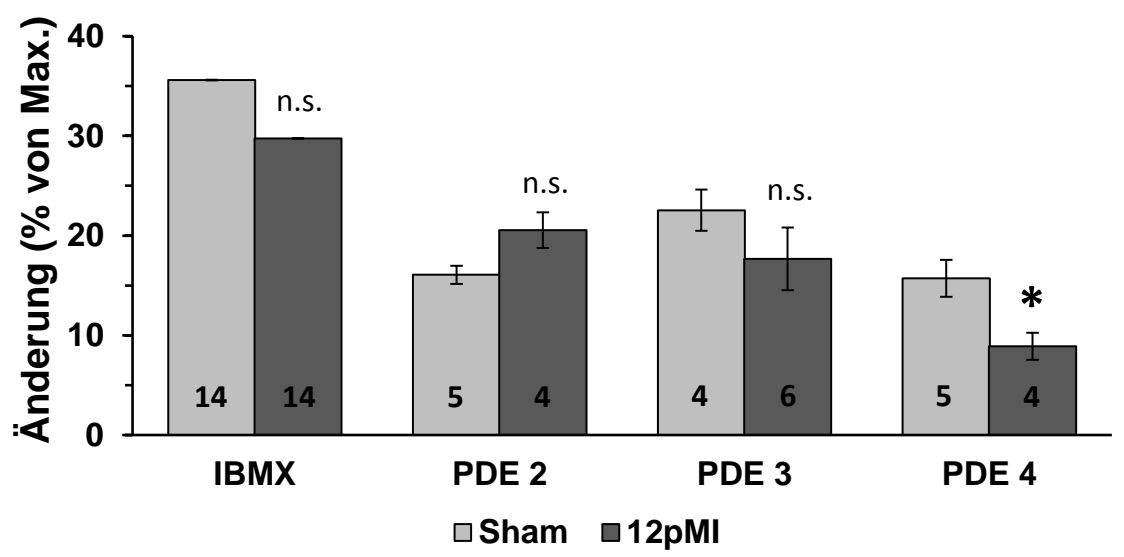

Abbildung 22: PDE4-Aktivität in der SERCA2a-Mikrodomäne ist unter basalen Bedingungen 12pMI signifikant reduziert. $\mathbf{A}$ und $\mathbf{B}$ zeigen repräsentative FRET-Spuren jeweils für die Shamund 12pMI-Gruppe während PDE4-Inhibition unter Ruhebedingungen. Durch Zugabe von IBMX und Iso wurde die maximale FRET-Antwort herbeigeführt. C Das Balkendiagramm vergleicht die Änderung der FRET-Ratio durch spezifische Inhibition der PDE2, PDE3 und PDE4 in Prozent der Maximalantwort jeweils bei Sham- vs. 12pMI-Intervention. Die prozentuale Steigerung der PDE4Aktivität ist im Vergleich zur Sham-Kontrollgruppe nach Ml signifikant reduziert. In den Balkendiagrammen sind Mittelwerten \pm Standardfehler dargestellt. Die jeweilige Anzahl an durchgeführten Experimenten ist in den jeweiligen Balken vermerkt. *: $p<0,05$. n.s.: nicht signifikant im Vergleich zur Sham-Gruppe. Substanzkonzentrationen: Iso $100 \mathrm{nM}$, Bay $100 \mathrm{nM}$, Cilo $10 \mu \mathrm{M}$, Roli $10 \mu \mathrm{M}$, IBMX $100 \mu \mathrm{M}$ 


\section{Diskussion}

\subsection{Erfolgreiche Induktion der Herzinsuffizienz}

\subsubsection{Das MI-Mausmodell}

Das für diese Arbeit gewählte Modell der Myokardinfarkt-induzierten Herzinsuffizienz ist eine seit Jahrzehnten angewandte Methode zur kontrollierten Erforschung der mit der Krankheit einhergehenden pathophysiologischen Vorgänge an Nagetieren. Bereits in den 1950ern wurde die Ligatur von Koronararterien bei Kleintieren zur experimentellen Erzeugung eines Ml durchgeführt (Johns und Olson 1954) und in den folgenden Jahren vor allem für die Anwendung in Ratten (Selye et al. 1960, Pfeffer et al. 1979) und Mäusen (Zolotareva und Kogan 1978) etabliert. Die Arbeit mit Mäusen kombiniert die Vorteile einer kurzen Generationszeit, der Verfügbarkeit einer Vielzahl transgener Mauslinien und die gut beschriebene Anwendung operativer Krankheitsmodelle (Tarnavski et al. 2004).

Die bei operativer Ml-Induktion in der Regel durchgeführte Unterbindung des Ramus interventrikularis anterior (RIVA) führt zur Nekrose seines myokardialen Versorgungsareals, welches schließlich zu Narbengewebe umgebaut wird. Da das zerstörte Gewebe die physiologische Herzfunktion nicht aufrecht erhalten kann, kommt es zu physiologischen und pathologischen Remodelingvorgängen und zur zunehmenden Ausbildung der Herzinsuffizienz (s.a. 1.1). Die funktionellen und strukturellen Veränderungen nach experimenteller MI-Induktion in Mäusen ähneln hierbei stark denen, die auch bei Patienten mit ischämischer Herzerkrankung auftreten (Kanno et al. 2002). Vergleicht man die in dieser Studie echokardiografisch ermittelten Prozentwerte (s. Tab. 7) der linksventrikulären Funktionsparameter (EF und FS), mit Referenzwerten medizinischer Leitlinien (Lang et al. 2005), lässt sich für die 12pMI-Gruppe das Bestehen einer mittelgradigen, moderat abnormalen Pumpfunktion feststellen. Ebenso ist die in der Krankheitsgruppe festgestellte linksventrikuläre Dilatation, die sich echokardiografisch durch Erhöhung von LVESD und LVEDD darstellt (s. Tab. 7), und die deutliche Kardiomyozytenhypertrophie (s. Abb. 9) als typische Veränderung im Rahmen der Herzinsuffizienz beschrieben (Burchfield et al. 2013).

Die operativ hervorgerufene kardiale Dysfunktion ähnelt also bezüglich des Pathomechanismus den Vorgängen, die auch bei Patienten mit ischämischer Herzerkrankung auftreten. Hierdurch grenzt sich die Methode von anderen weit verbreiteten Nagetier-Krankheitsmodellen wie der operativen transversen Aortenkonstriktion (TAC) klar ab, welcher ein entsprechendes klinisches Korrelat mit 
schlagartiger Induktion einer transaortalen Druckerhöhung fehlt (Patten und Hall-Porter 2009).

Das in dieser Studie verwendete post-MI-Mausmodell ist also ein relativ gut etabliertes und besonders geeignetes Verfahren, das heutzutage breite Anerkennung als Mittel zur Untersuchung Herzinsuffizienz-assoziierter Krankheitsabläufe findet.

\subsubsection{T-Tubulus Remodeling in Epac1-PLN-transgenen Kardiomyozyten gibt Hinweise auf Ausmaß der Erkrankung}

Wie bereits in Kapitel 1.5.1 aufgezeigt, wurden Remodelingvorgänge des TATS auf unterschiedliche und zum Teil sogar differentielle Art beschrieben. Abgesehen von der Tatsache, dass die Ergebnisse aus Untersuchungen verschiedener Modelle stammen, scheint wohl auch der Untersuchungszeitpunkt einen entscheidenden Einfluss auf Art des TATS-Remodeling zu haben, weshalb dessen Analyse Hinweise auf das Krankheitsstadium geben kann.

Eine Studie von Wei et al. an einem TAC-Modell bei Ratten zeigte, dass mit zunehmender Dekompensation der Herzfunktion auch vermehrt Unregelmäßigkeiten in der Anordnung des TATS nachweisbar waren. Die Abweichung der TATS-Elemente von der regulären Anordnung wurde durch Wei et al., nach bereits bekannter Strategie (Song et al. 2006), als indirekter zellweiter $\mathrm{TT}_{\text {power }}$ Index angegeben und stand in engem Zusammenhang mit dem Grad der globalen Einschränkung der linksventrikulären Pumpfunktion (Wei et al. 2010). Auch Louch et al. beschrieben nach Untersuchungen des TATS an einem MIMausmodell progressive Veränderungen in den ersten drei Wochen nach Infarkt. Zwar beschränkte sich die Beurteilung hier lediglich auf die beispielhafte Betrachtung und verblindete Zuordnung zu drei zunehmenden Schweregraden bezüglich der beobachteten Veränderungen, jedoch stimmten die Beobachtungen mit dem in der Studie von Louch et al. identifizierten TATS-Remodeling überein (Louch et al. 2006). Darüber hinaus zeigte auch eine aktuelle Studie von Crossman et al., dass für humane Proben bei terminaler Herzinsuffizienz ein enger, hochsignifikanter Zusammenhang zwischen dem Ausmaß des TATS-Remodeling und der lokalen Kontraktionsfähigkeit des Myokards besteht (Crossman et al. 2015).

Zusätzlich zu den obigen indirekten konfokalmikroskopischen Studienstrategien führten Wagner et al. neue nanometrisch detaillierte und insbesondere direkte Analysen des TATS mittels Superresolution-STED-Mikroskopie 4 (4pMI) und 8 (8pMI) Wochen nach Infarkt in einem post-MI-Mausmodell mit dem C57BI/6N Hintergrund durch. Hierbei zeigte 
sich, dass es 4pMl zu einer Zunahme der axialen Komponenten bei gleichzeitiger Abnahme transversaler Komponenten kommt, wobei 8pMl die axialen Komponenten zu Gunsten schräg verlaufender Komponenten weichen (Wagner et al. 2012). Dieses direkte TATS-Analyseverfahren für Lebendzellen wurde kürzlich in einem Video-Protokoll veröffentlicht und eignet sich auch für die Auswertung konfokalmikroskopischer Bilder (Wagner et al. 2014). Entsprechend wurde die beschriebenen TATS-Analysen auf prinzipiell ähnliche Weise in dieser Arbeit an Epac1-PLN-transgenen Kardiomyozyten, jedoch aus dem genetischen FVB/N-Hintergrund, angewendet, wodurch analytisch eine gute Vergleichbarkeit zu erwarten ist. Die in dieser Arbeit ermittelten Veränderungen des TATS der transgenen 12pMI-Kardiomyozyten zeigten, verglichen mit den jeweiligen Sham-Gruppen, ähnliche Charakteristika wie die oben beschriebenen 4pMI Daten von Wagner et al., was das Vorliegen eines frühen bis mittleren Krankheitsstadiums in dieser Studie nahe legt. Dies stimmt auch mit den Echokardiografiedaten überein, die wie unter 4.1.1 beschrieben auf eine mittelgradige, moderat abnormale Pumpfunktion hinweisen. Auch die relativ früh im Krankheitsverlauf stattfindenden proliferativen Prozesse die Wagner et al. erstmals durch eine Zunahme von Netzwerklänge und -komplexität 4pMI und 8pMl beschreiben (Wagner et al. 2012), lassen sich bei den in dieser Studie untersuchten transgenen 12pMI-Kardiomyozyten finden.

Darüber hinaus stimmt die in dieser Arbeit festgestellte Zunahme axialer Komponenten bei mittelgradiger Herzinsuffizienz (Sachse et al. 2012) und auch die Zunahme axialer Elemente bei gleichzeitiger Abnahme transversaler Elemente (Song et al. 2006) mit den Ergebnissen anderer Studien überein. Der durch Lyon et al. indirekt in Konfokalbildern nachgewiesene „Verlust von T-Tubuli“ konnte an einem Ratten Modell 16 Wochen nach Infarkt (16pMI) und an humanen Kardiomyozyten im Endstadium der Herzinsuffizienz nachgewiesen werden (Lyon et al. 2009). Da in diesen Fällen allerdings terminale Krankheitsstadien analysiert wurden, sind diese Ergebnisse für das hier untersuchte frühe bis mittlere Krankheitsstadium eher weniger relevant und können deshalb nicht direkt zugeordnet werden.

Beim Vergleich der Untersuchungszeitpunkte der hier vorgestellten Studien ist auffällig, dass trotz der vergleichsweise spät durchgeführten Experimente 12pMl ein eher nur frühes bis mittleres Krankheitsstadium vorliegt. Eine wahrscheinliche Erklärung hierfür findet sich im genetischen Hintergrund der FVB/N-Mauslinie. Verschiedene Studien zeigten bereits, dass FVB/N-Mäuse eine relativ hohe Resistenz bezogen auf die Entwicklung von Krankheiten zeigten, so beispielsweise gegen Parasiteninfektion (Knott et al. 2009) oder die Entwicklung von Übergewicht durch eine Hochfett-Diät (Kim et al. 1990). Die Untersuchung eines mittleren Krankheitsstadiums macht durchaus Sinn, da ein 
therapeutisches Eingreifen in der Praxis hier am meisten Bedeutung hat. Frühe Krankheitsstadien, die nach der New York Heart Association (NYHA) als Stadium I klassifiziert werden, gehen beim Menschen in der Regel ohne Symptome einher (McMurray et al. 2012) und werden deshalb praktisch kaum diagnostiziert. Späte Stadien hingegen haben eine schlechte Prognose mit hoher Letalität (Gavazzi et al. 2015), weshalb sie durch vorzeitige Intervention möglichst vermieden werden sollten.

Zusammengefasst konnte also gezeigt werden, dass übereinstimmend mit anderen Studien in Epac1-PLN-transgenen Kardiomyozyten Umbauvorgänge des TATS vorkommen und dass die genaue Betrachtung des Remodelings wichtige Hinweise zur Beurteilung des Krankheitsstadiums geben kann. Sicherlich wären zusätzliche Studien zu weiteren Zeitpunkten nützlich um den Verlauf der Umbauvorgänge noch konkreter beschreiben zu können und so eine noch exaktere Einordnung des Krankheitsstadiums zu ermöglichen; diese Arbeit untersucht jedoch zunächst Mechanismen der lokalen cAMP-Regulation in dem beschriebenen mittelgradigen Krankheitsstadium, in welchem potentielle Therapien den weiteren Krankheitsverlauf positiv beeinflussen könnten.

\subsubsection{Epac1-PLN-transgene Mäuse zeigen Herzinsuffizienz-typische Veränderungen der Proteinexpression}

Im Rahmen dieser Studie wurde in Epac1-PLN-transgenen Kardiomyozyten neben den Sensor-Proteinen, die im nächsten Kapitel besprochen werden, auch die Expression von SERCA2a und endogenem PLN überprüft. Wie unter 1.5.2 dargestellt, gibt es bereits Studien, die die Expression der beiden Proteine bei Herzinsuffizienz beschreiben. CSQ wurde in dieser Arbeit als Standard-Bezugsprotein gewählt, da es im Krankheitsfall unverändert vorliegt (Takahashi et al. 1992) und somit ein gutes Referenzmaß für veränderte Proteinexpression darstellt.

Der in dieser Studie 12pMl festgestellte signifikante Anstieg des Quotienten aus endogenem PLN zu SERCA2a (s. Abb. 20D) wurde auch bei herzinsuffiziente Patienten mit dilatativer Kardiomyopathie beschrieben (Meyer et al. 1995). Da PLN, wie unter 1.3 aufgeführt, eine inhibitorische Wirkung auf die SERCA2a-Pumpfunktion hat, postulieren Meyer et al. in der relativen Reduktion der SERCA2a gegenüber PLN bereits eine Verstärkung eben dieses Effektes im Krankheitsfall. Auch Chu und Kranias benannten den Anstieg des PLN/SERCA2a-Quotienten bei Herzinsuffizienz als beitragenden Faktor für die verstärkte Inhibition der SERCA2a und die daraus resultierende reduzierte Kontraktionsleistung des Myokards (Chu und Kranias 2006). 
Die tragende Rolle für die Störung des Proteinverhältnisse zwischen PLN und SERCA2a spielt wohl vor allem eine Herabregulierung der SERCA2a im Krankheitsfall. Eine verminderte SERCA2a-Expression wurde beispielsweise bei Patienten mit Herzinsuffizienz im Endstadium nach dilatativer Kardiomyopathie und KHK nachgewiesen (Studer et al. 1994). Eine Myokardfunktionsstudie, die ebenfalls an humanen Proben durchgeführt wurde, zeigte sogar, dass das Ausmaß der reduzierten SERCA2aExpression mit dem Grad der myokardialen Funktionseinschränkung korrelliert (Hasenfuss et al. 1994). Zarain-Herzberg et al. wiesen die progressive Reduktion der SERCA2a-Expression bei Ml-induzierter Herzinsuffizienz auch am Rattenmodell nach: Obwohl 4pMI bereits reduzierte mRNA Level und eine Aktivitätsminderung der SERCA2a zu erkennen war, konnte eine reduzierte Proteinmenge mittels Western Blot erst $8 \mathrm{pMI}$ und $16 \mathrm{pMI}$ nachgewiesen werden (Zarain-Herzberg et al. 1996). Dies stimmt auch mit den Ergebnissen dieser Studie überein, die zeigten dass 12pMl eine starke Tendenz der SERCA2a zur verminderten Expression im Vergleich zum Bezugsprotein CSQ bestand ( $p$-Wert = 0,08; s. Abb. 20 C). Wie oben beschrieben, lag unter Berücksichtigung der zu einem gewissen Grad angenommenen Resistenz der FVB/N-Mauslinie, für die Epac1PLN-transgenen Kardiomyozyten ein eher moderates Erkrankungsstadium vor, sodass die reduzierte SERCA2a-Expression 12pMI vermutlich noch nicht voll ausgeprägt war.

Für das endogene PLN konnte bei Verhältnisssetzung zum als konstant anzunehmenden CSQ in dieser Studie keine signifikante Zunahme 12pMI festgestellt werden (s. Abb. 20E). Dies deckt sich mit den Ergebnissen der bereits erwähnten Studie von Meyer et al., die auch bei Patienten mit dilatativer Kardiomypathie keine Veränderung des PLN relativ zu CSQ feststellen konnten (Meyer et al. 1995). Wie in der Einleitung dargestellt, entspricht dies auch der weit verbreiteten Meinung über das Verhalten von PLN im Krankheitsfall (s. 1.5.2). Zwar zeigten Studien von Linck et al., dass im Myokard herzinsuffizienter Patienten eine Reduktion des PLN-mRNA Levels vorliegt, dennoch konnten sie keine Veränderung seiner Expression nachweisen und interpretierten diese Veränderung folglich als nicht funktionsrelevant (Linck et al. 1996). Darüber hinaus hatten Arai et al. bei der Analyse der PLN mRNA-Level bereits signifikante Schwankungen zwischen einzelnen Proben festgestellt (Arai et al. 1993). Derartige krankheitsunabhängige Unterschiede bezüglich der Expression des endogenen PLN, könnten auch den bei Betrachtung von Abbildung 20E entstehenden Eindruck der Erhöhung des endogenen PLN/CSQQuotienten 12pMl erklären, der jedoch mit einem $\mathrm{p}$-Wert von 0,1 nicht signifikant ist.

Zusammengefasst wurden also an Epac1-PLN-transgenen Kardiomyozyten 12pMI Veränderungen festgestellt, die gut mit den Ergebnissen anderer Studien 
übereinstimmen. Dies ist zum einen ein weiterer Hinweis für die regelrechte Ausbildung der Pathologie in der transgenen Mauslinie und zeigt zum anderen das Verhalten wichtiger Proteine der in dieser Studie untersuchten SERCA2a-Mikrodomäne.

\subsection{Eignung des Epac1-PLN-Biosensor für Anwendung im Krankheitsmodell}

Die für diese Studie verwendete transgene Mauslinie Epac1-PLN exprimiert herzspezifisch einen FRET-Sensor, welcher an PLN gekoppelt ist und so die gezielte Messung von cAMP-Signalen in der SERCA2a-Mikrodomäne von Kardiomyozyten ermöglicht. Die direkte Verfügbarkeit frisch isolierter Zellen mit transgener SensorExpression in vivo ermöglicht Experimente unter möglichst physiologischen Bedingungen, was besonders im Hinblick auf Untersuchungen von Pathologien vorteilhaft ist. Durch Umgehung der Notwendigkeit einer Kultivierung, wie sie für die alternative In-vitro-SensorEinbringung mittels Adenovirus-Infektion nötig ist (Kirshenbaum et al. 1993), wird die Wahrscheinlichkeit für die Entwicklung artifizieller Veränderungen, die als Pathologiespezifisch fehlinterpretiert werden könnten, minimiert. Derartige Artefakte durch längere Zellkultivierung sind bereits für Rattenkardiomyozyten bekannt, die trotz Ausplattierung unter optimalen Bedingungen innerhalb weniger Tage Formveränderungen zeigten und sich im weiteren Verlauf entdifferenzierten und zunehmend atroph wurden (Horackova und Byczko 1997). Außerdem ist der Verzicht auf Kultivierung im Hinblick auf die beschriebene, schlechtere Überlebensfähigkeit von Mauskardiomyozyten verglichen mit nahe verwandten Nagetierspezien nach Isolation (Kabaeva et al. 2008) gerade im Krankheitsfall von Vorteil: Hier sind die Herzmuskelzellen pathologiebedingt durch verschieden Stressoren wie neurohumorale Überaktivierung, vermehrtes Vorkommen von Sauerstoffradikalen und Nährstoffunterversorgung bei erhöhtem Bedarf des insuffizienten Herzens vorbelastet (Hilfiker-Kleiner et al. 2006), sodass die Überlebensfähigkeit im Vergleich zu gesunden Zellen sogar noch weiter eingeschränkt ist.

Die Epac1-PLN-transgenen Mauslinie wurde bereits im Vorfeld durch Dr. Julia Sprenger im Rahmen ihrer Promotion generiert (s. 2.1) und der Erhalt der physiologischen Funktion der genetisch veränderten Mäuse durch Vergleich mit FVB/N-Wildtypen überprüft. Hierbei konnte allenfalls eine leicht gesteigerte Herzleistung nachgewiesen werden, die jedoch nicht mit einem messbar veränderten intrazellulären $\mathrm{Ca}^{2+}$-Metabolismus einherging und für die auch kein Hinweis auf Beeinflussung der cAMP-Messungen in der Mikrodomäne bestand (Sprenger 2014). Des Weiteren stellte Sprenger bereits fest, dass das transgene Sensor-PLN vergleichbare physiologische Eigenschaften wie das endogene PLN aufweist, wobei eine Phosphorylierung des Sensor-PLN an Serin-16 keine Änderung der 
FRET-Antwort bewirkte (Sprenger 2014). Zusammengefasst hatte Sprenger also bereits gezeigt, dass durch die Einbringung des physiologisch funktionellen Sensor-PLN weder ein Einfluss auf die SERCA2a Regulation nachgewiesen werden konnte, noch andere dramatische Funktionsabweichungen in den transgenen Mäusen oder Messbeeinflussungen feststellbar waren. Die Eignung der transgene Mauslinie zur Verwendung im Krankheitsmodell wurde bereits durch Induktion von Herzhypertrophie mittels TAC und nachfolgenden Experimenten an diesem Herzinsuffizienz-Vorstadium gezeigt (Sprenger et al. 2015).

Unter Berücksichtigung dieser Vorarbeiten war es also für dieses Projekt relevant, eine veränderte Sensor-Expression nach Myokardinfarkt-induzierter Herzinsuffizienz auszuschließen und das regelhafte Verbleiben des Sensors in der gewünschten Mikrodomäne zu überprüfen. Wie in Abbildung 20A dargestellt war die Sensor-PLNExpression im Verhältnis zu CSQ 12pMI unverändert im Vergleich zur Sham-Gruppe. Wie unter 4.1.3 bereits erwähnt, wird CSQ bei Herzinsuffizienz konstant exprimiert und ist deshalb gut als Referenzprotein zur Beurteilung quantitativer Veränderungen anderer Proteine geeignet. Durch die gleichbleibende Expression des Sensor-PLN auch im Krankheitsfall, ist die Beeinflussung der Messergebnisse durch abweichende SensorQuantität unwahrscheinlich. Auch bezüglich der Sensorlokalisation, die auf Grundlage von Kolokalisationsanalysen des Sensor-YFP mit SERCA2a anhand konfokalmikroskopischer Bilder erfolgte, konnten 12pMl keine Abweichungen zur Sham-Gruppe festgestellt werden: Sowohl die Korrelationskoeffizienten nach Pearson als auch nach Manders nahmen in beiden Gruppen vergleichbare Werte an (s. Abb. 18), was auch durch Streudiagramme (s. Abb. 17) veranschaulicht wurde. Zudem sprachen in beiden Gruppen hohe Korrelationskoeffizienten v.a. der Manders-Koeffizienten für die gute Deckung von Sensor-YFP mit SERCA2a (s. Abb. 18), und somit für die gewünschte Lokalisation des Sensors in der SERCA2a-Mikrodomäne.

\subsection{Veränderungen im PDE-Aktivitätsprofil der SERCA2a-Domäne 12pMI nachweisbar}

\subsection{1 $\beta$-adrenerge Vorstimulation hat keinen Einfluss auf den lokalen cAMP-Pool der SERCA2a-Mikrodomäne}

Ein bekanntes Phänomen, welches unter Herzinsuffizienz auftritt, ist die Desensibilisierung der kardialen $\beta$-ARs (Marks 2013, Kiuchi et al. 1993). Eine wichtige Ursache hierfür ist, wie auch unter 1.5 .2 beschrieben, die Herabregulierung der $\beta_{1}$-ARs im 
Krankheitsfall, welche beispielsweise durch reduzierte mRNA Level nachgewiesen wurde (Engelhardt et al. 1996).

Interessanterweise konnte in den hier erfolgten Experimenten 12pMI kein funktioneller Einfluss der $\beta$-AR-Desensibilisierung auf den cAMP-Spiegel der SERCA2a-Mikrodomäne nach $\beta$-adrenerger Vorstimulation festgestellt werden. Wie in Abbildung $21 \mathrm{C}$ dargestellt, unterschied sich der Anteil der durch Isoprenalin erzielten FRET-Antwort an der jeweiligen maximalen Antwort nicht zwischen den beiden Gruppen. Hierbei spielt möglicherweise eine Kompensation des reduzierten $\beta_{1}$-AR-Signales durch das Signal des $\beta_{2}$-AR in der SERCA2a-Mikrodomäne eine Rolle: Da es sich bei Isoprenalin um einen nicht-selektiven $\beta$-AR-Agonisten handelt, stimuliert dieser beide $\beta$-ARs gleichsam, was auf Grund der in Kapitel 1.5.2 beschriebenen pathologieassoziierten Verhältnisverschiebung zu Gunsten des $\beta_{2}$-AR, bei Herzinsuffizienz besondere Relevanz hat: So zeigten Bristow et al. bereits für humane Kardiomyozyten, dass im Krankheitsfall der $\beta_{2}$-AR auch einen höheren Anteil an der Vermittlung positiv inotroper Effekte nach nicht-selektiver $\beta$-AR Stimulation als der $\beta_{1}$-AR hatte, welcher unter normalen Bedingungen eigentlich vorrangig hierfür zuständig ist (Bristow et al. 1986). Darüber hinaus wiesen Nikolaev et al. eine Umverteilung des $\beta_{2^{-}}$ AR bei Herzinsuffizienz nach und zeigten zudem, dass das ursprünglich eher kompartimentierte cAMP-Signal nun dem diffusen Signal des $\beta_{1}$-AR gleicht (Nikolaev et al. 2010).

Neben diesen vermutlich Einfluss nehmenden Faktoren muss auch bedacht werden, dass bisher keinerlei Daten bezüglich des $\beta$-AR-vermittelten Signals in der SERCA2aMikrodomäne bei Herzinsuffizienz vorliegen. Die beschriebenen Beobachtungen bezüglich des Verhaltens der $\beta$-ARs bezogen sich stets auf membrannahe Vorgänge und zytosolische cAMP Signale, nicht jedoch auf lokale cAMP-Pools der SERCA2a-Domäne. Allerdings zeigten sich auch im Herzhypertrophie-Modell bei den durch Sprenger et al. durchgeführten TAC-Experimenten, in der SERCA2a-Mikrodomäne vergleichbare lokale cAMP-Pools zwischen Kontroll- und Krankheitsgruppe nach Iso Vorstimulation (Sprenger et al. 2015). Eine genauere Differenzierung und Zuordnung des in der SERCA2aMikrodomäne ankommenden cAMP-Signals zu den verschiedenen $\beta$-ARs und der Vergleich zwischen Krankheits- und Kontrollgruppe hätte den Rahmen dieser Arbeit leider gesprengt. Dennoch wäre die Prüfung eventueller Unterschiede diesbezüglich sicher ein interessanter Ansatzpunkt für weitere Studien. Hierfür könnte man beispielsweise vor der unselektiven Iso-Stimulation in FRET-Experimenten eine spezifische Blockade des $\beta_{1^{-}}$ bzw. $\beta_{2}-A R$ vornehmen oder die Experimente direkt mit selektiven Agonisten durchführen. 
Eine anteilig ähnliche FRET-Antwort bezüglich der $\beta$-adrenergen Vorstimulation zwischen Krankheits- und Kontrollgruppe lässt darauf schließen, dass für beide Gruppen ein vergleichbarer lokaler cAMP-Pool in der SERCA2a-Mikrodomäne vorlag. Dies bietet für die Auswertung der PDE-Experimente den Vorteil, dass die Beiträge der verschiedenen PDE-Familien zum Abbau dieses Pools vermutlich nicht durch unterschiedlich hohe cAMP-Spiegel in den Gruppen beeinflusst werden. Wie unter 1.3 beschrieben, ist vor allem die PDE4-Aktivität abhängig von einem Rückkopplungsmechansimus durch die cAMP-abhängige Proteinkinase (PKA), sodass dies vor allem im Hinblick auf die diesbezüglich beobachteten Veränderungen in dieser Arbeit relevant ist.

\subsubsection{Beitrag der PDE4 zum Abbau des cAMP-Pools der SERCA2a-Mikrodomäne nach $\beta$-adrenerger Vorstimulation und unter basalen Bedingungen 12pMI reduziert}

In dieser Arbeit wurden die Anteile der wichtigsten, zur lokalen cAMP-Begrenzung in der SERCA2a-Mikrodomäne beitragenden Phosphodiesterase-Familien (PDE2, 3 und 4) nach $\beta$-adrenerger Vorstimulation und unter basalen Bedingungen bestimmt sowie Unterschiede zwischen Krankheits- und Kontrollgruppe geprüft. Wie aus den Abbildungen 21D und 22C deutlich wird, konnte sowohl nach Vorstimulation mit Iso als auch unter basalen Bedingungen eine signifikante Verminderung der lokalen PDE4-Aktivität nachgewiesen werden. Dies stimmt mit Beobachtungen an Ratten mit kompensierter Herzhypertrophie überein, für die eine signifikante Reduktion der PDE4A- und PDE4BAktivität nachgewiesen wurde (Abi-Gerges et al. 2009). Ähnlich wiesen auch Richter et al. für humane Kardiomyozyten eine Reduktion der Funktion und Expression von PDE4A und PDE4D bei idopathischer dilatativer Kardiomyopathie nach (Richter et al. 2011).

Neben diesen Beobachtungen auf globalem Zellniveau, sind auch Untersuchungen bezüglich der PDE-Aktivitäten in der SERCA2a-Mikrodomäne nach TAC in der hier verwendeten Mauslinie bekannt: Sprenger et al. zeigten, dass der verminderte Beitrag der PDE4 zur Einschränkung des cAMP-Pools der SERCA2a-Mikrodomäne, der auch in dieser Arbeit nachgewiesen wurde (s. Abb. 22C), unter basalen Bedingungen bereits im Herzinsuffizienz-Vorstadium der Herzhypertrophie besteht (Sprenger et al. 2015). Interessanterweise konnte im Rahmen jener Studie auch gezeigt werden, dass es bei Herzhypertrophie nach Iso-Vorstimulation verglichen mit der Sham-Gruppe zu einer Zunahme der PDE2-Aktivität in der SERCA2a-Domäne kommt. Eine vermehrte PDE2Aktivität und -Expression ist auch bei humanen Kardiomyozyten und bei Hunden im Rahmen der Herzinsuffizienz bekannt und wird als protektiver Effekt zur Abschirmung der 
sympathischen Überstimulation (und folglich vermehrten cAMP-Produktion) diskutiert (Mehel et al. 2013).

Für das Fehlen dieses Effektes in dieser Studie kommen verschiedene Erklärungen in Frage: Zum einen könnte die festgestellte Abweichung der Ergebnisse auf die verschiedenen verwendeten Krankheitsmodelle und/oder die untersuchte Spezies zurück zu führen sein. Zum anderen besteht die Möglichkeit, dass eine kompensatorische Hochregulierung der PDE2-Aktivität nur passager auftritt und mit dem Fortschreiten der Erkrankung nicht mehr aufrecht erhalten werden kann: Sprenger et al. untersuchten in ihrer Studie am TAC-Modell nicht nur PDE-Aktivitäten der SERCA2a-Mikrodomäne, sondern auch, unter Verwendung einer anderen Mauslinie im gleichen Krankheitsstadium, PDE-Aktivitäten im Zytosol. Beim Vergleich der Daten zeigte sich, dass eine Erhöhung der PDE2-Aktivität nach $\beta$-adrenerger Vorstimulation nur in der SERCA2a-Region, nicht jedoch im Zytosol festzustellen war, wo statt dessen ebenfalls eine verminderte PDE4Aktivität vorlag (Sprenger et al. 2015). Dementsprechend könnte eine kompensatorisch vermehrte PDE2-Aktivität, die bei Herzhypertrophie in der Mikrodomäne noch aufrechterhalten werden kann, mit Fortschreiten der Erkrankung, wie in dieser Arbeit bei Herzinsuffizienz untersucht, gar nicht mehr vorhanden sein.

Für ein verzögertes Auftreten der verminderten PDE4-Aktivität würde auch die Tatsache sprechen, dass ihre Herabregulierung durch anhaltende cAMP-Stimulation hervorgerufen werden kann: In Experimenten mit Nagetieren zeigten McCahall et al., dass es durch erhöhte cAMP-Level, wie sie bei Herzinsufizienz auf Grund der andauernden Sympathikusstimulation auftreten, im Herzen zu einer verminderten Aktivität des PDE4A10-Promoters und infolgedessen zur verminderten Expression der PDE4-Isoform PDE4A10 kommt (McCahill et al. 2008). Auch wenn der genaue Nutzen dieser Herabregulierung noch nicht abschließend geklärt ist, könnten initial protektive Effekte eine Erklärung bieten. Solche sind - ebenfalls in Abhängigkeit von $\beta$-AR-Stimulation und PKA-Aktivierung - bereits aus anderen Studien bekannt: Beispielsweise besteht ein Zusammenhang zwischen PDE4 und dem ebenfalls in der SERCA2a-Mikrodomäne vorkommenden Protein Hsp20 (s.a. 1.5.2), welches einen Schutz vor Herzhypertrophie vermittelt (Sin et al. 2011). Wie Sin et al. in Experimenten an neonatalen Rattenkardiomyozyten zeigten, verzögerte die Aktivität der PDE4 die schützende Hsp20Phosphorylierung und somit die antihypertrophen Effekte. Folglich könnte eine Herabregulierung der PDE4 in der SERCA2a-Domäne initial möglicherweise protektiv sein. 
Nichtsdestoweniger scheint eine chronische Herabregulierung der PDE4 langfristig gesehen eher krankheitsfördernd zu sein, da diese PDE-Familie im Rahmen des lokalen cAMP-Abbaus eine relevante Rolle einnimmt: Aus Studien an PDE4D-KO-Mäusen ist bereits bekannt, dass ein Fehlen der PDE4D zu relativ früher PKA-vermittelten Hyperphosphorylierung des RyR2 beiträgt, welche mit einem $\mathrm{Ca}^{2+}$-Leck vom SR ins Zytosol bereits vor messbaren Herzveränderungen assoziiert ist (Lehnart et al. 2005). Im Rahmen dieser Untersuchung wiesen Lehnart et al. zudem nach, dass ein Fehlen der PDE4D3 mit einem gehäuften Auftreten Belastungs-induzierter ventrikulärer Tachykardien einhergeht und die latente Entwicklung einer Herzinsuffizienz bei zunehmendem Alter begünstigt. Wie Sprenger et al. zeigten, hat die PDE4 bei der Begrenzung des lokalen CAMP-Pools in der SERCA2a-Mikrodomäne unter physiologischen Bedingungen den wesentlichen Anteil (Sprenger et al. 2015), weshalb eine relevante Auswirkung der hier nachgewiesenen Aktivitätsminderung im Krankheitsfall nahe liegt.

Eine Studie, die die Expressionsmuster der kardialen PDE4 und ihre subzellulären Zielstrukturen zwischen Menschen und Nagetieren im Gesunden und bei Krankheit verglich, kam zu dem Schluss, dass hohe Ähnlichkeiten bezüglich der Subtypen, SpliceVarianten und der Anbindung an Signalkomplexe, hierunter auch der PLN-SERCA2aKomplex, zwischen diesen Spezien bestehen (Richter et al. 2011). Laut Richter et al. gelten diese Gemeinsamkeiten vor allem für die Kontrolle lokaler cAMP-Pools, so dass eine Übertragbarkeit der lokalen PDE4-Funktion zwischen den Spezien wahrscheinlich gegebenen ist. Da die hier festgestellte, Herzinsuffizienz-assoziierte PDE4-Aktivitätsminderung in der SERCA2a-Mikrodomäne folglich durchaus auch für Menschen gelten könnte, wird eine genaue Erforschung der einhergehenden Auswirkung umso wichtiger. Dies ist gerade im Hinblick auf seit einigen Jahren laut Leitlinien empfohlene PDE4Inhibitoren wie Roflumilast zur medikamentösen Therapie schwerer COPD besonders relevant. Wie bereits diskutiert, sind krankheitsfördernde Eigenschaften einer PDE4Defizienz bereits aus dem RyR2-Proteinkomplex bekannt (Lehnart et al. 2005), so dass gerade die Langzeittherapie mit derartigen Marktneuheiten im Hinblick auf die Entwicklung kardialer Pathologien kritisch beobachtet werden sollte (Lehnart und Marks 2006).

In Übereinstimmung mit anderen Studien auf globalem Zellniveau und in anderen Mikrodomänen wurde also gezeigt, dass auch im lokalen Bereich der SERCA2a-Domäne eine verminderte Aktivität der PDE4 unter den pathologischen Bedingungen der Herzinsuffizienz nachweisbar ist. Eine kompensatorische Aktivitätssteigerung der PDE2, wie sie in einzelnen Studien beschrieben wurde, konnte beim hier vorliegenden Krankheitsstadium und -modell jedoch nicht nachgwiesen werden. 


\section{Zusammenfassung und Ausblick}

Im Rahmen dieser Studie wurden Regulationsmechanismen des lokalen cAMP-Pools der SERCA2a-Mikrodomäne in kardialen Mausmyozyten unter den pathologischen Rahmenbedingungen der Herzinsuffizienz untersucht. Für die durchgeführten Experimente wurde eine transgene Mauslinie verwendet, die einen FRET-cAMPBiosensor (Epac1-PLN) exprimiert, welcher über PLN in der SERCA2a-Mikrodomäne verankert ist. Dies ermöglichte die Ermittlung lokaler cAMP-Dynamiken mittels EchtzeitFRET-Messung an frisch isolierten Kardiomyozyten, die ohne die Notwendigkeit einer Kultivierung direkt verwendet werden konnten. Als Krankheitsmodell wurde eine Myokardinfarkt-induzierende Operation gewählt, in deren Folge es zur Ausbildung der Herzinsuffizienz kommt. Die regelhafte Ausbildung des Krankheitsbildes wurde 12 Wochen nach der operativen Intervention (12pMI) mittels Echokardiografie, Zellvermessung und Beurteilung des pathologischen Remodelings des transversal-axialen Tubulus-Systems (TATS), welches ebenfalls Hinweise auf das Krankheitsausmaß gibt, validiert. Anhand der Analyse dieser Daten wurde auf das Vorliegen eines mittelgradigen Erkrankungsstadiums der 12pMl-Gruppe geschlossen. Nach Überprüfung der Eignung des Epac1-PLN-Biosensors zur Anwendung im vorliegenden Krankheitsmodell wurden FRET-Experimente unter basalen Bedingungen und in Folge $\beta$-adrenerger Vorstimulation durchgeführt und mit Hilfe von PDE-Inhibitoren Aktivitätsprofile der PDE2, 3 und 4 erstellt. Hierbei wurde gezeigt, dass in der SERCA2a-Mikrodomäne unter beiden Bedingungen $12 \mathrm{pMl}$ eine signigikante Aktivitätsminderung der PDE4, verglichen mit der Sham-Gruppe, nachweisbar ist. Da dies mit Veränderungen im lokalen cAMP-Pool einhergeht, welcher wesentlichen Einfluss auf die Regulation der SERCA2a hat, könnte diese Beobachtung durchaus Relevanz bezüglich der im Krankheitsfall auftretenden Funktionsabweichungen haben. Die genauen molekularen Auswirkungen der in dieser Studie nachgewiesenen Minderung der PDE4-Aktivität bei Herzinsuffizienz auf regulatorische oder funktionelle Mechanismen der SERCA2a-Mikrodomäne bieten eine interessante Grundlage für weitere Untersuchungen und mögliche therapeutische Ansätze. 


\section{Anhang}

\subsection{Chemikalien}

\begin{tabular}{|c|c|c|}
\hline Substanz & Firma & Bestellnummer \\
\hline Acrylamide (Rotiphorese $\AA$ Gel 30) & Roth & 3029.1 \\
\hline Ammoniumpersulfat & Sigma-Aldrich & A3672-25G \\
\hline Bay 60-7550 & Santa Cruz & sc-205219 \\
\hline BDM (2,3-Butandion Monoxim) & Sigma-Aldrich & B0753 \\
\hline Bovines Kälberserum & Thermo Scientific & SH30073 \\
\hline Bromphenolblau Natriumsalz & Applichem & A1120 \\
\hline BSA (Bovines Serum Albumin) & Sigma-Aldrich & A8806 \\
\hline $\mathrm{CaCl}_{2} \times 2 \mathrm{H}_{2} \mathrm{O}$ & Merck & 17257 \\
\hline Cilostamid & Sigma-Aldrich & C7971 \\
\hline di-8-ANEPPS & Life Technologies & D-3167 \\
\hline EGTA & Sigma-Aldrich & E4378 \\
\hline Essigsäure & Merck & 1000632500 \\
\hline Glukose & Sigma-Aldrich & G7021 \\
\hline Glycerin & Sigma-Aldrich & G8773 \\
\hline Glycine & Roth & 3908.3 \\
\hline $\mathrm{HCl} 37 \%$ & Sigma-Aldrich & 84422 \\
\hline HEPES & Sigma-Aldrich & H4034 \\
\hline 3-Isobutyl-1-methylxanthin & Applichem & A0695 \\
\hline Isoproterenolhydrochlorid & Sigma-Aldrich & 16504 \\
\hline $\mathrm{KCl}$ & Sigma-Aldrich & P5405 \\
\hline $\mathrm{KHCO}_{3}$ & Sigma-Aldrich & P7682 \\
\hline $\mathrm{KH}_{2} \mathrm{PO}_{4}$ & Merck & 4873 \\
\hline Laminin & Sigma-Aldrich & L2020 \\
\hline Liberase DH & Roche & 05401054001 \\
\hline 2-Mercaptoethanol & Sigma & M3148 \\
\hline Methanol & Roth & HN41.2 \\
\hline $\mathrm{MgCl}_{2} \times 6 \mathrm{H}_{2} \mathrm{O}$ & Applichem & A1036 \\
\hline $\mathrm{MgSO}_{4} \times 7 \mathrm{H}_{2} \mathrm{O}$ & Sigma-Aldrich & M2773 \\
\hline Milchpulver & Roth & T145.1 \\
\hline $\mathrm{NaCl}$ & Sigma-Aldrich & S5886 \\
\hline $\mathrm{NaHCO}_{3}$ & Sigma-Aldrich & S5761 \\
\hline $\mathrm{Na}_{2} \mathrm{HPO}_{4} \times 2 \mathrm{H}_{2} \mathrm{O}$ & Sigma-Aldrich & 71643 \\
\hline $\mathrm{NaOH}$ & Roth & 6771.3 \\
\hline Paraformaldehyd & Sigma-Aldrich & 158127 \\
\hline PBS (Phosphatgepufferte Kochsalzlösung) & Gibco & 10010 \\
\hline Phenolrot Natriumsalz & Sigma-Aldrich & P5530 \\
\hline PhosSTOP & Roche & 04906837001 \\
\hline Ponceau S & Sigma-Aldrich & P3504 \\
\hline ProLong® Gold Antifade Mountant & Life Technologies & P36934 \\
\hline Protease Inhibitor Cocktail & Roche & 11872580001 \\
\hline Protein Marker V & Peqlab & $27-2211$ \\
\hline Saccharose & Sigma-Aldrich & S0389 \\
\hline SDS (20\% Natriumdodecylsulfat-Lösung) & Fluka & 05030 \\
\hline $\begin{array}{l}\text { SuperSignal West Pico Chemiluminescent } \\
\text { Substrate }\end{array}$ & Thermo Scientific & 34080 \\
\hline Rolipram & Sigma-Aldrich & R6520 \\
\hline Taurin & Sigma-Aldrich & T8691 \\
\hline TEMED (N,N,N`,N“-Tetramethylethylendiamin) & Sigma-Aldrich & T9281 \\
\hline
\end{tabular}




\begin{tabular}{lll}
\hline Triton X-100 & Sigma-Aldrich & T9284 \\
TRIS (tris-(hydroxymethyl)-aminomethan) & Roth & 4855.3 \\
Trypsin 2,5\% & Gibco & 15090 \\
Tween ${ }^{820}$ & Sigma-Aldrich & P1379 \\
\hline
\end{tabular}

\subsection{Antikörper}

\subsubsection{Primäre Antikörper}

\begin{tabular}{lllll}
\hline Antikörper & Firma & Bestellnr. & Anwendung & Verdünnung \\
\hline mouse anti-Cav3 & BD & 610421 & Immunfärbung & $1: 500$ \\
mouse anti-PLN A1 & Badrilla & A010-14 & Western Blot & $2: 5000$ \\
mouse anti-RyR2 & Thermo Scientific & MA3-916 & Immunfärbung & $1: 500$ \\
rabbit anti-CSQ & Thermo Scientific & PA1-913 & Western Blot & $1: 10000$ \\
rabbit anti-SERCA2a & Badrilla & A010-20 & Immunfärbung & $1: 250$ \\
& & & Western Blot & $1: 5000$ \\
\hline
\end{tabular}

\subsubsection{Sekundäre Antikörper}

\begin{tabular}{lllll}
\hline Antikörper & Firma & Bestellnr. & Anwendung & Verdünnung \\
\hline $\begin{array}{l}\text { AlexaFluor® } 568 \text { goat } \\
\text { anti-mouse }\end{array}$ & Life Technologies & A-11004 & Immunfärbung & $1: 1000$ \\
$\begin{array}{l}\text { AlexaFluor® } 633 \text { goat } \\
\text { anti-rabbit }\end{array}$ & Life Technologies & A-21071 & Immunfärbung & $1: 1000$ \\
$\begin{array}{l}\text { Goat anti-mouse } \\
\text { Goat anti-rabbit }\end{array}$ & $\begin{array}{l}\text { Bio Rad } \\
\text { Bio Rad }\end{array}$ & $170-5047$ & Western Blot & $1: 5000$ \\
\hline
\end{tabular}

\subsection{Verbrauchsgegenstände und andere Materialien}

\begin{tabular}{ll}
\hline Gegenstand & Firma \\
\hline Deckgläser (Glas, $\varnothing 18 \mathrm{~mm}$ ) & Thermo Scientific \\
Deckgläser (Glas, $\varnothing 24 \mathrm{~mm})$ & Thermo Scientific \\
Deckgläser (Glas, $\varnothing 42 \mathrm{~mm})$ & Thermo Scientific \\
Eppendorf-Röhrchen & Eppendorf \\
Falkon-Röhrchen & BD Falcon \\
Faser-Pads für Western Blot & Bio Rad \\
U-40 Insulin, 30Gx1/2 & Braun \\
21 G Kanüle & BD Microlane \\
Medical X-Ray Film & Fujifilm \\
Short plates für Western Blot & Bio Rad \\
Spacer plates für Western Blot & Bio Rad \\
Superfrost® Plus Objektträger & Thermo Scientific \\
Protran® Nitrozellulose Transfer & Whatman \\
Membran & \\
6 Well Platte & Starlab \\
12 Well Platte & Greiner Bio-One \\
96 Well Platte & Nunc \\
\hline
\end{tabular}




\subsection{Fluoreszenzmikroskop und zugehörige Elemente}

\begin{tabular}{ll}
\hline Gegenstand & Firma \\
\hline Arduino I/O board & Sparkfun Electronics \\
Attofluor® Zellkammer & Invitrogen \\
CFP/YFP filter set & Chroma Technology \\
CoolLED 440 nm & CoolLED \\
ORCA 03G CCD-Kamera & Hamamatsu Photonics \\
DualView Filter Slider & Photometrics \\
DV2 DualView & Photometrics \\
Ti-S Inverses Fluoreszenzmikroskop & Nikon \\
Fluar 40x/1,3 Öl-Objektiv & Carl Zeiss \\
\hline
\end{tabular}

\subsection{Weitere Geräte}

\begin{tabular}{ll}
\hline Gerät & Firma \\
\hline Biotek Reader (für BCA Assay) & BIOTEK Instruments \\
$\mathrm{CO}_{2}$-Inkubator & Sanyo \\
LSM710 & Carl Zeiss \\
pH Meter & Inolab \\
POC-R2 Messkammer & PeCon \\
X-ray film processor SRX 101A & Konica \\
Zentrifuge & Thermo Scientific \\
\hline
\end{tabular}

\subsection{Software}

\begin{tabular}{lll}
\hline Programm & Einsatzbereich & Anbieter \\
\hline Fiji & Bildanalyse und -bearbeitung & http://fiji.sc \\
ImageJ & Bildanalyse und -bearbeitung & National Institutes of Health \\
Micromanager 1.4 & Steuerung des FRET-Mikroskops & Vale Lab, University of \\
& & California \\
& & Microsoft Inc. \\
Office 2010 & Text- und Datenbearbeitung & Carl Zeiss \\
ZEN 2009 & Konfokalmikroskopie (LSM710) & Center of History and New \\
Zotero & Literaturverwaltung & Media, Mason University, USA \\
& & \\
\hline
\end{tabular}




\section{Literaturverzeichnis}

Abi-Gerges A, Richter W, Lefebvre F, Mateo P, Varin A, Heymes C, Samuel J-L, Lugnier C, Conti M, Fischmeister R, Vandecasteele G (2009): Decreased expression and activity of cAMP phosphodiesterases in cardiac hypertrophy and its impact on $\beta$-adrenergic cAMP signals. Circ Res $\underline{105}$, 784-792

Ahmad F, Murata T, Shimizu K, Degerman E, Maurice D, Manganiello V (2015): Cyclic nucleotide phosphodiesterases: important signaling modulators and therapeutic targets. Oral Dis $\underline{21}$, e25-50

Allen LA, Fonarow GC, Grau-Sepulveda MV, Hernandez AF, Peterson PN, Partovian C, Li S-X, Heidenreich PA, Bhatt DL, Peterson ED, Krumholz HM (2014): Hospital Variation in Intravenous Inotrope Use for Patients Hospitalized With Heart Failure Insights From Get With The Guidelines. Circ Heart Fail $\underline{7}, 251-260$

Allen MD, Zhang J (2006): Subcellular dynamics of protein kinase A activity visualized by FRETbased reporters. Biochem Biophys Res Commun $\underline{348}, 716-721$

Altarejos JY, Montminy M (2011): CREB and the CRTC co-activators: sensors for hormonal and metabolic signals. Nat Rev Mol Cell Biol 12, 141-151

Anger M, Samuel JL, Marotte F, Wuytack F, Rappaport L, Lompré AM (1994): In situ mRNA distribution of sarco(endo)plasmic reticulum $\mathrm{Ca}(2+)$-ATPase isoforms during ontogeny in the rat. J Mol Cell Cardiol 26, 539-550

Arai M (2000): Function and regulation of sarcoplasmic reticulum Ca2+-ATPase: advances during the past decade and prospects for the coming decade. Jpn Heart J $\underline{41}, 1-13$

Arai M, Alpert NR, MacLennan DH, Barton P, Periasamy M (1993): Alterations in sarcoplasmic reticulum gene expression in human heart failure. A possible mechanism for alterations in systolic and diastolic properties of the failing myocardium. Circ Res $\underline{72}, 463-469$

Balijepalli RC, Lokuta AJ, Maertz NA, Buck JM, Haworth RA, Valdivia HH, Kamp TJ (2003): Depletion of T-tubules and specific subcellular changes in sarcolemmal proteins in tachycardia-induced heart failure. Cardiovasc Res $\underline{59}$, 67-77

Beard MB, Olsen AE, Jones RE, Erdogan S, Houslay MD, Bolger GB (2000): UCR1 and UCR2 Domains Unique to the cAMP-specific Phosphodiesterase Family Form a Discrete Module via Electrostatic Interactions. J Biol Chem 275, 10349-10358

Beca S, Helli PB, Simpson JA, Zhao D, Farman GP, Jones P, Tian X, Wilson LS, Ahmad F, Chen SRW et al. (2011): Phosphodiesterase 4D (PDE4D) regulates baseline sarcoplasmic reticulum $\mathrm{Ca} 2+$ release and cardiac contractility, independently of L-type Ca2+current. Circ $\operatorname{Res} \underline{109}, 1024-1030$

Beca S, Ahmad F, Shen W, Liu J, Makary S, Polidovitch N, Sun J, Hockman S, Chung YW, Movesian M et al. (2013): PDE3A Regulates Basal Myocardial Contractility through Interacting with SERCA2a-Signaling Complexes in Mouse Heart. Circ Res 112, 289-297

Belge C, Hammond J, Dubois-Deruy E, Manoury B, Hamelet J, Beauloye C, Markl A, Pouleur A-C, Bertrand L, Esfahani $\mathrm{H}$ et al. (2014): Enhanced expression of $\beta 3$-adrenoceptors in cardiac myocytes attenuates neurohormone-induced hypertrophic remodeling through nitric oxide synthase. Circulation $\underline{129}, 451-462$

Berrebi-Bertrand I, Souchet M, Camelin J-C, Laville M-P, Calmels T, Bril A (1998): Biophysical interaction between phospholamban and protein phosphatase 1 regulatory subunit GM. FEBS Lett 439, 224-230 
Bers DM, Ziolo MT (2001): When Is cAMP Not cAMP? Effects of Compartmentalization. Circ Res $\underline{89}, 373-375$

Bokník P, Fockenbrock M, Herzig S, Knapp J, Linck B, Lüss H, Müller FU, Müller T, Schmitz W, Schröder F, Neumann J (2000): Protein phosphatase activity is increased in a rat model of long-term beta-adrenergic stimulation. Naunyn Schmiedebergs Arch Pharmacol 362, 222231

Brette F, Orchard C (2003): T-Tubule Function in Mammalian Cardiac Myocytes. Circ Res $\underline{92}$, 1182-1192

Bristow MR, Ginsburg R, Minobe W, Cubicciotti RS, Sageman WS, Lurie K, Billingham ME, Harrison DC, Stinson EB (1982): Decreased catecholamine sensitivity and betaadrenergic-receptor density in failing human hearts. N Engl J Med 307, 205-211

Bristow MR, Ginsburg R, Umans V, Fowler M, Minobe W, Rasmussen R, Zera P, Menlove R, Shah $P$, Jamieson S (1986): Beta 1- and beta 2-adrenergic-receptor subpopulations in nonfailing and failing human ventricular myocardium: coupling of both receptor subtypes to muscle contraction and selective beta 1-receptor down-regulation in heart failure. Circ Res $\underline{59}$, 297-309

Brittsan AG, Ginsburg KS, Chu G, Yatani A, Wolska BM, Schmidt AG, Asahi M, MacLennan DH, Bers DM, Kranias EG (2003): Chronic SR Ca2+-ATPase Inhibition Causes Adaptive Changes in Cellular Ca2+ Transport. Circ Res 92, 769-776

Brodde O-E, Bruck H, Leineweber K (2006): Cardiac adrenoceptors: physiological and pathophysiological relevance. J Pharmacol Sci 100, 323-337

Brown KM, Lee LCY, Findlay JE, Day JP, Baillie GS (2012): Cyclic AMP-specific phosphodiesterase, PDE8A1, is activated by protein kinase A-mediated phosphorylation. FEBS Lett $\underline{586}, 1631-1637$

Brudvik KW, Taskén K (2012): Modulation of T cell immune functions by the prostaglandin E2 cAMP pathway in chronic inflammatory states. Br J Pharmacol $\underline{166}, 411-419$

Brunton LL, Hayes JS, Mayer SE (1981): Functional compartmentation of cyclic AMP and protein kinase in heart. Adv Cyclic Nucleotide Res $\underline{14}, 391-397$

Bucchi A, Baruscotti M, Robinson RB, DiFrancesco D (2007): Modulation of rate by autonomic agonists in SAN cells involves changes in diastolic depolarization and the pacemaker current. J Mol Cell Cardiol $\underline{43}, 39-48$

Buitrago M, Lorenz K, Maass AH, Oberdorf-Maass S, Keller U, Schmitteckert EM, Ivashchenko Y, Lohse MJ, Engelhardt S (2005): The transcriptional repressor Nab1 is a specific regulator of pathological cardiac hypertrophy. Nat Med $\underline{11}, 837-844$

Burchfield JS, Xie M, Hill JA (2013): Pathological ventricular remodeling: mechanisms: part 1 of 2. Circulation 128, 388-400

Buxton IL, Brunton LL (1983): Compartments of cyclic AMP and protein kinase in mammalian cardiomyocytes. J Biol Chem 258, 10233-10239

Calebiro D, Nikolaev VO, Gagliani MC, de Filippis T, Dees C, Tacchetti C, Persani L, Lohse MJ (2009): Persistent cAMP-signals triggered by internalized G-protein-coupled receptors. PLoS Biol $\underline{7}$, e1000172

Chu G, Kranias EG (2006): Phospholamban as a therapeutic modality in heart failure. Novartis Found Symp 274, 156-171; discussion 172-175, 272-276 
Chu G, Lester JW, Young KB, Luo W, Zhai J, Kranias EG (2000): A Single Site (Ser16) Phosphorylation in Phospholamban Is Sufficient in Mediating Its Maximal Cardiac Responses to $\beta$-Agonists. J Biol Chem $\underline{275}$, 38938-38943

Chu G, Egnaczyk GF, Zhao W, Jo S-H, Fan G-C, Maggio JE, Xiao R-P, Kranias EG (2004): Phosphoproteome Analysis of Cardiomyocytes Subjected to $\beta$-Adrenergic Stimulation Identification and Characterization of a Cardiac Heat Shock Protein p20. Circ Res $\underline{94}, 184$ 193

Cohn JN, Ferrari R, Sharpe N (2000): Cardiac remodeling-concepts and clinical implications: a consensus paper from an international forum on cardiac remodeling. J Am Coll Cardiol $\underline{35}$, 569-582

Communal C, Singh K, Sawyer DB, Colucci WS (1999): Opposing effects of beta(1)- and beta(2)adrenergic receptors on cardiac myocyte apoptosis : role of a pertussis toxin-sensitive $G$ protein. Circulation $100,2210-2212$

Craven KB, Zagotta WN (2006): CNG and HCN channels: two peas, one pod. Annu Rev Physiol $\underline{68}, 375-401$

Crossman DJ, Young AA, Ruygrok PN, Nason GP, Baddelely D, Soeller C, Cannell MB (2015): ttubule disease: Relationship between t-tubule organization and regional contractile performance in human dilated cardiomyopathy. J Mol Cell Cardiol $\underline{84}, 170-178$

Daaka Y, Luttrell LM, Lefkowitz RJ (1997): Switching of the coupling of the beta2-adrenergic receptor to different $G$ proteins by protein kinase A. Nature $\underline{390}$, 88-91

De Rooij J, Zwartkruis FJT, Verheijen MHG, Cool RH, Nijman SMB, Wittinghofer A, Bos JL (1998): Epac is a Rap1 guanine-nucleotide-exchange factor directly activated by cyclic AMP. Nature 396, 474-477

Depry C, Allen MD, Zhang J (2011): Visualization of PKA activity in plasma membrane microdomains. Mol Biosyst $\underline{7}, 52-58$

Despa S, Brette F, Orchard CH, Bers DM (2003): $\mathrm{Na} / \mathrm{Ca}$ exchange and $\mathrm{Na} / \mathrm{K}-\mathrm{ATPase}$ function are equally concentrated in transverse tubules of rat ventricular myocytes. Biophys $\mathrm{J} \underline{\mathbf{8 5}}, 3388$ 3396

DiFrancesco D (2010): The role of the funny current in pacemaker activity. Circ Res $\underline{106}, 434-446$

DiFrancesco D, Tortora P (1991): Direct activation of cardiac pacemaker channels by intracellular cyclic AMP. Nature $\underline{351}, 145-147$

DiPilato LM, Cheng X, Zhang J (2004): Fluorescent indicators of cAMP and Epac activation reveal differential dynamics of cAMP signaling within discrete subcellular compartments. Proc Natl Acad Sci U S A 101, 16513-16518

Dodge KL, Khouangsathiene S, Kapiloff MS, Mouton R, Hill EV, Houslay MD, Langeberg LK, Scott JD (2001): mAKAP assembles a protein kinase A/PDE4 phosphodiesterase cAMP signaling module. EMBO J $\underline{20}, 1921-1930$

El-Armouche A, Pamminger T, Ditz D, Zolk O, Eschenhagen T (2004): Decreased protein and phosphorylation level of the protein phosphatase inhibitor-1 in failing human hearts. Cardiovasc Res $\underline{61}, 87-93$

El-Armouche A, Gocht F, Jaeckel E, Wittköpper K, Peeck M, Eschenhagen T (2007): Long-term beta-adrenergic stimulation leads to downregulation of protein phosphatase inhibitor-1 in the heart. Eur J Heart Fail $\underline{9}$, 1077-1080 
Engelhardt S, Böhm M, Erdmann E, Lohse MJ (1996): Analysis of beta-adrenergic receptor mRNA levels in human ventricular biopsy specimens by quantitative polymerase chain reactions: progressive reduction of beta 1-adrenergic receptor mRNA in heart failure. J Am Coll Cardiol 27, 146-154

Engelhardt S, Hein L, Wiesmann F, Lohse MJ (1999): Progressive hypertrophy and heart failure in $\beta 1$-adrenergic receptor transgenic mice. Proc Natl Acad Sci $\underline{96}, 7059-7064$

Eschenhagen T (2013): PDE4 in the human heart - major player or little helper? Br J Pharmacol $\underline{169}, 524-527$

Fabiato A (1983): Calcium-induced release of calcium from the cardiac sarcoplasmic reticulum. Am J Physiol 245, C1-14

Fabiato A, Fabiato $F$ (1975): Contractions induced by a calcium-triggered release of calcium from the sarcoplasmic reticulum of single skinned cardiac cells. J Physiol 249, 469-495

Fan G-C, Chu G, Mitton B, Song Q, Yuan Q, Kranias EG (2004): Small Heat-Shock Protein Hsp20 Phosphorylation Inhibits $\beta$-Agonist-Induced Cardiac Apoptosis. Circ Res 94, 1474-1482

Fan G-C, Ren X, Qian J, Yuan Q, Nicolaou P, Wang Y, Jones WK, Chu G, Kranias EG (2005): Novel Cardioprotective Role of a Small Heat-Shock Protein, Hsp20, Against Ischemia/Reperfusion Injury. Circulation 111, 1792-1799

Fan G-C, Yuan Q, Song G, Wang Y, Chen G, Qian J, Zhou X, Lee YJ, Ashraf M, Kranias EG (2006): Small Heat-Shock Protein Hsp20 Attenuates $\beta$-Agonist-Mediated Cardiac Remodeling Through Apoptosis Signal-Regulating Kinase 1. Circ Res 99, 1233-1242

Fischmeister R, Castro LRV, Abi-Gerges A, Rochais F, Jurevicius J, Leroy J, Vandecasteele G (2006): Compartmentation of cyclic nucleotide signaling in the heart: the role of cyclic nucleotide phosphodiesterases. Circ Res $\underline{99}$, 816-828

Florian C, Mons N, Roullet P (2006): CREB antisense oligodeoxynucleotide administration into the dorsal hippocampal CA3 region impairs long- but not short-term spatial memory in mice. Learn Mem Cold Spring Harb N 13 , 465-472

Forbes MS, van Neil EE (1988): Membrane systems of guinea pig myocardium: ultrastructure and morphometric studies. Anat Rec 222, 362-379

Förster T (1948): Zwischenmolekulare Energiewanderung und Fluoreszenz. Ann Phys 437, 55-75

Frank KF, Bölck B, Erdmann E, Schwinger RHG (2003): Sarcoplasmic reticulum Ca2+-ATPase modulates cardiac contraction and relaxation. Cardiovasc Res $\underline{57}, 20-27$

Frantz S, Klaiber M, Baba HA, Oberwinkler H, Völker K, Gaßner B, Bayer B, Abeßer M, Schuh K, Feil $R$ et al. (2013): Stress-dependent dilated cardiomyopathy in mice with cardiomyocyterestricted inactivation of cyclic GMP-dependent protein kinase I. Eur Heart J $\underline{34}$, 12331244

Fujii J, Ueno A, Kitano K, Tanaka S, Kadoma M, Tada M (1987): Complete complementary DNAderived amino acid sequence of canine cardiac phospholamban. J Clin Invest $\underline{79}, 301-304$

Gao T, Yatani A, Dell'Acqua ML, Sako H, Green SA, Dascal N, Scott JD, Hosey MM (1997): cAMPdependent regulation of cardiac L-type $\mathrm{Ca2}+$ channels requires membrane targeting of PKA and phosphorylation of channel subunits. Neuron $\underline{19}, 185-196$

Gavazzi A, De Maria R, Manzoli L, Bocconcelli P, Di Leonardo A, Frigerio M, Gasparini S, Humar F, Perna G, Pozzi R et al. (2015): Palliative needs for heart failure or chronic obstructive 
pulmonary disease: Results of a multicenter observational registry. Int J Cardiol $\underline{184}, 552-$ 558

Go AS, Mozaffarian D, Roger VL, Benjamin EJ, Berry JD, Borden WB, Bravata DM, Dai S, Ford ES, Fox CS et al. (2013): Heart Disease and Stroke Statistics-2013 Update A Report From the American Heart Association. Circulation 127, e6-e245

Götz KR, Nikolaev VO (2013): Advances and techniques to measure cGMP in intact cardiomyocytes. Methods Mol Biol Clifton NJ $\underline{1020}, 121-129$

Gu Y, Gorelik J, Spohr HA, Shevchuk A, Lab MJ, Harding SE, Vodyanoy I, Klenerman D, Korchev YE (2002): High-resolution scanning patch-clamp: new insights into cell function. FASEB J Off Publ Fed Am Soc Exp Biol 16, 748-750

Guereschi MG, Araujo LP, Maricato JT, Takenaka MC, Nascimento VM, Vivanco BC, Reis VO, Keller AC, Brum PC, Basso AS (2013): Beta2-adrenergic receptor signaling in CD4+ Foxp3+ regulatory $\mathrm{T}$ cells enhances their suppressive function in a PKA-dependent manner. Eur J Immunol 43, 1001-1012

Gupta RC, Mishra S, Yang X-P, Sabbah HN (2005): Reduced inhibitor 1 and 2 activity is associated with increased protein phosphatase type 1 activity in left ventricular myocardium of one-kidney, one-clip hypertensive rats. Mol Cell Biochem 269, 49-57

Gustavsson M, Verardi R, Mullen DG, Mote KR, Traaseth NJ, Gopinath T, Veglia G (2013): Allosteric regulation of SERCA by phosphorylation-mediated conformational shift of phospholamban. Proc Natl Acad Sci U S A 110, 17338-17343

Hagemann D, Kuschel M, Kuramochi T, Zhu W, Cheng H, Xiao R-P (2000): Frequency-encoding Thr17 Phospholamban Phosphorylation Is Independent of Ser16 Phosphorylation in Cardiac Myocytes. J Biol Chem 275, 22532-22536

Hasenfuss G, Reinecke H, Studer R, Meyer M, Pieske B, Holtz J, Holubarsch C, Posival H, Just H, Drexler H (1994): Relation between myocardial function and expression of sarcoplasmic reticulum $\mathrm{Ca}(2+)$-ATPase in failing and nonfailing human myocardium. Circ Res $\underline{75}$, 434442

Hayes JS, Brunton LL, Brown JH, Reese JB, Mayer SE (1979): Hormonally specific expression of cardiac protein kinase activity. Proc Natl Acad Sci U S A $\underline{76}, 1570-1574$

He J, Conklin MW, Foell JD, Wolff MR, Haworth RA, Coronado R, Kamp TJ (2001): Reduction in density of transverse tubules and L-type $\mathrm{Ca}(2+)$ channels in canine tachycardia-induced heart failure. Cardiovasc Res $\underline{49}, 298-307$

Head BP, Patel HH, Roth DM, Lai NC, Niesman IR, Farquhar MG, Insel PA (2005): G-proteincoupled receptor signaling components localize in both sarcolemmal and intracellular caveolin-3-associated microdomains in adult cardiac myocytes. J Biol Chem $\underline{280}$, 3103631044

Heinzel FR, Bito V, Biesmans L, Wu M, Detre E, Wegner F von, Claus P, Dymarkowski S, Maes F, Bogaert $\mathrm{J}$ et al. (2008): Remodeling of T-Tubules and Reduced Synchrony of $\mathrm{Ca2}+$ Release in Myocytes From Chronically Ischemic Myocardium. Circ Res 102, 338-346

Heyen MV, Heymans S, Antoons G, Reed T, Periasamy M, Awede B, Lebacq J, Vangheluwe P, Dewerchin M, Collen D et al. (2001): Replacement of the Muscle-Specific Sarcoplasmic Reticulum Ca2+-ATPase Isoform SERCA2a by the Nonmuscle SERCA2b Homologue Causes Mild Concentric Hypertrophy and Impairs Contraction-Relaxation of the Heart. Circ Res $\underline{89}, 838-846$ 
Hilfiker-Kleiner D, Landmesser U, Drexler H (2006): Molecular Mechanisms in Heart Failure: Focus on Cardiac Hypertrophy, Inflammation, Angiogenesis, and Apoptosis. J Am Coll Cardiol $\underline{48}$, A56-A66

Ho KKL, Pinsky JL, Kannel WB, Levy D (1993): The epidemiology of heart failure: The Framingham Study. J Am Coll Cardiol $\underline{22}$, A6-A13

Horackova M, Byczko Z (1997): Differences in the Structural Characteristics of Adult Guinea Pig and Rat Cardiomyocytes during Their Adaptation and Maintenance in Long-Term Cultures: Confocal Microscopy Study. Exp Cell Res 237, 158-175

Houslay MD, Adams DR (2003): PDE4 cAMP phosphodiesterases: modular enzymes that orchestrate signalling cross-talk, desensitization and compartmentalization. Biochem $\mathrm{J}$ $\underline{370}, 1-18$

Huang B, Wang S, Qin D, Boutjdir M, El-Sherif N (1999): Diminished Basal Phosphorylation Level of Phospholamban in the Postinfarction Remodeled Rat Ventricle Role of $\beta$-Adrenergic Pathway, Gi Protein, Phosphodiesterase, and Phosphatases. Circ Res $\underline{85}$, 848-855

Hübscher D: Myokardinfarktregeneration unter Verwendung kardiovaskulärer Vorläuferzellen aus murinen und humanen pluripotenten Stammzellen. Rer. nat. Diss. Göttingen 2012

Jessup M, Greenberg B, Mancini D, Cappola T, Pauly DF, Jaski B, Yaroshinsky A, Zsebo KM, Dittrich H, Hajjar RJ (2011): Calcium Upregulation by Percutaneous Administration of Gene Therapy in Cardiac Disease (CUPID) A Phase 2 Trial of Intracoronary Gene Therapy of Sarcoplasmic Reticulum Ca2+-ATPase in Patients With Advanced Heart Failure. Circulation $\underline{124}, 304-313$

Johns TNP, Olson BJ (1954): Experimental Myocardial Infarction: I. A Method of Coronary Occlusion in Small Animals. Ann Surg $\underline{140}, 675-682$

Kabaeva Z, Zhao M, Michele DE (2008): Blebbistatin extends culture life of adult mouse cardiac myocytes and allows efficient and stable transgene expression. Am J Physiol Heart Circ Physiol 294, H1667-1674

Kanno S, Lerner DL, Schuessler RB, Betsuyaku T, Yamada KA, Saffitz JE, Kovacs A (2002): Echocardiographic evaluation of ventricular remodeling in a mouse model of myocardial infarction. J Am Soc Echocardiogr Off Publ Am Soc Echocardiogr 15, 601-609

Kemi OJ, Hoydal MA, Macquaide N, Haram PM, Koch LG, Britton SL, Ellingsen O, Smith GL, Wisloff $U$ (2011): The effect of exercise training on transverse tubules in normal, remodeled, and reverse remodeled hearts. J Cell Physiol 226, 2235-2243

Keravis T, Lugnier C (2012): Cyclic nucleotide phosphodiesterase (PDE) isozymes as targets of the intracellular signalling network: benefits of PDE inhibitors in various diseases and perspectives for future therapeutic developments. $\mathrm{Br} \mathrm{J}$ Pharmacol $\underline{165}, 1288-1305$

Kim HW, Steenaart NA, Ferguson DG, Kranias EG (1990): Functional reconstitution of the cardiac sarcoplasmic reticulum $\mathrm{Ca2}(+)$-ATPase with phospholamban in phospholipid vesicles. J Biol Chem 265, 1702-1709

Kirshenbaum LA, MacLellan WR, Mazur W, French BA, Schneider MD (1993): Highly efficient gene transfer into adult ventricular myocytes by recombinant adenovirus. J Clin Invest $\underline{92}, 381-$ 387

Kiuchi K, Shannon RP, Komamura K, Cohen DJ, Bianchi C, Homcy CJ, Vatner SF, Vatner DE (1993): Myocardial beta-adrenergic receptor function during the development of pacinginduced heart failure. J Clin Invest $\underline{91}, 907-914$ 
Knott ML, Hogan SP, Wang H, Matthaei KI, Dent LA (2009): FVB/N mice are highly resistant to primary infection with Nippostrongylus brasiliensis. Parasitology $\underline{136}$, 93-106

Kranias EG (1985): Regulation of calcium transport by protein phosphatase activity associated with cardiac sarcoplasmic reticulum. J Biol Chem 260, 11006-11010

Kranias EG, Hajjar RJ (2012): Modulation of Cardiac Contractility by the Phopholamban/SERCA2a Regulatome. Circ Res $\underline{110}, 1646-1660$

Lang RM, Bierig M, Devereux RB, Flachskampf FA, Foster E, Pellikka PA, Picard MH, Roman MJ, Seward J, Shanewise JS et al. (2005): Recommendations for chamber quantification: a report from the American Society of Echocardiography's Guidelines and Standards Committee and the Chamber Quantification Writing Group, developed in conjunction with the European Association of Echocardiography, a branch of the European Society of Cardiology. J Am Soc Echocardiogr Off Publ Am Soc Echocardiogr 18, 1440-1463

Lee DI, Kass DA (2012): Phosphodiesterases and Cyclic GMP Regulation in Heart Muscle. Physiology 27, 248-258

Lee LCY, Maurice DH, Baillie GS (2013): Targeting protein-protein interactions within the cyclic AMP signaling system as a therapeutic strategy for cardiovascular disease. Future Med Chem $\underline{5}, 451-464$

Lehnart SE, Marks AR (2006): Phosphodiesterase 4D and heart failure: a cautionary tale. Expert Opin Ther Targets $\underline{10}, 677-688$

Lehnart SE, Wehrens XHT, Reiken S, Warrier S, Belevych AE, Harvey RD, Richter W, Jin S-LC, Conti M, Marks AR (2005): Phosphodiesterase 4D Deficiency in the Ryanodine-Receptor Complex Promotes Heart Failure and Arrhythmias. Cell 123, 25-35

Linck B, Bokník P, Eschenhagen T, Müller FU, Neumann J, Nose M, Jones LR, Schmitz W, Scholz $H$ (1996): Messenger RNA expression and immunological quantification of phospholamban and SR-Ca2+-ATPase in failing and nonfailing human hearts. Cardiovasc Res 31, 625-632

Liu S, Zhang J, Xiang YK (2011): FRET-based direct detection of dynamic protein kinase A activity on the sarcoplasmic reticulum in cardiomyocytes. Biochem Biophys Res Commun $\underline{404}$, $581-586$

Lohse MJ, Engelhardt S, Eschenhagen T (2003): What is the role of beta-adrenergic signaling in heart failure? Circ Res $\underline{93}$, 896-906

Lompré A-M, Hajjar RJ, Harding SE, Kranias EG, Lohse MJ, Marks AR (2010): Ca2+ Cycling and New Therapeutic Approaches for Heart Failure. Circulation 121, 822-830

Louch WE, Mørk HK, Sexton J, Strømme TA, Laake P, Sjaastad I, Sejersted OM (2006): T-tubule disorganization and reduced synchrony of $\mathrm{Ca2}+$ release in murine cardiomyocytes following myocardial infarction. J Physiol $\underline{574}, 519-533$

Lygren B, Carlson CR, Santamaria K, Lissandron V, McSorley T, Litzenberg J, Lorenz D, Wiesner B, Rosenthal W, Zaccolo M et al. (2007): AKAP complex regulates Ca2+ re-uptake into heart sarcoplasmic reticulum. EMBO Rep $\underline{8}, 1061-1067$

Lymperopoulos A (2013): Physiology and pharmacology of the cardiovascular adrenergic system. Front Physiol 4, 240

Lynch MJ, Baillie GS, Mohamed A, Li X, Maisonneuve C, Klussmann E, Heeke G van, Houslay MD (2005): RNA Silencing Identifies PDE4D5 as the Functionally Relevant cAMP Phosphodiesterase Interacting with $\beta$ Arrestin to Control the Protein Kinase A/AKAP79mediated Switching of the $\beta 2$-Adrenergic Receptor to Activation of ERK in HEK293B2 Cells. J Biol Chem 280, 33178-33189 
Lyon AR, MacLeod KT, Zhang Y, Garcia E, Kanda GK, Lab MJ, Korchev YE, Harding SE, Gorelik J (2009): Loss of T-tubules and other changes to surface topography in ventricular myocytes from failing human and rat heart. Proc Natl Acad Sci U S A 106, 6854-6859

Lyon AR, Bannister ML, Collins T, Pearce E, Sepehripour AH, Dubb SS, Garcia E, O'Gara P, Liang L, Kohlbrenner E et al. (2011): SERCA2a Gene Transfer Decreases SR Calcium Leak and Reduces Ventricular Arrhythmias in a Model of Chronic Heart Failure. Circ Arrhythm Electrophysiol $\underline{4}, 362-372$

Manders EMM, Verbeek FJ, Aten JA (1993): Measurement of co-localization of objects in dualcolour confocal images. J Microsc 169 , 375-382

Mann DL (1999): Mechanisms and Models in Heart Failure A Combinatorial Approach. Circulation $\underline{100}, 999-1008$

Marks AR (2013): Calcium cycling proteins and heart failure: mechanisms and therapeutics. J Clin Invest $\underline{123}, 46-52$

Martinez SE, Wu AY, Glavas NA, Tang X-B, Turley S, Hol WGJ, Beavo JA (2002): The two GAF domains in phosphodiesterase $2 A$ have distinct roles in dimerization and in cGMP binding. Proc Natl Acad Sci U S A $\underline{99}$, 13260-13265

Marx SO, Reiken S, Hisamatsu Y, Jayaraman T, Burkhoff D, Rosemblit N, Marks AR (2000): PKA phosphorylation dissociates FKBP12.6 from the calcium release channel (ryanodine receptor): defective regulation in failing hearts. Cell 101, 365-376

Mauban JRH, O'Donnell M, Warrier S, Manni S, Bond M (2009): AKAP-scaffolding proteins and regulation of cardiac physiology. Physiol Bethesda Md $\underline{24}, 78-87$

McCahill A, Campbell L, McSorley T, Sood A, Lynch MJ, Li X, Yan C, Baillie GS, Houslay MD (2008): In cardiac myocytes, cAMP elevation triggers the down-regulation of transcripts and promoter activity for cyclic AMP phosphodiesterase-4A10 (PDE4A10). Cell Signal 20, 2071-2083

McMurray JJV, Adamopoulos S, Anker SD, Auricchio A, Böhm M, Dickstein K, Falk V, Filippatos G, Fonseca C, Gomez-Sanchez MA et al. (2012): ESC guidelines for the diagnosis and treatment of acute and chronic heart failure 2012: The Task Force for the Diagnosis and Treatment of Acute and Chronic Heart Failure 2012 of the European Society of Cardiology. Developed in collaboration with the Heart Failure Association (HFA) of the ESC. Eur J Heart Fail 14, 803-869

Mehel H, Emons J, Vettel C, Wittköpper K, Seppelt D, Dewenter M, Lutz S, Sossalla S, Maier LS, Lechêne $P$ et al. (2013): Phosphodiesterase-2 is up-regulated in human failing hearts and blunts $\beta$-adrenergic responses in cardiomyocytes. J Am Coll Cardiol 62, 1596-1606

Meyer M, Dillmann WH (1998): Sarcoplasmic reticulum Ca2+-ATPase overexpression by adenovirus mediated gene transfer and in transgenic mice. Cardiovasc Res $\underline{37}, 360-366$

Meyer M, Schillinger W, Pieske B, Holubarsch C, Heilmann C, Posival H, Kuwajima G, Mikoshiba K, Just H, Hasenfuss G (1995): Alterations of Sarcoplasmic Reticulum Proteins in Failing Human Dilated Cardiomyopathy. Circulation 92, 778-784

Milano CA, Allen LF, Rockman HA, Dolber PC, McMinn TR, Chien KR, Johnson TD, Bond RA, Lefkowitz RJ (1994): Enhanced myocardial function in transgenic mice overexpressing the beta 2-adrenergic receptor. Science $\underline{264}, 582-586$

Miller CL, Yan C (2010): Targeting Cyclic Nucleotide Phosphodiesterase in the Heart: Therapeutic Implications. J Cardiovasc Transl Res $\underline{3}, 507-515$ 
Miyamoto SD, Stauffer BL, Nakano S, Sobus R, Nunley K, Nelson P, Sucharov CC (2014): Betaadrenergic adaptation in paediatric idiopathic dilated cardiomyopathy. Eur Heart J $\underline{35}, 33-$ 41

Moens AL, Yang R, Watts VL, Barouch LA (2010): Beta 3-adrenoreceptor Regulation of Nitric Oxide in the Cardiovascular System. J Mol Cell Cardiol $\underline{48}, 1088-1095$

Mokni W, Keravis T, Etienne-Selloum N, Walter A, Kane MO, Schini-Kerth VB, Lugnier C (2010): Concerted regulation of CGMP and CAMP phosphodiesterases in early cardiac hypertrophy induced by angiotensin II. PloS One $\underline{5}$, e14227

Mongillo M, Tocchetti CG, Terrin A, Lissandron V, Cheung Y-F, Dostmann WR, Pozzan T, Kass DA, Paolocci N, Houslay MD, Zaccolo M (2006): Compartmentalized phosphodiesterase-2 activity blunts beta-adrenergic cardiac inotropy via an NO/cGMP-dependent pathway. Circ Res $\underline{98}, 226-234$

Morel E, Marcantoni A, Gastineau M, Birkedal R, Rochais F, Garnier A, Lompré A-M, Vandecasteele G, Lezoualc'h F (2005): cAMP-binding protein Epac induces cardiomyocyte hypertrophy. Circ Res $\underline{97}, 1296-1304$

Morozov A, Muzzio IA, Bourtchouladze R, Van-Strien N, Lapidus K, Yin D, Winder DG, Adams JP, Sweatt JD, Kandel ER (2003): Rap1 couples cAMP signaling to a distinct pool of p42/44MAPK regulating excitability, synaptic plasticity, learning, and memory. Neuron $\underline{39}$, 309-325

Movsesian MA, Nishikawa M, Adelstein RS (1984): Phosphorylation of phospholamban by calciumactivated, phospholipid-dependent protein kinase. Stimulation of cardiac sarcoplasmic reticulum calcium uptake. J Biol Chem $\underline{259}$, 8029-8032

Muthuramu I, Lox M, Jacobs F, De Geest B (2014): Permanent Ligation of the Left Anterior Descending Coronary Artery in Mice: A Model of Post-myocardial Infarction Remodelling and Heart Failure. J Vis Exp JoVE

Nichols CB, Rossow CF, Navedo MF, Westenbroek RE, Catterall WA, Santana LF, McKnight GS (2010): Sympathetic stimulation of adult cardiomyocytes requires association of AKAP5 with a subpopulation of L-type calcium channels. Circ Res 107, 747-756

Nikolaev VO, Bünemann M, Hein L, Hannawacker A, Lohse MJ (2004): Novel Single Chain cAMP Sensors for Receptor-induced Signal Propagation. J Biol Chem 279, 37215-37218

Nikolaev VO, Bünemann M, Schmitteckert E, Lohse MJ, Engelhardt S (2006): Cyclic AMP imaging in adult cardiac myocytes reveals far-reaching beta1-adrenergic but locally confined beta2adrenergic receptor-mediated signaling. Circ Res $\underline{99}, 1084-1091$

Nikolaev VO, Moshkov A, Lyon AR, Miragoli M, Novak P, Paur H, Lohse MJ, Korchev YE, Harding SE, Gorelik J (2010): Beta2-adrenergic receptor redistribution in heart failure changes cAMP compartmentation. Science $\underline{327}, 1653-1657$

Okumura S, Fujita T, Cai W, Jin M, Namekata I, Mototani Y, Jin H, Ohnuki Y, Tsuneoka Y, Kurotani $\mathrm{R}$ et al. (2014): Epac1-dependent phospholamban phosphorylation mediates the cardiac response to stresses. J Clin Invest 124, 2785-2801

Ostrom RS, Gregorian C, Drenan RM, Xiang Y, Regan JW, Insel PA (2001): Receptor Number and Caveolar Co-localization Determine Receptor Coupling Efficiency to Adenylyl Cyclase. J Biol Chem 276, 42063-42069

Park WJ, Oh JG (2013): SERCA2a: a prime target for modulation of cardiac contractility during heart failure. BMB Rep $\underline{46}, 237-243$ 
Patel HH, Murray F, Insel PA (2008): G-protein-coupled receptor-signaling components in membrane raft and caveolae microdomains. Handb Exp Pharmacol 167-184

Patrucco E, Albergine MS, Santana LF, Beavo JA (2010): Phosphodiesterase 8A (PDE8A) Regulates Excitation-Contraction Coupling in Ventricular Myocytes. J Mol Cell Cardiol $\underline{49}$, 330-333

Patten RD, Hall-Porter MR (2009): Small Animal Models of Heart Failure Development of Novel Therapies, Past and Present. Circ Heart Fail $\underline{2}$, 138-144

Perera RK, Nikolaev VO (2013): Compartmentation of cAMP signalling in cardiomyocytes in health and disease. Acta Physiol Oxf Engl 207, 650-662

Periasamy M, Bhupathy P, Babu GJ (2008): Regulation of sarcoplasmic reticulum Ca2+ ATPase pump expression and its relevance to cardiac muscle physiology and pathology. Cardiovasc Res $\underline{77}, 265-273$

Pfeffer MA, Pfeffer JM, Fishbein MC, Fletcher PJ, Spadaro J, Kloner RA, Braunwald E (1979): Myocardial infarct size and ventricular function in rats. Circ Res $44,503-512$

Ponsioen B, Zhao J, Riedl J, Zwartkruis F, van der Krogt G, Zaccolo M, Moolenaar WH, Bos JL, Jalink K (2004): Detecting cAMP-induced Epac activation by fluorescence resonance energy transfer: Epac as a novel cAMP indicator. EMBO Rep $\underline{5}, 1176-1180$

Qi L, Saberi M, Zmuda E, Wang Y, Altarejos J, Zhang X, Dentin R, Hedrick S, Bandyopadhyay G, Hai T et al. (2009): Adipocyte CREB Promotes Insulin Resistance in Obesity. Cell Metab $\underline{9}$, 277-286

Qian J, Ren X, Wang X, Zhang P, Jones WK, Molkentin JD, Fan G-C, Kranias EG (2009): Blockade of Hsp20 Phosphorylation Exacerbates Cardiac Ischemia/Reperfusion Injury by Suppressed Autophagy and Increased Cell Death. Circ Res 105, 1223-1231

Rababa'h A, Singh S, Suryavanshi SV, Altarabsheh SE, Deo SV, McConnell BK (2015): Compartmentalization role of A-kinase anchoring proteins (AKAPs) in mediating protein kinase A (PKA) signaling and cardiomyocyte hypertrophy. Int J Mol Sci $\underline{16}$, 218-229

Richter W, Xie M, Scheitrum C, Krall J, Movsesian MA, Conti M (2011): Conserved expression and functions of PDE4 in rodent and human heart. Basic Res Cardiol 106, 249-262

Ruiz-Hurtado G, Morel E, Domínguez-Rodríguez A, Llach A, Lezoualc'h F, Benitah J-P, Gomez AM (2013): Epac in cardiac calcium signaling. J Mol Cell Cardiol 58, 162-171

Rybin VO, Xu X, Lisanti MP, Steinberg SF (2000): Differential targeting of beta -adrenergic receptor subtypes and adenylyl cyclase to cardiomyocyte caveolae. A mechanism to functionally regulate the cAMP signaling pathway. J Biol Chem $\underline{275}$, 41447-41457

Sachse FB, Torres NS, Savio-Galimberti E, Aiba T, Kass DA, Tomaselli GF, Bridge JH (2012): Subcellular Structures and Function of Myocytes Impaired during Heart Failure are Restored by Cardiac Resynchronization Therapy. Circ Res 110, 588-597

Sande JB, Sjaastad I, Hoen IB, Bøkenes J, Tønnessen T, Holt E, Lunde PK, Christensen G (2002): Reduced level of serine16 phosphorylated phospholamban in the failing rat myocardium: a major contributor to reduced SERCA2 activity. Cardiovasc Res $\underline{53}, 382-391$

Schmidt M, Dekker FJ, Maarsingh H (2013): Exchange protein directly activated by cAMP (epac): a multidomain CAMP mediator in the regulation of diverse biological functions. Pharmacol $\operatorname{Rev} \underline{65}, 670-709$ 
Schweizer PA, Duhme N, Thomas D, Becker R, Zehelein J, Draguhn A, Bruehl C, Katus HA, Koenen M (2010): cAMP Sensitivity of HCN Pacemaker Channels Determines Basal Heart Rate But Is Not Critical for Autonomic Rate Control. Circ Arrhythm Electrophysiol $\underline{3}, 542-$ 552

Schwinger RH, Münch G, Bölck B, Karczewski P, Krause EG, Erdmann E (1999): Reduced Ca(2+)sensitivity of SERCA $2 a$ in failing human myocardium due to reduced serin-16 phospholamban phosphorylation. J Mol Cell Cardiol $\underline{31}$, 479-491

Schwinger RHG, Böhm M, Schmidt U, Karczewski P, Bavendiek U, Flesch M, Krause E-G, Erdmann E (1995): Unchanged Protein Levels of SERCA II and Phospholamban but Reduced Ca2+ Uptake and Ca2+-ATPase Activity of Cardiac Sarcoplasmic Reticulum From Dilated Cardiomyopathy Patients Compared With Patients With Nonfailing Hearts. Circulation 92, 3220-3228

Scott JD, Santana LF (2010): A-Kinase Anchoring Proteins Getting to the Heart of the Matter. Circulation $\underline{121}, 1264-1271$

Selye H, Bajusz E, Grasso S, Mendell P (1960): Simple Techniques for the Surgical Occlusion of Coronary Vessels in the Rat. Angiology 11, 398-407

Simmerman HK, Collins JH, Theibert JL, Wegener AD, Jones LR (1986): Sequence analysis of phospholamban. Identification of phosphorylation sites and two major structural domains. J Biol Chem 261, 13333-13341

Sin YY, Edwards HV, Li X, Day JP, Christian F, Dunlop AJ, Adams DR, Zaccolo M, Houslay MD, Baillie GS (2011): Disruption of the cyclic AMP phosphodiesterase-4 (PDE4)-HSP20 complex attenuates the $\beta$-agonist induced hypertrophic response in cardiac myocytes. J Mol Cell Cardiol $\underline{50}, 872-883$

Singh A, Redden JM, Kapiloff MS, Dodge-Kafka KL (2011): The large isoforms of A-kinase anchoring protein 18 mediate the phosphorylation of inhibitor- 1 by protein kinase $A$ and the inhibition of protein phosphatase 1 activity. Mol Pharmacol $\underline{79}, 533-540$

Soeller C, Cannell MB (1999): Examination of the Transverse Tubular System in Living Cardiac Rat Myocytes by 2-Photon Microscopy and Digital Image-Processing Techniques. Circ Res $\underline{84}$, 266-275

Song L-S, Guatimosim S, Gómez-Viquez L, Sobie EA, Ziman A, Hartmann H, Lederer WJ (2005): Calcium biology of the transverse tubules in heart. Ann N Y Acad Sci $\underline{1047}, 99-111$

Song L-S, Sobie EA, McCulle S, Lederer WJ, Balke CW, Cheng H (2006): Orphaned ryanodine receptors in the failing heart. Proc Natl Acad Sci U S A $\underline{103}$, 4305-4310

Sonnenburg WK, Seger D, Beavo JA (1993): Molecular cloning of a cDNA encoding the „61-kDa“ calmodulin-stimulated cyclic nucleotide phosphodiesterase. Tissue-specific expression of structurally related isoforms. J Biol Chem $\underline{268}, 645-652$

Soto D, De Arcangelis V, Zhang J, Xiang Y (2009): Dynamic protein kinase a activities induced by beta-adrenoceptors dictate signaling propagation for substrate phosphorylation and myocyte contraction. Circ Res 104, 770-779

Sprenger JU: Local cAMP dynamics in the SERCA2a signalling complex. Rer. nat. Diss. Göttingen 2014

Sprenger JU, Nikolaev VO (2013): Biophysical Techniques for Detection of cAMP and cGMP in Living Cells. Int J Mol Sci 14, 8025-8046

Sprenger JU, Perera RK, Götz KR, Nikolaev VO (2012): FRET microscopy for real-time monitoring of signaling events in live cells using unimolecular biosensors. J Vis Exp JoVE e4081 
Sprenger JU, Perera RK, Steinbrecher JH, Lehnart SE, Maier LS, Hasenfuss G, Nikolaev VO (2015): In vivo model with targeted cAMP biosensor reveals changes in receptormicrodomain communication in cardiac disease. Nat Commun $\underline{6}, 6965$

Statistisches Bundesamt 2004: Fachserie 12 Reihe 6.2.1- Gesundheit - Diagnosedaten der Patienten und Patientinnen in Krankenhäusern (einschl. Sterbe- und Stundenfälle) 2000, https://www.destatis.de/DE/Publikationen/Thematisch/Gesundheit/AlteAusgaben/Diagnose datenKrankenhausAlt.html [25.02.2015]

Statistisches Bundesamt 2014: Fachserie 12 Reihe 4 - Gesundheit - Todesursachen in Deutschland,

https://www.destatis.de/DE/Publikationen/Thematisch/Gesundheit/Todesursachen/Todesur sachen.html [25.02.2015]

Statistisches Bundesamt 2015: Fachserie 12 Reihe 6.2.1 - Gesundheit - Diagnosedaten der Patienten und Patientinnen in Krankenhäusern (einschl. Sterbe- und Stundenfälle) 2013, https://www.destatis.de/DE/Publikationen/Thematisch/Gesundheit/Krankenhaeuser/Diagno sedatenKrankenhaus.html [25.02.2015]

Studer R, Reinecke H, Bilger J, Eschenhagen T, Böhm M, Hasenfuss G, Just H, Holtz J, Drexler H (1994): Gene expression of the cardiac $\mathrm{Na}(+)-\mathrm{Ca} 2+$ exchanger in end-stage human heart failure. Circ Res $\underline{75}, 443-453$

Sun B, Li H, Shakur Y, Hensley J, Hockman S, Kambayashi J, Manganiello VC, Liu Y (2007): Role of phosphodiesterase type $3 \mathrm{~A}$ and $3 \mathrm{~B}$ in regulating platelet and cardiac function using subtype-selective knockout mice. Cell Signal $\underline{19}, 1765-1771$

Sun Y, Wallrabe H, Seo S-A, Periasamy A (2011): FRET microscopy in 2010: The legacy of Theodor Förster on the 100th anniversary of his birth. Chemphyschem Eur J Chem Phys Phys Chem 12, 462-474

Swift F, Franzini-Armstrong C, Øyehaug L, Enger UH, Andersson KB, Christensen G, Sejersted OM, Louch WE (2012): Extreme sarcoplasmic reticulum volume loss and compensatory Ttubule remodeling after Serca2 knockout. Proc Natl Acad Sci U S A 109, 3997-4001

Takahashi T, Allen PD, Lacro RV, Marks AR, Dennis AR, Schoen FJ, Grossman W, Marsh JD, Izumo S (1992): Expression of dihydropyridine receptor (Ca2+ channel) and calsequestrin

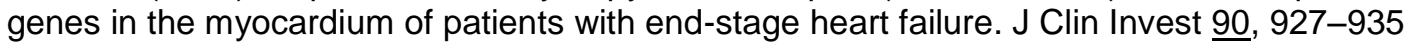

Tarnavski O, McMullen JR, Schinke M, Nie Q, Kong S, Izumo S (2004): Mouse cardiac surgery: comprehensive techniques for the generation of mouse models of human diseases and their application for genomic studies. Physiol Genomics 16, 349-360

Vafiadaki E, Arvanitis DA, Sanoudou D, Kranias EG (2013): Identification of a protein phosphatase$1 /$ phospholamban complex that is regulated by cAMP-dependent phosphorylation. PloS One $\underline{8}$, e80867

Vandeput F, Wolda SL, Krall J, Hambleton R, Uher L, McCaw KN, Radwanski PB, Florio V, Movsesian MA (2007): Cyclic Nucleotide Phosphodiesterase PDE1C1 in Human Cardiac Myocytes. J Biol Chem 282, 32749-32757

Vangheluwe P, Sipido KR, Raeymaekers L, Wuytack F (2006): New perspectives on the role of SERCA2's Ca2+ affinity in cardiac function. Biochim Biophys Acta BBA - Mol Cell Res $\underline{1763}, 1216-1228$

Vila Petroff MG, Egan JM, Wang X, Sollott SJ (2001): Glucagon-like peptide-1 increases cAMP but fails to augment contraction in adult rat cardiac myocytes. Circ Res $\underline{89}, 445-452$

Wagner E, Lauterbach MA, Kohl T, Westphal V, Williams GSB, Steinbrecher JH, Streich J-H, Korff B, Tuan H-TM, Hagen B et al. (2012): Stimulated emission depletion live-cell super- 
resolution imaging shows proliferative remodeling of T-tubule membrane structures after myocardial infarction. Circ Res $\underline{111}$, 402-414

Wagner E, Brandenburg S, Kohl T, Lehnart SE (2014): Analysis of tubular membrane networks in cardiac myocytes from atria and ventricles. J Vis Exp JoVE e51823

Wang Y, Yuan J, Qian Z, Zhang X, Chen Y, Hou X, Zou J (2015): $\beta 2$ adrenergic receptor activation governs cardiac repolarization and arrhythmogenesis in a guinea pig model of heart failure. Sci Rep $\underline{5}, 7681$

Wegener AD, Simmerman HK, Lindemann JP, Jones LR (1989): Phospholamban phosphorylation in intact ventricles. Phosphorylation of serine 16 and threonine 17 in response to betaadrenergic stimulation. J Biol Chem 264, 11468-11474

Wei S, Guo A, Chen B, Kutschke WJ, Xie Y-P, Zimmerman K, Weiss RM, Anderson ME, Cheng H, Song L-S (2010): T-tubule remodeling during transition from hypertrophy to heart failure. Circ Res 107, 520-531

Xiang Y, Kobilka BK (2003): Myocyte Adrenoceptor Signaling Pathways. Science $\underline{300}$, 1530-1532

Zaccolo M, Movsesian MA (2007): CAMP and cGMP Signaling Cross-Talk Role of Phosphodiesterases and Implications for Cardiac Pathophysiology. Circ Res 100, 15691578

Zarain-Herzberg A, Afzal N, Elimban V, Dhalla NS (1996): Decreased expression of cardiac sarcoplasmic reticulum $\mathrm{Ca}(2+)$-pump ATPase in congestive heart failure due to myocardial infarction. Mol Cell Biochem 163-164, 285-290

Zhai J, Schmidt AG, Hoit BD, Kimura Y, MacLennan DH, Kranias EG (2000): Cardiac-specific Overexpression of a Superinhibitory Pentameric Phospholamban Mutant Enhances Inhibition of Cardiac Functionin Vivo. J Biol Chem 275, 10538-10544

Zheng M, Han Q-D, Xiao R-P (2004): Distinct beta-adrenergic receptor subtype signaling in the heart and their pathophysiological relevance. Sheng Li Xue Bao 56, $1-15$

Zinchuk V, Zinchuk O, Okada T (2007): Quantitative colocalization analysis of multicolor confocal immunofluorescence microscopy images: pushing pixels to explore biological phenomena. Acta Histochem Cytochem $\underline{40}, 101-111$

Zolotareva AG, Kogan ME (1978): Production of experimental occlusive myocardial infarction in mice. Cor Vasa 20, 308-314

Zvaritch E, Backx PH, Jirik F, Kimura Y, Leon S de, Schmidt AG, Hoit BD, Lester JW, Kranias EG, MacLennan DH (2000): The Transgenic Expression of Highly Inhibitory Monomeric Forms of Phospholamban in Mouse Heart Impairs Cardiac Contractility. J Biol Chem 275, 1498514991 


\section{Danksagung}

An dieser Stelle würde ich mich gerne bei den Menschen bedanken, die die Anfertigung dieser Arbeit ermöglicht und mich bei der Durchführung unterstützt haben. Mein besonderer Dank geht an:

Prof. Dr. Viacheslav Nikolaev für die Überlassung des Themas, das Interesse und die Bereitschaft zur Betreuung meiner Promotion sowie die hilfreichen Anmerkungen während der Entstehung meiner Arbeit und in der Phase des Schreibens.

Prof. Dr. Stephan Lehnart für die Vermittlung des Projektes, dem fortbestehenden Interesse an meiner Arbeit einschließlich der Unterstützung durch Drittmittel sowie der konstruktiven Kritik.

Dr. Eva Wagner für die kompetente Betreuung meines Projektes, die Unterstützung sowohl bei Versuchen als auch bei deren Auswertung und nicht zuletzt die hilfreichen Korrekturen während der Niederschreibung meiner Ergebnisse. „Danke, dass du dir trotz deiner zahlreichen eigenen Aufgaben immer Zeit genommen hast mir beratend zur Seite zu stehen und mich bestmöglichst zu unterstützen. Ohne dich wäre ich sicher an dem einen oder anderen Hindernis verzweifelt."

Dr. Julia Sprenger für die Bereitstellung von Versuchstieren ihrer Mauslinie und die Unterstützung und Weitergabe hilfreichen Tipps zur Durchführung der FRET-Experimente und Western Blots.

Dr. Daniela Hübscher für die Einarbeitung zu Beginn meines Projektes und vor allem für die Durchführung der Ml- und Sham-Operationen, die eine wichtige Grundlage meiner Arbeit bildeten.

Roland Blume und Marcel Zoremba für die Durchführung der echokardiografischen Untersuchungen sowie Beate Knocke für die Auswertung der echokardiografischen Daten.

Der gesamten AG Lehnart sowie AG Nikolaev für die nette Aufnahme in die Gruppen, das tolle Arbeitsumfeld und die stetige Hilfsbereitschaft und Unterstützung während meiner Zeit im Labor und darüber hinaus. 